\title{
An analysis of the dynamics of two high-value export chains: smallholder participation, standards and trust
}

Dissertation

to obtain the Ph.D. degree

in the International Ph.D. Program for Agricultural Sciences in Göttingen (IPAG),

at the Faculty of Agricultural Sciences,

Georg-August-University Göttingen, Germany

presented by:

Cristina María Romero Granja

born in Riobamba, Ecuador

Göttingen, June 2015 


\section{D7}

1. Name of supervisor: Jr. Prof. Dr. Meike Wollni

2. Name of co-supervisor: Prof. Dr. Matin Qaim

3. Name of further member of the examination committee: Prof. Dr. Stephan Klasen 


\section{Summary}

Globalization and growing demand for high-quality food have facilitated and increased international trade in food products and at the same time opened up new and promising business opportunities for farmers worldwide. Given this trend, the expansion of smallholders' income opportunities through their participation in high value chains been promoted as a promising measure to promote rural economic growth and contribute to poverty reduction. Linking small farmers to global markets through contract farming has become an important policy recommendation aiming to increase farmers' income and foster rural development. Different studies conclude that the access to these new markets has a positive impact on rural welfare either through product or labor markets (Maertens and Swinnen 2009; Bellemare 2012; Minten et al. 2009). Moreover, contractual arrangements can provide farmers in developing countries with a secure market and thus potentially support investments into farm-level upgrading and standard adoption. However, overcoming the initial constraints and gaining access to the export market may not be sufficient to guarantee sustained benefits from market participation in the long run. Some of the arrangements involving small farmers have been reported to loose participants or collapse over time. Constructing a sustainable marketing relationship also depends on whether both actors fulfill the terms of the contract and on the relational capital that is built through the interactions. Trust is a part of this capital that can discourage opportunism and facilitate the compliance of contracts, especially in regions with expensive or weak legal systems. Nevertheless, both topics: contract compliance and trust in the agribusiness context, has been addressed to our knowledge only by very few authors and from a theoretical point or view. Empirical studies to understand the dynamics of small farmers' participation in high value chains in the long run are still missing.

This dissertation is an empirical analysis of the dynamics of two small farmers' high value chains supplying the export market and how they are affected by transaction risks. It is based on the study of two cases: broccoli in Ecuador and pineapple in Costa Rica. Both cases represent typical agricultural value chains for fresh products characterized by vertically coordinated agribusiness producing for the export market and with high quality requirements.

First, an analysis of the extent of broccoli smallholders' participation in the export market over an 11year time period using correlated random effects and diff-GMM models is conducted. Jointly, the hazards of dropping out of the export chain based on a multi-spell cox duration model are also estimated (chapter two). Results suggest that small-scale farmers' exit from the export sector is accelerated by hold-ups experienced in the past and that family ties and being a member in a famers' group play an important role in farmers' marketing decisions. Negative external shocks - such as the 
bankruptcy of the main buyer in our case study - represent a major threat towards the sustainability of this chain.

In a second study (chapter 3), an artefactual framed field experiment with prior signaling is played with a sub-sample of 180 broccoli farmers to explore the effect of opportunistic behavior on their trust. The results reveal that this group of individuals has lower than average trust towards unknown people. Furthermore, signal that mimics the payment of a loan before the predesigned trust game is used to unravel farmer's behavior when facing possible opportunism. Results show that a positive signal increases trust, but a negative signal has no effect on it. Reacting slowly to external negative signs can threaten individuals who fail to protect themselves rapidly towards opportunism. If farmers do not react quickly enough, they might face larger losses that can threaten their presence in the chain.

A third approach uses data from a household survey conducted with pineapple growers in Costa Rica and analyzes the determinants of contract choice and the dynamics of standard adoption. An evaluation of the effects of different market arrangements on pineapple revenues, transaction risks and relational capital is also carried out. The study reveals that while contracts represent an important catalyst for farm-level upgrading, major transaction risks in the supply chain remain unresolved. In particular, farmers in formal contract schemes face high rejection rates and long payment delays. Verbal agreements appear to be a flexible option for farmers which lead to an increase in total revenues, low transaction risks and higher levels of trust and loyalty towards the buyer.

The thesis concludes by summarizing the main results of this work and its contribution to the literature in the field of rural development. Policy recommendations are also developed in an attempt to contribute with propositions that could improve the current state of agribusinesses and achieve more stable relations between small farmers and exporting firms. I further state the limitations of the study and ideas for future research. 


\section{Acknowledgements}

During this three year $\mathrm{PhD}$ experience, I have had the luck to collect unforgettable memories and to be in touch with great people. This work developed within the Global Food Research Training Group of the Göttingen University. I gratefully acknowledge the financial support of the German Research Foundation who made this work possible. I want to express my deepest gratitude to my supervisor, Meike Wollni, for all the support, patience and guidance throughout this path. Her constant openness encouraged me to achieve this goal. I would also like to thank Prof. Matin Qaim for being my second supervisor and for his comments on my work. Similarly, to Prof. Stephan Klasen, third member of the board of examiners. Furthermore, I am thankful for the support I got from the farmers' group HGZ and to the group of people who supported me during the data collection phase.

.I am extremely grateful also to my family. Thanks to my dad and mom for all the unconditional and constant support. I owe you everything!!! To my sisters and especially to my Abuela for showing me that life can always be simple and enjoyable (even when doing a $\left.\mathrm{PhD}()_{)}\right)$.

Thanks to all the Global Food members and to my colleagues in the chair for all the valuable comments during the formal and informal meetings. Thanks for making of this experience an extraordinary one, for your kindness and for your willingness to share your knowledge and cultures with me. Finally, thanks to my dear flat mates Laura and Steffi and my friend Daniel, who became my family in Germany, and to all the special friends that (no matter the distance for some of them) always had the right words of encouragement that kept me going. 


\section{Table of contents}

Summary $\quad$ iii

Acknowledgements $v$

Table of contents $\quad v i$

List of Tables $\quad$ ix

List of Figures $x$

1. Introduction 1

1.1. General Introduction 1

1.2. High-value export chains and standards 2

1.3. Linking small farmers through contract farming 3

1.4. Hold up problems 4

1.5. Problem statement and research objectives 6

References 9

2. Dynamics of smallholder participation in horticultural export chains- Evidence from

$\begin{array}{ll}\text { Ecuador - } & 13\end{array}$

$\begin{array}{ll}\text { Abstract } & 13\end{array}$

2.1. Introduction 13

2.2. The broccoli market in Ecuador 15

2.3. Conceptual framework 18

2.4. Empirical analysis 20

2.4.1. Data collection 20

2.4.2. Model specification $\quad 22$

2.4.2.1. Extent of participation 22

2.4.2.2. Dropping out of a high-value chain 24

2.4.2.3. Potential determinants 25

$\begin{array}{ll}\text { 2.5. Descriptive results } & 27\end{array}$

2.6. Econometric results 31

2.6.1. Extent of participation 31

2.6.2. Dropping out of a high-value chain 34

$\begin{array}{llr}\text { 2.7. } & \text { Conclusions } & 38\end{array}$ 
3. The effect of opportunistic behavior on trust: An experimental approach

3.1. Introduction

3.2. The broccoli export chain and small farmers in Ecuador

3.3. Conceptual framework

3.3.1. Trust and enforcement mechanisms

3.3.2. Measuring trust

3.4. Experimental approach

3.4.1. Instructions for the game and predictions

3.4.2. Data collection

3.4.3. Determinants of trust

3.5. Results and discussion

3.5.1. Results from the experimental game

3.5.2. Determinants of trust considering sample selection

4. Inclusive and beneficial? Governance in global food value chains in Costa Rica

4.2 Governance in the Costa Rican pineapple sector.

4.2.1 Coordination and regulatory system

4.2.2 Transaction risks and asset-specific investments

4.3.2 Methodology to analyze contract choice

4.3.3 Methodology to analyze standard adoption 
4.1 Characteristics of marketing arrangements 87

4.4.2 Determinants of contract choice 88

4.5 Vertical coordination and upgrading 89

4.5.1 Investments into pineapple cultivation $\quad 89$

4.5.2 Dynamics of standard adoption 91

4.6 Sustainability of marketing relationships 93

4.6.1 Impacts on pineapple revenues 94

4.6.2 Impacts on transaction risks 95

$\begin{array}{lll}\text { 4.6.3 Implications for relational capital } & 96\end{array}$

$\begin{array}{lll}\text { 4.6.4 Sensitivity analysis } & 97\end{array}$

$\begin{array}{lll}4.7 & \text { Conclusions } & 97\end{array}$

$\begin{array}{ll}\text { References } & 99\end{array}$

$\begin{array}{ll}\text { Appendix } 3 & 103\end{array}$

$\begin{array}{lll}\text { 5. Concluding remarks } & 104\end{array}$

$\begin{array}{lll}\text { 5.1. Synopsis } & 104\end{array}$

5.2. Implications for policy makers. 107

5.3. Limitations and ideas for further research 109 


\section{List of Tables}

Table 2-1 Transaction risks associated with export market participation. .......................................... 19

Table 2-2 Household, farm and transaction characteristics in 2012, by participation status. ${ }^{a}$................ 28

Table 2-3 Results on the exteng of participation in the export sector.................................................. 32

Table 2-4 Results on the hazard of dropping out of the export sector................................................. 35

Table 3-1 Trust towards different marketing channels..................................................................... 53

Table 3-2 Trust and trustworthiness according to the signal received. ................................................. 60

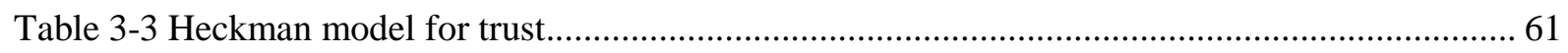

Table 4-1 Description of market arrangements in the pineapple sector.............................................. 88

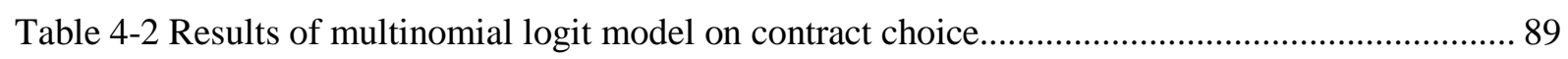

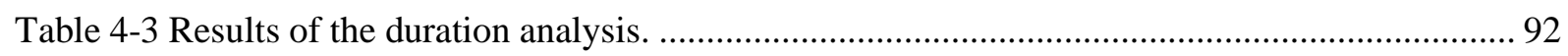

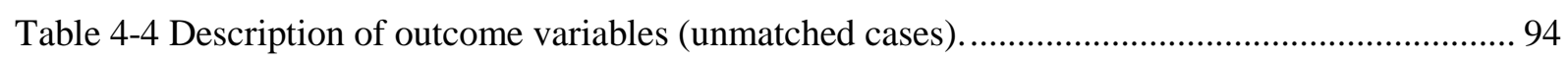

Table 4-5 Impact on outcome variables (matched cases)........................................................................ 95

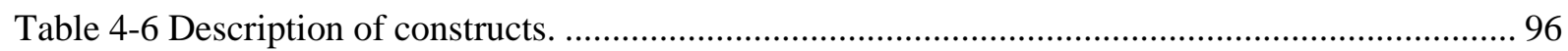




\section{List of Figures}

Figure 2-1 Prices and quantities exported by Ecuador during the past decade. .................................. 16

Figure 2-2 Number of suppliers and quantity delivered per year to the collection center. ................... 18

Figure 2-3 Problems experienced by farmers in the export sector ${ }^{a}$................................................... 30

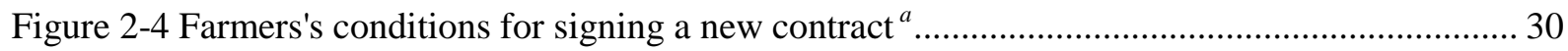

Figure 3-1 Payment delays experienced by broccoli farmers and number of farmers supplying the

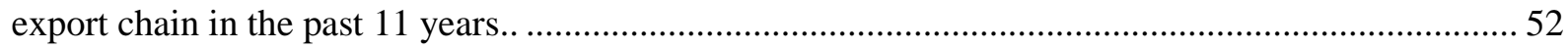

Figure 3-2 Graphic representation of the trust game with signaling. ................................................... 56

Figure 4-1 Transaction risks faced by producers in the pineapple chain. ........................................... 82

Figure 4-2 Average pineapple area by type of market arrangement .................................................. 90

Figure 4-3 Vertical coordination and standard adoption. ................................................................... 91

Figure 4-4 Kaplan-Meier survival estimates by type of agreement. .................................................... 93 


\section{Introduction}

\subsection{General Introduction}

Agriculture plays a central role in poverty reduction which ranks as one of the most important goals set by the United Nations aiming to increase the living standards of the world population. In the developing world, three out of four poor people ${ }^{1}$ live in rural areas (World Bank 2007) where there are around 500 million farms of less than 2 hectares (Wiggins et al. 2010). For these people, who also have to cope with undernourishment, agriculture is the main source of livelihoods and job opportunities (FAO, IFAD and WFP 2013; World Bank 2007). Evidence suggests that investing in agriculture is 2.5 to 3 times more effective for increasing income levels of the poor (World Bank 2007). In the same way, achieving agricultural growth lifts more people out of poverty in comparison to what can be accomplished by promoting growth in other sectors (Diao et al. 2007) Therefore, great efforts have been made to stimulate agricultural and rural development. International, governmental and non-governmental organizations have focused on improving farmer and agro-industrial access to markets. The production of non-traditional fruits and vegetables for high value markets has been a strategy of developing countries to generate income and partially diversify exports from traditional products (Llambi 1994). Nonetheless, there is still work to be done on understanding and reducing the risks faced by producers once they overcome existing entry barriers and become food suppliers of high value markets (Cleaver 2013).

In this context, supporting smallholders ${ }^{2}$ has become a priority. Peasant agriculture is part of a complex natural and social form of organization structured around family and community labor (Guarín 2013). As smallholders are more likely to be poor, raising their income has a direct effect on poverty reduction. Smallholders are also a source of temporal rural employment during periods when labor demands are not fulfilled by the family circle. Last but not less important, these farmers are more likely to spend their income locally which further stimulates the rural non-farm economy (Kydd et al. 2004). Studies suggest that smallholders in developing countries are efficient users of resources but poor (Schultz 1964; Wiggins et al. 2010), and therefore struggle to access all the necessary inputs required. Besides the limited access to information and technology, smallholders also often face missing markets linked to a lack of credits, insurance and secure outlet markets that makes it more difficult to comply with the market demands (Key and Runsten 1999). In their process of integrating to world markets, these producers additionally face serious limitations caused by stringent standards and regulations set by importing countries (Dolan and Humphrey 2000; Henson et al. 2005).

\footnotetext{
${ }^{1}$ Living on less than $\$ 2$ a day.

${ }^{2}$ Smallholder, small farmer and peasant are used as synonyms throughout this document.
} 
Nevertheless, participating in high-value markets can bring significant benefits (e.g. higher revenues, higher household income, higher productivity) to the small farmer population as pointed out in different studies (Miyata et al. 2009; Minten et al. 2009; Bellemare 2012; Narayanan 2014; Maertens and Swinnen 2009). This thesis focuses on the determinants of smallholders' long term participation in high-value export markets in the context of evolving food safety and quality standards. Special attention is paid to the transaction risks faced by suppliers and the effects these have on marketing decisions and behavior. Factors influencing the form of vertical coordination adopted by suppliers and their implication on different scopes -income, transaction risks and relational capital- are also analyzed. The rest of this section provides the basic conceptual elements for understanding the emergence and development of contract farming and standards in high value chains in developing countries. Uncertainties and risks experienced by suppliers when participating in the export sector are also explained under the context of weak formal institutions.

\subsection{High-value export chains and standards}

In the past three decades global food chains have changed drastically due to market liberalization, an increase in foreign or domestic investments and an increase in the demand for food due to urbanization and increasing incomes (Reardon et al. 2009). These huge structural changes have driven the sector towards the modernization of the procurement system (in order to reduce costs and ensure food security) and the appearance of high value markets demanding innocuous and high quality products. The modernization process involves the appearance of newer and stricter standards, the possibility of global sourcing, a shift from spot market transactions to vertical coordination and a higher degree of concentration at the wholesale, processing and retail level (Gereffi et al. 2005; Lee et al. 2012; Reardon et al. 2009). There is a great amount of literature dealing with the restructuring process at the different stages of the chain that shows a tendency for higher coordination to ensure that supply meets the requirements of consumers (Dolan and Humphrey 2000; Reardon et al. 2009). This tendency has led to a consolidation process which in turn has brought about new challenges for participating farmers such as the increased power of buying firms that are now in the position to impose new requirements. In contrast to the many benefits expected from small farmers' participation in highvalue chains, some potential threats can also appear if adequate regulations are not in place. Some studies claim that farmers can become dependent on a few cash crops, locked into unbalanced relationships and that tensions within the household or community can increase (Chemnitz et al. 2007; Cungu et al. 2008; Echanove and Steffen 2005; Key and Runsten 1999). Furthermore financial benefits might appear not significant in some particular cases (Narayanan 2014).

After several scandals related to food security, governments and food retailers have tightened up food regulations triggering the emergence and proliferation of complex public and private standards. Nowadays, these new regulations do not only comprise food safety public regulations (e.g. pesticide 
residues and food additives), but are also established by private entities and have expanded to cover quality, social and environmental issues. Actors within the chain -especially retailers- use private standards as tools to help coordinate supply chains by standardizing product requirements (World Bank 2007). Moreover, private standards help differentiate their products from the competitors' through signaling and in this way reach new markets where they can obtain a price premium that consumers, especially in the developed world, are willing to pay (Lee et al. 2012). A growing market has developed nowadays for products with special characteristics such as organic, "fairly produced” or “environmentally friendly" (Hughner et al. 2007). These events have led to a debate on how the increasing numbers of standards affect producers' participation in world markets. From a smallholder's perspective, standards can act as a catalyst for farm upgrading (i.e. improve farming techniques and product quality) but these can also become market entry barriers given that compliance often requires new investments and access to information and networks (Henson and Humphrey 2009).

\subsection{Linking small farmers through contract farming}

Contract farming has become a popular tool to solve the missing market problems faced by producers (e.g. no access to credits, insurances, technical support, information, stable outlet markets). Through an oral or written agreement a firm purchases the harvest of independent producers, acquiring certain control over the production process without making high investments (i.e. the firm does not invest in land or engage in labor monitoring), and producers gain access to credit, information and a secure market outlet (Echanove and Steffen 2005; Key and Runsten 1999). Moreover, contract arrangements can help smallholders to comply with high standard requirements.

A firm will decide to work with the suppliers that allow the maximum possible profit to be obtained while minimizing risks (including food safety risks). From a transaction cost perspective, firms prefer to source from large farms to reduce procurement costs including negotiation, monitoring and administrative costs (Key and Runsten 1999). In addition, to facilitate traceability and standard compliance they prefer to deal with only a small group of suppliers (Dolan and Humphrey 2000). Different studies (Berdegué et al. 2005; Carter and Mesbah 1993; Dolan and Humphrey 2000; Reardon et al. 2007; Rao and Qaim 2011) show evidence of smallholder exclusion from high value markets and mention that export companies or local supermarkets source only a small percentage of their produce from smallholders. However, these become attractive to firms when there is a scarcity of land and/or water, when the crop of interest is labor intensive or when larger producers have higher profit expectations and better marketing options compared to smaller ones (Barrett et al. 2012; Reardon et al. 2007; Wiggins et al. 2010). In countries characterized by a high fractionalization of land or where the access to it is limited by law, firms have no other choice than to incorporate smallholders 
to their supplier base (Key and Runsten 1999; Raynolds 1997). This is also the case when the product is labor intensive as small farmers rely on family labor that is flexible to work whenever needed without any monitoring. A farmer, on the other hand, will be willing to participate in an export marketing channel if the incentives offered are high enough in comparison to the traditional market and if he has the capacity to make the required farm and non-farm investments. However, in reality, small producers in developing countries face limited access to the information and technology needed to cultivate and sell nontraditional products (Gibbon 2003). In addition, they frequently miss secure outlet markets and find it hard to get access to credit, insurance and factors of production, plus they endure high risks and information asymmetry (Key and Runsten 1999). In response, contract farming has evolved as a support structure to help small farmers adjust to the new market requirements (Kersting and Wollni 2012) and reach global modern markets in a "competitive" way (Miyata et al. 2009).

To facilitate the relationship, negotiate better terms of trade and reduce transaction costs, producers have organized themselves into farmer groups that act as intermediaries who deal with the firm on one side and with individual farmers on the other (Barrett et al. 2012; Kersting and Wollni 2012). Moreover, interventions of governmental or non-governmental institutions appear necessary to facilitate standard adoption, organize and support farmers' organizations and stimulate relationships with private firms (Henson et al. 2005; Kersting and Wollni 2012; Poulton et al. 2010).

Despite the tendency towards vertical integration, the constraints faced by producers and the potential problems that are associated with such schemes, high value food chains are still considered important links between small farmers in developing countries and wealthy consumers in developed ones. Participants who overcome the existing barriers and become successful suppliers of lucrative markets are expected to increase their income and improve their livelihoods. Several studies report successful stories involving smallholders and show an increase in their incomes and positive spillovers to the rural economy (Bellemare 2012; Maertens and Swinnen 2009; Minten et al. 2009; Reardon et al. 2009; Schipmann and Qaim 2010).

\subsection{Hold up problems}

Actors will engage and honor a contract as long as the benefits they perceive from this arrangement are greater than the costs. Nevertheless, contract farming is not free of problems. There is an ongoing debate on the advantages and disadvantages of contract farming from the producers' perspective. Chemnitz et al. (2007), for example, points to the dangers and high dependencies that this structure could bring to producers in the long run. Small farmers may find themselves locked in an unbalanced power relationship where firms are able to transfer all production risks and costs to their suppliers 
(Key and Runsten 1999). Furthermore, Echanove and Steffen (2005) list social differentiation between producers, loss of producers' independence and increased gender inequalities as other negative effects of contract farming.

In the course of the relationship, producers and buyers are exposed to moral hazards and hold up situations exerted by their business partners. According to Gow and Swinnen (1998), a moral hazard appears when "one party is subjected to the hazard that the other party will engage in activities that are undesirable" and hold-ups are ex post problems in which "each party worries about being forced to accept disadvantageous terms after it has sunk an investment”. The farmer, for example, can fail to deliver the agreed volume and quality on time because there is a better price in the spot market (i.e. side selling). In contrast, the firm can choose to reject the product, lower the price ex post or default on the payment (Barrett et al. 2012; Cungu et al. 2008; Klein 1996). This dissertation will focus on two hold up problems experienced by the farmer: (1) high rejections and (2) delay on payment. When market conditions are not favorable for the firm, higher quality standards can appear, producing higher rejections that become losses to the farmer if he struggles to find another buyer for his perishable produce (Echanove and Steffen 2005). In a similar way, delay of payment decreases the real price received by the producer and can cause severe cash flow problems. This practice is used by some firms as a way to get interest free loans from their suppliers (Gow and Swinnen 1998). To our knowledge only a few studies have approached the topic in the context of food production and high value chains from an empirical point of view (Cungu et al. 2008; Gow and Swinnen 1998; Guo and Jolly 2008). Getting access to adequate data to quantify the impact of hold ups on farmers' decisions has been a challenge so far (Barrett et al. 2012; Gow and Swinnen 1998). This dissertation adds to the existing literature by analyzing a panel data set from a collection center supplying the export market and containing detailed marketing information for all its suppliers. Furthermore, the topic is approached from a behavioral point of view by collecting information on farmers' decisions using a framed field experiment.

Market agreements should be enforced through public and/or private mechanisms to secure their compliance. If third party enforceable mechanisms are well functioning, adequate contracts could decrease the risk for potential hold-ups but this is not the case in many developing countries where formal institutions are oftentimes weak and the cost to use the legal system is usually high (Torero and Viceisza 2011). The risks of experiencing hold ups can affect farmers' agricultural production and marketing decisions (i.e. decrease in farmers' investments or decision to sell to other buyers), especially when markets and legal institutions are imperfect (Gow and Swinnen 1998). However, in the context of an unreliable and expensive legal system, informal mechanisms (e.g. trust and loyalty) can discourage opportunism and facilitate market transactions (Cardenas and Carpenter 2008; Fafchamps and Minten 2001; Klein 1996; North 1990; Poulton et al. 2010). Understanding farmers' informal norms can help us unravel the causes for the lack of stability of high value chains where 
farmers start side selling to alternative markets. The alternative to high value chains, had farmers decided to look for an additional buyer because formal or informal institutions are not sufficient to enforce an agreement, are traditional markets. In such a market, transactions are regulated by price, while quality or standards do not play a major role. Additionally, traditional markets are characterized by numerous producers and buyers. Traditional markets can become alternative outlets for farmers with a diversified production which provide immediate cash as opposed to specialized chains where farmers have to wait at least some weeks in order to obtain the payment (Guarín 2013). Nevertheless, they are still characterized by information asymmetry problems and high transaction costs that increase the final price to the consumer.

Establishing close ties between buyers and suppliers can increase performance in global supply chains by discouraging opportunism and enhancing market transactions (Klein 1996; North 1990; Fafchamps and Minten 2001). The existing relational capital between the actors can be assessed by the degree of respect, trust and close interaction among them (Cousins et al. 2006). It has been shown that trust has a positive influence on the development of agricultural trade: Lyon (2000), Höhmann et al. (2002), Fafchamps and Minten (2001), Echanove and Steffen (2005) mention that in order to avoid contract breaching, firms attempt to establish links of trust, patronage and reciprocity with their producers.

\subsection{Problem statement and research objectives}

Factors influencing smallholder participation in modern markets, exclusion problems and the impact on welfare, as well as market failures and contract farming have been recurrent topics of research. Yet, the sustainability of these emerging chains has not been properly addressed. Some authors suggests that contract farming schemes lose participants or collapse over time (Barrett et al. 2012). Possible risks and conflicts arising within contract farming have already been mentioned, but the ways in which they affect production and marketing decisions and household livelihoods are still not well understood. Recent studies have started to approach this topic (Andersson et al. 2015; Holzapfel and Wollni 2014; Carletto et al. 2010), but they make use of either a two year panel dataset or rely on recall data due to the difficulty of obtaining information for longer periods of time. Thus, it may be argued that these are not precise enough to reveal the importance of transaction risks, or the effects of learning from past contract performance on present contract status (Gow and Swinnen 1998). Furthermore, studies on relational capital and the effects of hold ups in farmers' behavior are still missing.

This dissertation sheds some light on why food supply chains are not stable over time. Our work questions the expected advantageous situation of smallholders once they overcome market failures and achieve export market participation. Their low bargaining power and the obligations acquired during 
the upgrading process (i.e. credits and inputs) leaves them in a vulnerable situation vis à vis large exporting firms. Even when organized, they still face high transaction risks which influence their participation over time. A good understanding of the weaknesses in the farmer-buyer relationship within a high-value export chain will be helpful for identifying means of improving relations and to define policies that support weaker actors.

The specific research objectives that will be addressed in the following chapters are as follows:

1. To analyze the role of transaction risks on small farmers' decisions to deliver their produce to the export market and to investigate determinants of withdrawing from a horticultural export chain temporarily or permanently.

2. To examine the effects of firms' opportunistic behavior in the form of delayed payment on small farmers' trust and investment decisions.

3. To analyze the determinants of contract choice and its influence on standard adoption and to evaluate the effects of different market arrangements -signed contracts, verbal agreements or spot market- on revenues, transaction risks and relational capital.

The research objectives are addressed in the context of two case studies carried out with exportoriented smallholders in Ecuador and Costa Rica. Both cases represent typical agricultural value chains for fresh products characterized by vertically coordinated agribusiness producing for the export market and with buying firms powerful enough to impose their requirements and conditions on their suppliers.

To approach the first objective, household survey data were collected from a random sample of 401 small broccoli farmers in the highlands of Ecuador. These data was merged with records provided by a farmers' group containing information on the quantity of broccoli delivered to the export market from 2002 to 2012, the days to payment, and the quantity rejected by the exporter per delivery. Appropriate econometric methods were used to take advantage of the panel data and obtain precise estimations after controlling for unobserved heterogeneity of farmers. To analyze the second objective, a trust framed field experiment was run with a subsample of 180 broccoli farmers. The experiment measured how trust varies in our group of farmers according to a previous treatment that exposes participants to opportunistic behavior in the form of delayed payment. The level of trust measured in the treatment group (farmers receiving either a positive signal in the form of on time payment or a negative signal in the form of delayed payment) was compared to a the one measured in a control group (farmers not receiving any signal) in order to understand the informal codes of conduct involving smallholders. Finally, to analyze the third objective, a database collected through a household survey run with 173 pineapple farmers in the Huetar Norte Region in northern Costa Rica is used. In this region, farmers use different market arrangements with their buyers and have adopted different standards throughout 
time. This diversity in terms of coordination mechanisms allow us to determine the characteristics of farmers opting for different paths and the implications they have for income, transaction characteristics and trust and loyalty.

The remainder of this dissertation is structured as follows: The second chapter deals with the effects of transaction risks on the dynamics of participation in a horticultural export chain. The effect of rejection and delay on payment on the extent of participation and hazard of withdrawal is modeled using different approaches to analyze panel data. Chapter 3 analyzes farmers' responses to opportunism from a behavioral point of view. It quantifies the effect of delay of payment on farmers' trust and investment decisions using an experimental approach. Chapter 4 deals with the determinants of contract choice and the dynamics of standard adoption. Additionally, it evaluates the effect of different market arrangements on three dimensions of the relationship: revenue, transaction risks and relational capital. To finalize, Chapter 5 recaps the most important results of this work and presents the conclusions and policy implications as well as the limitations and ideas for future research. 


\section{References}

Andersson, Camilla I. M., Christine G. K. Chege, Elizaphan J. O. Rao, and Matin Qaim. 2015. "Following Up on Smallholder Farmers and Supermarkets in Kenya." American Journal of Agricultural Economics, February, aav006. doi:10.1093/ajae/aav006.

Barrett, Christopher B., Maren E. Bachke, Marc F. Bellemare, Hope C. Michelson, Sudha Narayanan, and Thomas F. Walker. 2012. "Smallholder Participation in Contract Farming: Comparative Evidence from Five Countries." World Development 40 (4): 715-30. doi:10.1016/j.worlddev.2011.09.006.

Bellemare, Marc F. 2012. “As You Sow, So Shall You Reap: The Welfare Impacts of Contract Farming.” World Development 40 (7): 1418-34. doi:10.1016/j.worlddev.2011.12.008.

Berdegué, Julio A., Fernando Balsevich, Luis Flores, and Thomas Reardon. 2005. "Central American Supermarkets' Private Standards of Quality and Safety in Procurement of Fresh Fruits and Vegetables.” Food Policy 30 (3): 254-69. doi:10.1016/j.foodpol.2005.05.003.

Cardenas, J.C., Carpenter, J., 2008. Behavioural Development Economics: Lessons from Field Labs in the Developing World. J. Dev. Stud. 44, 311-338. doi:10.1080/00220380701848327

Carletto, C., Kirk, A., Winters, P.C., Davis, B., 2010. Globalization and Smallholders: The Adoption, Diffusion, and Welfare Impact of Non-Traditional Export Crops in Guatemala. World Dev. 38, 814-827. doi:10.1016/j.worlddev.2010.02.017

Carter, Michael R., and Dina Mesbah. 1993. “Can Land Market Reform Mitigate the Exclusionary Aspects of Rapid Agro-Export Growth?” World Development 21 (7): 1085-1100. doi:10.1016/0305-750X(93)90001-P.

Chemnitz, Christine, Harald Grethe, and Ulrich Kleinwechter. 2007. "Quality Standards for Food Products: A Particular Burden for Small Producers in Developing Countries?” 83/2007. Working Paper, Wirtschafts- und Sozialwissenschaften an der LandwirtschaftlichGärtnerischen Fakultät, Humboldt-Universität $\quad$ zu Berlin. http://www.econstor.eu/handle/10419/96464.

Cleaver, Kevin. 2013. "The Importance of Scaling up for Agricultural and Rural Development.” IFAD.

Cousins, Paul D., Robert B. Handfield, Benn Lawson, and Kenneth J. Petersen. 2006. “Creating Supply Chain Relational Capital: The Impact of Formal and Informal Socialization Processes.” Journal of Operations Management, Incorporationg Behavioral Theory in OM Empirical Models AND Replication in Operations Management Research, 24 (6): 851-63. doi:10.1016/j.jom.2005.08.007.

Cungu, Azeta, Hamish Gow, Johan F. M. Swinnen, and Liesbet Vranken. 2008. "Investment with Weak Contract Enforcement: Evidence from Hungary during Transition.” European Review of Agricultural Economics 35 (1): 75-91. doi:10.1093/erae/jbn001. 
Diao, Xinshen, Hazell P.B.R, Resnick Danielle, and Thurlow James. 2007. The Role of Agriculture in Development: Implications for Sub-Saharan Africa. Intl Food Policy Res Inst.

Dolan, C., and J. Humphrey. 2000. "Governance and Trade in Fresh Vegetables: The Impact of UK Supermarkets on the African Horticulture Industry.” Journal of Development Studies 37 (2): 147-76. doi:10.1080/713600072.

Echanove, F, and C Steffen. 2005. "Agribusiness and Farmers in Mexico: The Importance of Contractual Relations” 171 (2): 166-76. doi:10.1111/j.1475-4959.2005.00157.x.

Fafchamps, Marcel, and Bart Minten. 2001. "Property Rights in a Flea Market Economy.” Economic Development and Cultural Change 49 (2): 229-67. doi:10.1086/edcc.2001.49.issue-2.

FAO, IFAD and WFP. 2013. "The State of Food Insecurity in the World 2013. THe Multiple Dimensions of Food Insecurity.”

Gereffi, Gary, John Humphrey, and Timothy Sturgeon. 2005. "The Governance of Global Value Chains.” Review of International Political Economy 12 (1): 78-104. doi:10.1080/09692290500049805.

Gibbon, Peter. 2003. "Value-Chain Governance, Public Regulation and Entry Barriers in the Global Fresh Fruit and Vegetable Chain into the EU.” Development Policy Review 21 (5-6): 615-25. doi:10.1111/j.1467-8659.2003.00227.x.

Gow, Hamish R., and Johan F. M. Swinnen. 1998. "Up- and Downstream Restructuring, Foreign Direct Investment, and Hold-up Problems in Agricultural Transition.” European Review of Agricultural Economics 25 (3): 331-50. doi:10.1093/erae/25.3.331.

Guarín, Alejandro. 2013. "The Value of Domestic Supply Chains: Producers, Wholesalers, and Urban Consumers in Colombia.” Development Policy Review 31 (5): 511-30. doi:10.1111/dpr.12023.

Guo, Hongdong, and Robert W. Jolly. 2008. "Contractual Arrangements and Enforcement in Transition Agriculture: Theory and Evidence from China.” Food Policy 33 (6): 570-75. doi:10.1016/j.foodpol.2008.04.003.

Henson, S, and J Humphrey. 2009. "The Impacts of Private Food Standards on the Food Chain and on Public Standard-Setting Processes.” Joint FAO/WHO Food Standards Programme, Codex Alimentarius Commission.

Henson, Spencer, Oliver Masakure, and David Boselie. 2005. "Private Food Safety and Quality Standards for Fresh Produce Exporters: The Case of Hortico Agrisystems, Zimbabwe.” Food Policy 30 (4): 371-84. doi:10.1016/j.foodpol.2005.06.002.

Höhmann, Hans-Hermann, Teemu Kautonen, Bernhard Lageman, and Friederike Welter. 2002. "Entrepreneurial Strategies and Trust: A Position Paper." Entrepreneurial Strategies and Trust, 4. 
Holzapfel, Sarah, and Meike Wollni. 2014. "Is GlobalGAP Certification of Small-Scale Farmers Sustainable? Evidence from Thailand.” The Journal of Development Studies 50 (5): 731-47. doi:10.1080/00220388.2013.874558.

Hughner, Renée Shaw, Pierre McDonagh, Andrea Prothero, Clifford J. Shultz, and Julie Stanton. 2007. "Who Are Organic Food Consumers? A Compilation and Review of Why People Purchase Organic Food.” Journal of Consumer Behaviour 6 (2-3): 94-110. doi:10.1002/cb.210.

Kersting, Sarah, and Meike Wollni. 2012. "New Institutional Arrangements and Standard Adoption: Evidence from Small-Scale Fruit and Vegetable Farmers in Thailand.” Food Policy 37 (4): 452-62. doi:10.1016/j.foodpol.2012.04.005.

Key, Nigel, and David Runsten. 1999. “Contract Farming, Smallholders, and Rural Development in Latin America: The Organization of Agroprocessing Firms and the Scale of Outgrower Production.” World Development 27 (2): 381-401. doi:10.1016/S0305-750X(98)00144-2.

Klein, Benjamin. 1996. "Why Hold-Ups Occur: The Self-Enforcing Range of Contractual Relationships.” Economic Inquiry 34 (3): 444-63. doi:10.1111/j.1465-7295.1996.tb01388.x.

Kydd, Jonathan, Andrew Dorward *, Jamie Morrison, and Georg Cadisch. 2004. "Agricultural Development and Pro-poor Economic Growth in sub-Saharan Africa: Potential and Policy.” Oxford Development Studies 32 (1): 37-57. doi:10.1080/1360081042000184110.

Lee, Joonkoo, Gary Gereffi, and Janet Beauvais. 2012. "Global Value Chains and Agrifood Standards: Challenges and Possibilities for Smallholders in Developing Countries." Proceedings of the National Academy of Sciences 109 (31): 12326-31. doi:10.1073/pnas.0913714108.

Llambi, Luis. 1994. “Comparative Advantages and Disadvantages in Latin American Nontraditional Fruit and Vegetable Exports.” In The Global Restructuring of Agro-Food Systems, edited by Philip McMichael. Ithaca, NY: Cornell University Press.

Lyon, Fergus. 2000. "Trust, Networks and Norms: The Creation of Social Capital in Agricultural Economies in Ghana.” World Development 28 (4): 663-81. doi:10.1016/S0305750X(99)00146-1.

Maertens, Miet, and Johan F.M. Swinnen. 2009. "Trade, Standards, and Poverty: Evidence from Senegal.” World Development 37 (1): 161-78. doi:10.1016/j.worlddev.2008.04.006.

Minten, Bart, Lalaina Randrianarison, and Johan F.M. Swinnen. 2009. “Global Retail Chains and Poor Farmers: Evidence from Madagascar.” World Development 37 (11): 1728-41. doi:10.1016/j.worlddev.2008.08.024.

Miyata, Sachiko, Nicholas Minot, and Dinghuan Hu. 2009. "Impact of Contract Farming on Income: Linking Small Farmers, Packers, and Supermarkets in China.” World Development 37 (11): 1781-90. doi:10.1016/j.worlddev.2008.08.025. 
Narayanan, Sudha. 2014. "Profits from Participation in High Value Agriculture: Evidence of Heterogeneous Benefits in Contract Farming Schemes in Southern India.” Food Policy 44 (February): 142-57. doi:10.1016/j.foodpol.2013.10.010.

North, D.C., 1990. Institutions, Institutional Change and Economic Performance. Cambridge University Press.

Poulton, Colin, Andrew Dorward, and Jonathan Kydd. 2010. "The Future of Small Farms: New Directions for Services, Institutions, and Intermediation.” World Development, The Future of Small Farms Including Special Section: Impact Assessment of Policy-Oriented International $\begin{array}{llllll}\text { Agricultural } & \text { Research } & \text { (pp. 1453-1526), } & 38 & \text { (10): 1413-28. }\end{array}$ doi:10.1016/j.worlddev.2009.06.009.

Rao, Elizaphan J. O., and Matin Qaim. 2011. "Supermarkets, Farm Household Income, and Poverty: Insights from Kenya.” World Development $39 \quad$ (5): 784-96. doi:10.1016/j.worlddev.2010.09.005.

Raynolds, L. 1997. "Restructuring National Agriculture, Agro-Food Trade and Agrarian Livelihoods in the Caribbean.” In Globalising Food. Agrarian Questions and Global Restructuring, edited by D Goodman and M Watts, 119-32. Routledge, London.

Reardon, Thomas, Christopher B. Barrett, Julio A. Berdegué, and Johan F. M. Swinnen. 2009. “Agrifood Industry Transformation and Small Farmers in Developing Countries.” World Development 37 (11): 1717-27. doi:10.1016/j.worlddev.2008.08.023.

Reardon, Thomas, Spencer Henson, and Julio Berdegué. 2007. “'Proactive Fast-Tracking’ Diffusion of Supermarkets in Developing Countries: Implications for Market Institutions and Trade.” Journal of Economic Geography 7 (4): 399-431. doi:10.1093/jeg/lbm007.

Schipmann, Christin, and Matin Qaim. 2010. "Spillovers from Modern Supply Chains to Traditional Markets: Product Innovation and Adoption by Smallholders.” Agricultural Economics 41 (34): 361-71. doi:10.1111/j.1574-0862.2010.00438.x.

Schultz, T. W. 1964. “Transforming Traditional Agriculture.” Yale University Press.

Torero, Maximo, and Angelino Viceisza. 2011. "Potential Collusion and Trust Evidence from a Field Experiment in Vietnam.” IFPRI.

Wiggins, Steve, Johann Kirsten, and Luis Llambí. 2010. “The Future of Small Farms.” World Development, The Future of Small Farms Including Special Section: Impact Assessment of Policy-Oriented International Agricultural Research (pp. 1453-1526), 38 (10): 1341-48. doi:10.1016/j.worlddev.2009.06.013.

World Bank. 2007. "World Development Report 2008: Agriculture for Development.” 


\title{
2. Dynamics of smallholder participation in horticultural export chains - Evidence from Ecuador ${ }^{1}$ -
}

\begin{abstract}
In this paper we study the dynamics of smallholder participation in export value chains focusing on the example of small-scale broccoli producers in the highlands of Ecuador. We analyze the extent of participation over an 11-year time period using correlated random effects and diff-GMM models and explain the hazards of dropping out of the export chain based on a multi-spell cox duration model. The empirical results suggest that small-scale farmers' exit from the export sector is accelerated by holdups experienced in the past and that family ties play an important role in farmers' marketing decisions. Negative external shocks - such as the global financial crisis starting in 2007 that was associated with the bankruptcy of the main buyer in our case study - represent a major threat towards the sustainability of smallholder inclusion in high-value chains.
\end{abstract}

Keywords: high-value supply chains, market participation, panel data, duration model, transaction costs

\subsection{Introduction}

During the past three decades the agri-food industry has undergone rapid structural changes. The growing demand for innocuous and high quality food has led to the modernization of procurement systems inducing a shift from spot market transactions to vertical coordination (Reardon et al. 2009). These structural supply and demand side changes have opened up new marketing opportunities for small-scale farmers in developing countries. Farmers' inclusion in global agri-food markets through producer groups and contract farming schemes is often considered a promising way to increase farm incomes and thus foster rural development (Braun, Hotchkiss, and Immink 1989; Kydd et al. 2004; Hernández, Reardon, and Berdegué 2007; Maertens and Swinnen 2009). Based on the argument that participation in high-value markets can provide an avenue out of poverty in rural areas, promoting and

\footnotetext{
${ }^{1}$ This chapter is co-authored by Meike Wollni. The authors's contributions are as follows: both authors contributed to the conceptualization and design of the research. CR implemented the survey. Both authors contributed to the data analysis, interpretation of the results, writing the manuscript and revising it.
} 
linking small farmers to these markets has become a main focus of donors and NGOs in recent years (Altenburg 2006).

While the export of fresh products from developing to high-income countries has increased over the past decades, smallholders often face major barriers in their access to high-value markets (Dolan and Humphrey 2000; Henson et al. 2005; Schuster and Maertens 2013). An extensive set of literature dealing with the determinants of smallholder participation in modern food markets offers mixed results. Berdegué et al. (2005), Dolan and Humphrey (2000), Reardon et al. (2007), Schuster and Maertens (2013), and Rao and Qaim (2011) show evidence for the exclusion of small-scale farmers from high-value markets and reveal that export companies or local supermarkets source only a small percentage of their produce from smallholders. In contrast, Bellemare (2012), Henson et al. (2005), Maertens and Swinnen (2009), Minten et al. (2009), Reardon et al. (2009), and Schipmann and Qaim (2010) describe successful cases of smallholder inclusion that rely on institutional innovations, such as contract farming schemes.

While these studies provide some evidence on the determinants of participation at a particular point in time, little research has been done on the sustainability of smallholder inclusion in high-value chains over time. This is of particular relevance as some evidence suggests that contract farming schemes regularly lose participants or collapse entirely (Barrett et al. 2012). Therefore, the dynamics of participation may be much more complex than suggested by cross-sectional studies and may also explain to some extent seemingly contradictory results. A few recent studies have investigated the dynamics of market participation focusing on domestic supermarkets in Kenya (Andersson et al. 2015), export-related standard adoption in Thailand (Holzapfel and Wollni 2014), and the disadoption of horticultural export crops in Guatemala (Carletto et al. 2010). However, due to the difficulty of obtaining consistent data on farmers' marketing choices over several years, these studies rely on twoyear panel or recall data. These data are usually too short or not precise enough to reveal the complex dynamics of (multiple) entries and exits from a high-value chain and the relative importance of transaction risks for contract performance.

The aim of this study is to address this research gap by analyzing the factors influencing smallholders' decision to deliver their produce to the export market as well as the decision to remain a supplier or to drop out temporarily or permanently from the export chain. We place particular emphasis on the role of transaction risks (i.e. payment delays and product rejections) that may influence and shape the farmers' marketing decisions. We thus investigate the effects of household characteristics and past experiences in the supply chain on the extent of participation (measured in terms of the quantity delivered to the export chain). Furthermore, we analyze the determinants of withdrawal from the export chain, taking into consideration that farmers may enter and exit the chain multiple times. 
Our analyses are based on a unique data set consisting of original household survey data collected in 2012 and the records of a collection center to which all broccoli from small-scale farmers destined for the export market is delivered. The records of the collection center contain transaction level information for every transaction of all the suppliers during the past eleven years (i.e. since it was established). Our data shows that a large percentage of small-scale farmers do not participate continuously in the high-value export market channel, but instead decide to abandon it temporarily or completely and return to the local market. Using panel data we can investigate the dynamic relationships within the supply chain while controlling for unobserved heterogeneity of farmers and for yearly shocks that may affect production levels (e.g. weather shocks, price shocks, etc.).

The article is organized as follows. The next section gives background information on the broccoli sector in Ecuador. The third section discusses the conceptual framework for the empirical analysis. Section four provides information on data collection and develops the econometric models. Finally, section five and six present the results and section seven concludes.

\subsection{The broccoli market in Ecuador}

Broccoli was introduced as a crop in Ecuador in the 1990's and since then its cultivation has spread rapidly until it became the country's second most important non-traditional export product. In 2008, Ecuador became the $6^{\text {th }}$ largest exporting country of broccoli and cauliflower ( $5^{\text {th }}$ in value exported) with around 60 thousand tons sent to North American and European markets representing around 57 million dollars (FAOSTAT, 2013). However, in the following years exports started to decrease, and by 2010 Ecuador was relegated to the $11^{\text {th }}$ place (34 thousand tons and 35.5 million dollars). Figure 2.1 presents export prices and quantities of broccoli and cauliflower ${ }^{2}$ since 1992, showing a constant and significant increase in quantity until 2009 and after that a constant drop until present times (National Central Bank, 2013) ${ }^{3}$. During the same time, prices have been relatively stable spiking in 1996 and then again since 2007 showing an increasing tendency.

\footnotetext{
${ }^{2}$ Data for broccoli alone are not available.

${ }^{3}$ The price/ton depicted in the graph was obtained dividing total broccoli and cauliflower exported per year by total income received obtained from national statistics. Therefore, it is the average of the price obtained in the international market, which increased over the years, but it does not necessarily represent the price paid by exporting firms to local producers.
} 
Chapter 2. Dynamics of smallholder participation in horticultural export chains.

Figure 2-1 Prices and quantities exported by Ecuador during the past decade.

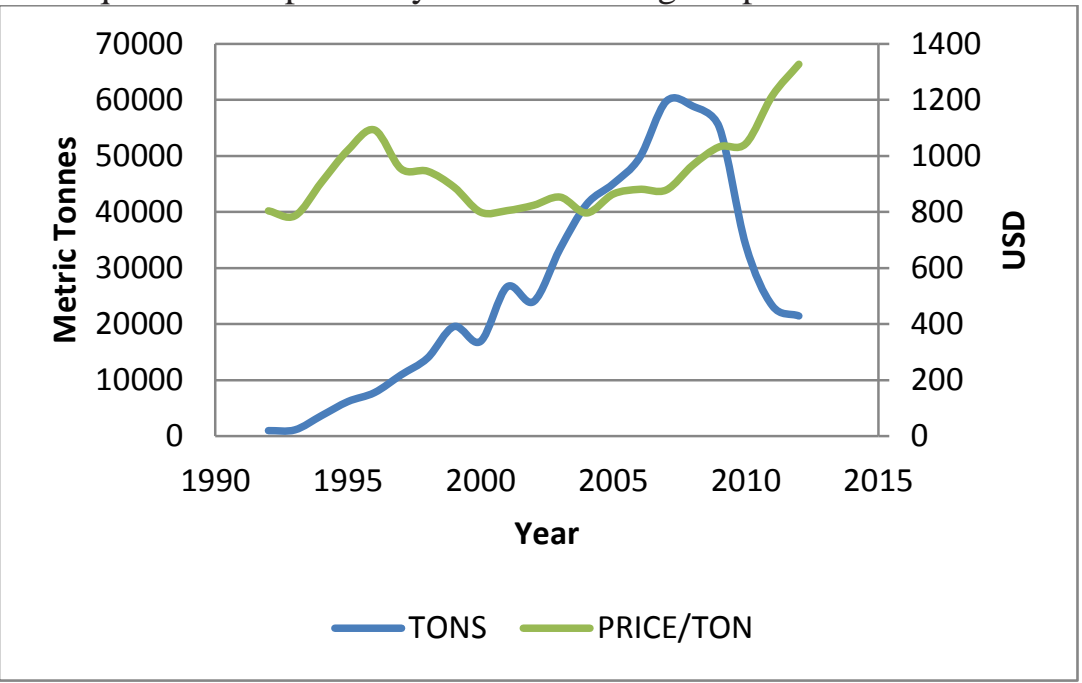

Source: National Central Bank, 2013

Initially, broccoli was only cultivated on large plantations and exported by a few processors, but since the year 2001 small-scale farmers from the Chimborazo province ${ }^{4}$ were linked to the export market. A few years later, small-scale farms ${ }^{5}$ represented one-third of the total broccoli area planted for the international market and the remaining two-thirds were cultivated by medium and large-scale farms as well as by the same exporting firms in vertically integrated production units ${ }^{6}$ (Gall 2009).

Small-scale farmers were linked to the export market through a producer organization that served as an intermediary between farmers and the export firm. The producer organization established a collection center in the village in order to assemble the broccoli and send it to a private processingexporting firm (from here on referred to as exporter). This firm cut the broccoli into small pieces, froze it and exported it to international markets. The first eight months only members of the association supplied the export sector through the collection center. Over the following years, the number of members of the association remained constant and no new members were admitted. However, hundreds of producers from neighboring villages joined the chain as suppliers ${ }^{7}$.

Between the exporter and the producer organization a written contract was signed, in which the volume, a fixed price, quality and payment conditions were specified. The producer organization relied on verbal agreements with smallholder farmers regarding the quantity and quality specifications of broccoli deliveries. A typical production contract system was put into operation with the exporter providing the plants through the collection center and facilitating access to inputs, credit, market and technical information. The farmers on the other hand were in charge of growing broccoli on their land

\footnotetext{
${ }^{4}$ Small-scale farmers were supported by a local NGO to form a producer group and produce broccoli for the export market.

${ }^{5}$ Defined as farmers owning less than 20 ha (Gall, 2009).

${ }^{6}$ Large and medium scale plantations are located in the province of Cotopaxi and were not included in our analysis.

${ }^{7}$ For more insights on the advantages of working with smallholders in this specific case refer to Gall (2009).
} 
under the firm's technical direction and had to deliver the product to the collection center in order to pay for the services received.

In summary, the broccoli harvest and post-harvest process consists of the following stages: i) prior to the harvest, the farmer has to decide where to sell his product according to its quality, which is assessed by a collection center's worker, ii) the broccoli going to the export sector is delivered to the collection center, where it undergoes a first grading process in the presence of the farmer, iii) the broccoli meeting the quality criteria at the collection center is further sent to the exporter, where a second grading process takes place, this time in the absence of the farmer ${ }^{8}$. Until 2010, the broccoli from different farmers was sent to the exporter in separate bins. As the overall quantity delivered by smallholders has decreased, the broccoli from different producers is nowadays mixed in the same container and sent to the firm. Therefore, since 2010 the quantity rejected by the exporter is divided equally among the farmers who sent their product with that specific shipment (on average one truck is dispatched every working day from the collection center to the firm). Finally, iv) the product meeting the exporting firm's quality requirements is accepted and the payment is made two weeks later according to the terms of the contract. Due to the fact that broccoli for the export market is harvested differently than that for the local market and due to its high perishability, the broccoli rejected at the exporter level can no longer be sold in the local market and thus represents a monetary loss to the farmer ${ }^{9}$.

Nowadays, twelve years after the inclusion process started, a large percentage of small-scale suppliers have abandoned the scheme and the collection center faces a shortage of broccoli supplies. In consequence of the global financial crisis starting in 2007, the export broccoli chain underwent a major crisis in 2009, when the exporting firm sourcing from the collection center went bankrupt and left the scene without paying for the product delivered over several months. As a consequence, the collection center faced a liquidity crisis, and payments to farmers were delayed for extended time periods. Formal legal institutions have not solved the problem so far and the farmers' collection center still has a large debt to recover from the exporter. After their original buyer went out of business, the farmers' collection center established a new marketing contact with one of the remaining broccoli processors-exporters in the country. This exporter agreed to source from the collection center to supplement its own estate production. The contract scheme outlined above still applies in this new marketing relationship, and is re-negotiated on an annual basis.

In personal interviews, the exporters have emphasized the existing demand for Ecuadorian broccoli in the international market and the constant need for new and efficient suppliers given land constraints

\footnotetext{
${ }^{8}$ The rejection data in our data set refer to the rejections at the exporter level, and do not take into account rejections at the collection center where the farmer can assist and verify the process.

${ }^{9}$ When harvested for the export market only the head of the broccoli is cut and the rest of the plant is left in the field, while for the intermediaries and local market the head has to be covered by several plant leafs.
} 
that hinder the expansion of their own plantations. Yet, they have also pointed out their reluctance to work with smallholders because of the associated coordination problems, especially since there is a shortage of suppliers. When the collection center was booming with suppliers, trucks were filled faster and dispatched to the processing plant immediately. In addition, traceability was easier to implement since the broccoli from different farmers could be kept in separate bins. Nowadays, it takes longer for the truck to fill and the waiting time affects the quality of the product. Moreover, planning is difficult, because the exporter cannot rely on certain volumes being delivered by the collection center.

Fig. 2.2 shows the dynamics of broccoli supplies to the collection center during the last decade. The amount of broccoli delivered to the export sector drastically declined in 2009 and since then has been further decreasing. Suppliers have joined and abandoned the supply chain at different points in time. The total number of farmers who have ever participated in the export sector is around 630 from eight different villages located in the province of Chimborazo. The largest number of suppliers (403 smallholder farmers) was registered in 2005. Nowadays, there are only 108 active suppliers of which only 47 are members of the producer organization.

Figure 2-2 Number of suppliers and quantity delivered per year to the collection center.

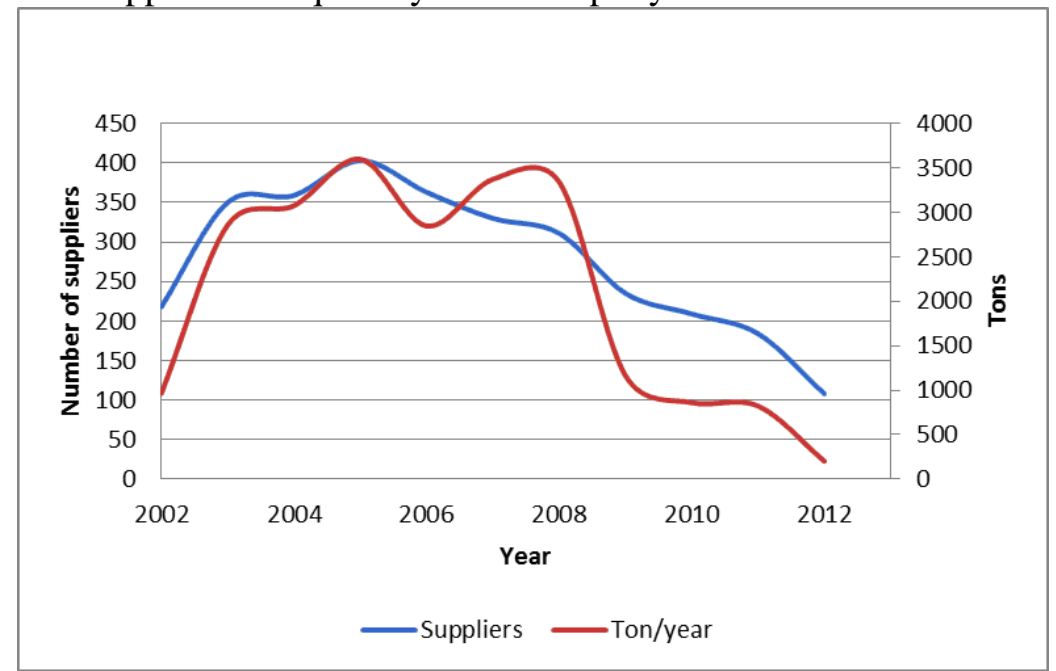

Source: Farmers' collection center records

\subsection{Conceptual framework}

Broccoli producers in Ecuador can choose between two alternative marketing channels to sell their produce: 1.) The spot market: coordinated by price and characterized by nonrecurring transactions with no prior arrangements and no promise of repeating the transaction in the future. It takes place at the local market or at small market points close to each community. There are multiple buyers and multiple sellers and payment is usually made at the moment of the transaction. 2.) The export market: characterized by vertical coordination between the parties to supply a fixed quantity of broccoli with certain characteristics, during a certain time period and at a constant price. The payment is usually 
made 15 days after delivery and the closer relationship between the parties can facilitate the flow of information. While large-scale farmers are offered individual contracts directly with the exporting firm, small-scale farmers can only access the export market through verbal agreements with the collection center managed by the farmers' group under study.

In order to participate in the export marketing channel, farmers have to fulfill stringent requirements related to the quality, quantity and timing of deliveries. The farmer's ability to meet these conditions determines the probability and extent of participation. In principle, we assume that farmers decide to participate in the export market if their utility derived from participation is higher than their utility derived from non-participation, or in other words, higher than their opportunity costs of participation (Barrett et al. 2012). The farmer's utility associated with participation in the export chain is influenced by several factors including revenues and production costs as well as the transaction risks associated with selling broccoli in the export sector. Based on the framework proposed by Williamson (1979) and extended by Hobbs and Young (2000), Table 2.1 summarizes the transaction risks associated with the commercialization of broccoli in the export chain compared to the alternative, i.e., the local market.

Table 2-1 Transaction risks associated with export market participation.

\begin{tabular}{ll}
\hline Transaction risks related to: & $\begin{array}{l}\text { Exposure in export market } \\
\text { (compared to local market) }\end{array}$ \\
\hline Price uncertainty & Lower (annually fixed price) \\
Timing of payment uncertainty & Higher (frequent delays) \\
Buyer uncertainty & Lower (secure buyer) \\
Quality uncertainty & Higher (frequent product rejections) \\
$\begin{array}{l}\text { Relationship-specific investments } \\
\text { (and related exposure to opportunistic behavior) }\end{array}$ & Higher (in particular after harvest)
\end{tabular}

While certain types of risks are typically reduced through contract farming arrangements that link smallholders to export markets similar to the one studied here, other types of risks can be exacerbated (Barrett et al. 2012). Uncertainty related to the price and to finding a suitable buyer is usually lower compared to transactions in the local market, given that a purchase agreement exists with a secure buyer and the price is negotiated ex-ante, thus allowing farmers to plan production costs accordingly. However, new uncertainties may be introduced, e.g., related to the farmer's ability to meet strict quality requirements. Furthermore, even though an ex-ante agreement exists, the exporter may renege on the agreement ${ }^{10}$, e.g. by rejecting produce inappropriately or by delaying or defaulting on the final

\footnotetext{
${ }^{10}$ This refers to both situations in which the exporter is experiencing a negative shock and is therefore unable to fulfill his contract obligations as well as situations in which the exporter is behaving opportunistically.
} 
payment ${ }^{11}$ (Barrett et al. 2012). When high quality requirements are defined, as in the export market, uncertainty surrounding the compliance with these quality criteria increases (in particular when criteria are difficult to determine objectively and depend on subjective assessment). As a result, the grading process, often performed in the absence of the farmer, is characterized by asymmetric information and can be susceptible to opportunistic behavior (as reported e.g. by Saenger et al. 2014). Furthermore, the threat of opportunistic behavior is exacerbated by relationship-specific investments incurred by farmers producing for the export market. In the broccoli sector, these become especially relevant after harvest, due to distinct harvesting technologies between the two markets. Thus, once the product has been harvested for the export market, the farmer is locked into the marketing relationship with the exporter, given that his second best option of marketing the broccoli elsewhere now tends towards zero $^{12}$. We expect that the realization of these transaction risks, i.e., to what extent the exporter takes advantage of holdup opportunities, determines the gains accruing to farmers, and thus, in the long term the dynamics of smallholder participation in the export market. In particular, past holdups experienced by the farmer threaten the sustainability of the chain by reducing the farmer's willingness to invest, and thus the quantity of produce delivered, and - if transaction risks become too high - can even induce a farmer to drop out of the export market entirely.

\subsection{Empirical analysis}

\subsubsection{Data collection}

In order to disentangle the dynamics of small-scale farmers supplying the export market we collected quantitative as well as qualitative data on the marketing decisions of broccoli producers in Ecuador. Qualitative methods were used to collect general information on broccoli production and on the organization of the broccoli sector in the province of Cotopaxi - where the processing firms and largescale farms are located - and in the province of Chimborazo. In a first step, we conducted semistructured interviews with members of the farmers' group, exporting firms and government entities supporting inclusive business ${ }^{13}$ in order to understand the structure of the sector, its development since the 90's and the current state of the value chain. Subsequently, quantitative research was carried out in the province of Chimborazo, where the small-scale farmers are located. The farmers' association under study is the only organized group of smallholders producing broccoli for the export sector in the

\footnotetext{
${ }^{11}$ When payments are delayed, the contracting firm is effectively extracting rents from its suppliers by getting access to interest-free loans. Suppliers on the other hand experience economic losses and can face cash-flow shortages, especially if they are credit-constrained.

${ }^{12}$ In the local market, asset specificity is lower, because multiple buyers exist. Accordingly, even if one buyer turns down the produce, other equally good marketing options exist in the spot market.

${ }^{13}$ The main purpose of inclusive business is to link small/poor producers to the market in a sustainable way.
} 
country. It has supplied exporting firms through contract farming for over a decade ${ }^{14}$. A household survey was carried out from November 2012 to February 2013 in nine villages of the province of Chimborazo. We covered all eight villages where former and active suppliers of the collection center live. In addition, we interviewed farmers who never participated in the export market living in the same eight villages and from a ninth village located in the same province (with the same infrastructure and climatic characteristics).

Three categories of farmers were identified for the analysis: Active suppliers of the export market (current participants, $n=108$ ), former participants who stopped supplying the export market channel (former participants, $n=522$ ) and farmers who have always supplied the local market (nonparticipants, $n=$ approx. 1500). A stratified random sample was used to select farmers for the interviews. Given their comparatively small number, we decided to over-sample current suppliers in order to ensure sufficient observations for analysis. Current and former participants were randomly chosen from a complete list of active and former producers provided by the association. If producers were not available or did not agree to participate in the interviews, they were replaced with the next person on the list. Non-participants were selected using a random walk sampling approach. In order to obtain a comparable control group, households were chosen only if they have been producing broccoli during the last 12 months.

The final sample is composed of 401 farmers: 88 farmers who still participate in the export chain, 195 farmers who have dropped out of the scheme, and 118 farmers who have always grown broccoli exclusively for the local market. A structured questionnaire was used to collect information on socioeconomic and farm characteristics, agricultural production and marketing, group memberships, family ties and household assets. Information on farm size and on family members who have worked in the collection center was obtained for the past eleven years using recall data. The respondent's attitude towards risk was measured using an experimental risk lottery designed by Binswanger (1980), where real payoffs were offered. Enumerators visited each household and conducted a face-to-face interview of approximately 1.5 hours with a household member involved in the cultivation and commercialization of broccoli. The data collected for the current and former suppliers of the export chain was merged with records provided by the farmers' association containing data on the quantity of broccoli delivered from 2002 to 2012, the days to payment, and the quantity rejected by the exporter per delivery.

\footnotetext{
${ }^{14}$ Nowadays, smallholders can only access the export chain through a farmers' group given that firms do not sign individual contracts with small-scale producers. Sporadic participation in the export chain of non-organized small-scale suppliers was possible during the 90s and early 2000s.
} 


\subsubsection{Model specification}

\subsubsection{Extent of participation}

Each year farmers have to decide how much of their broccoli they allocate to the export sector and how much they sell in the local market. We model this marketing decision by analyzing the factors influencing the extent of participation in the export chain specifying the following model:

$Q_{i t}=\alpha Q_{i(t-1)}+\beta T R_{i(t-1)}+\theta \boldsymbol{X}_{i t}+\pi \boldsymbol{Z}_{i}+c_{i}+\mu_{i t}$

The extent of participation is measured as the quantity $Q$ that farmer $i$ delivers to the export market in year $t^{15}$. $Q_{i t}$ is specified as a function of previous deliveries $Q_{i(t-1)}$, the transaction risks experienced by the household in the previous period $T R_{i(t-1)}$, a vector of other time variant covariates $X_{i t}$, and a vector of time invariant covariates $Z_{i}$ potentially influencing the marketing decision. The error term is composed of a time constant unobserved heterogeneity term $\left(c_{i}\right)$ reflecting the unobserved characteristics of each individual (e.g. management ability, motivation, cognitive ability, etc.), and a time varying error term $\left(\mu_{\mathrm{it}}\right)$, which reflects external shocks that are non-systematic. If the farmer does not deliver any broccoli to the export market during a specific year, $\mathrm{Q}_{\mathrm{it}}$ is set to zero, i.e. the observation enters the analysis. However, transaction risks are not observed during years in which the farmer does not participate in the export market, resulting in missing values in the subsequent year, and thus giving our panel an unbalanced structure.

There are three potential sources of endogeneity in our estimation: i) The decision to participate each year may be correlated with the constant unobserved characteristics of each individual $\left(c_{i}\right)$ (e.g. loyal individuals may participate more consistently, while others decide to participate only sporadically). ii) $c_{i}$ may be correlated with the independent variables (e.g. the motivation of a farmer can influence the quantity delivered to the export sector, but also the quality of the broccoli and thus the quantity rejected). iii) Controlling for persistence in supplying behavior may cause endogeneity, because the lag term of the dependent variable $Q_{i(t-1)}$ is likely to be positively correlated with the error term (due to $c_{i}$ ) (Bond 2002). Even though we are not interested in the effect of $Q_{i(t-1)}$, Bond (2002) states the necessity to control for possible autoregressive dynamics in order to obtain consistent estimates of the remaining parameters. We propose two estimation techniques to address these problems: a) a Correlated Random Effects model for unbalanced panel data to control for unobserved heterogeneity $\left(c_{i}\right)$, and b) a First-Differenced General Method of Moments model, which eliminates $c_{i}$ and controls for the endogeneity of $Q_{i(t-1)}$.

\footnotetext{
${ }^{15} Q_{i t}$ equals zero if the farmer does not deliver any broccoli to the export market in a specific year.
} 


\section{Correlated random effects (CRE) model for unbalanced panels}

With panel data, one way of controlling for time constant unobserved heterogeneity $\left(c_{i}\right)$ is to use Fixed Effects estimators. This removes, however, all time constant explanatory variables $\left(Z_{i}\right)$ from the analysis, which are often of interest for understanding the drivers and barriers to participation. This disadvantage can be overcome using the Mundlak-Chamberlain approach, which controls for fixed effects by including a correlated random effects (CRE) estimator. Wooldridge (2010) show that this method is also valid for obtaining unbiased estimators with unbalanced panels, as long as we can assume that selection is not correlated with the time varying error term $\left(\mu_{\mathrm{it}}\right)$.

The CRE model allows for linear correlation between the unobserved heterogeneity term $c_{i}$ and the observed explanatory variables by including a vector of variables containing the means of all timevarying covariates for each household as indicated in the following equation:

$$
Q_{i t}=\alpha Q_{i(t-1)}+\beta \boldsymbol{X}_{i t}+\pi \boldsymbol{Z}_{i}+\xi \bar{X}_{l}+a_{i}+\mu_{i t}
$$

where $\boldsymbol{X}_{i t}$ contains all time-varying covariates including $T R_{i(t-1)}$, and $\bar{X}_{l}$ is a vector of variables containing the means of the time-varying covariates including the time dummies (Wooldridge 2010). In unbalanced panels, the calculation of means is based only on the selected observations that enter the estimation in the specific year (Wooldridge 2010). With this approach we eliminate the problem of self-selection based on $c_{i}$ and the endogeneity caused by possible correlation between covariates and $c_{i}$. The model is estimated using Random Effects and standard errors are clustered at the household level to obtain estimates robust to heteroskedasticity and correlation among the disturbances as recommended by Wooldridge (2010).

\section{Generalized Method of Moments}

The second estimation strategy is First-Diff GMM developed by Arellano and Bond (1991). It uses first differences to eliminate the unobserved heterogeneity term $\left(c_{i}\right)$ and an instrumental variable approach to eliminate the endogeneity of the lagged dependent variable $\left(Q_{i(t-1)}\right)$. For this purpose, further lags of $Q_{i(t-1)}$ in levels are used as instruments. The final model to be estimated is specified in the following equation:

$\Delta Q_{i t}=\alpha \Delta Q_{i(t-1)}+\beta \Delta \boldsymbol{X}_{i t}+\Delta \mu_{i t}|\alpha|<1$

where $\Delta \boldsymbol{X}_{i t}$ contains all differences of the time-variant covariates including $T R_{i(t-1)}$. First difference GMM is expected to perform poorly if the series used in the estimation are random walks or highly persistent (Bond 2002). A necessary assumption for the model is that the time-varying errors are not serially correlated. This implies that $Q_{i(t-2)}$ and past lagged levels are not correlated with $\Delta \mu_{i t}$ and therefore can be used as instruments for $\Delta Q_{i(t-1)}$. The assumption of no serial correlation is fulfilled if 
there is no second-order serial correlation in the first-differenced residuals ${ }^{16}$. The validity of the instruments can be tested using the Sargan test of over-identifying restrictions.

An indication of the consistency of $\alpha$ can be obtained by comparing the first-differenced GMM results with those obtained with OLS and Fixed Effects. Since $Q_{i(t-1)}$ is correlated with the individual effects $\left(c_{i}\right)$, the OLS estimate is expected to be biased upwards. On the other end, the Fixed Effects estimate will be biased downwards, because of the negative correlation introduced between the transformed lagged dependent variable and the transformed error term. Therefore, a consistent estimator of $\alpha$ is expected to lie between the ones obtained with OLS and FE (Bond, Hoeffler, and Temple 2001; Bond 2002).

\subsubsection{Dropping out of a high-value chain}

Time duration models estimate the probability that an individual switches from one stage to another given that he has not done so in the previous period (Dadi, Burton, and Ozanne 2004). We model the farmer's decision to withdraw from the export marketing channel, by estimating the probability that the farmer changes his position from participation to non-participation at the beginning of time period $t$, given that he has not done so before $t$. We organize our data in a discrete time fashion, where each farmer has eleven observations, one for each year of the time period under study (2002 - 2012). Given that the withdrawal from the export sector is conditional on previous participation, we exclude those farmers who never participated in the export sector from the analysis. The event of withdrawal is called failure, and we denote the discrete time to failure with $T$. The dependent variable is a dummy variable that equals zero in every year that the farmer supplies the export sector and one in the year he stops supplying (failure). Multiple spells are allowed, which means that farmers can decide to participate a second or third time after withdrawing. The spell or time of duration starts when the farmer starts supplying the export market and finishes when he decides to withdraw. A vector of time variant covariates $\left(\mathrm{X}_{\mathrm{it}}\right)$ is included, which is fixed within the interval $t$ and speeds up or delays the failure time of the individual. A vector of time invariant covariates $\left(\boldsymbol{Z}_{t}\right)$ is also observed, which is constant over the whole period under study.

The hazard function $\left(\alpha_{\mathrm{i}}\right)$, which characterizes $T$, is given by the conditional probability for the risk of failure in interval $t$ (Fahrmeir 1997) given that the individual has not failed before $t$ and is expressed by:

$$
\alpha_{\mathrm{i}}\left(\mathrm{t} \mid \mathrm{X}_{\mathrm{it}}, Z_{t}\right)=\operatorname{Pr}\left(\mathrm{T}_{\mathrm{i}}=\mathrm{t} \mid \mathrm{T}_{\mathrm{i}} \geq \mathrm{t}, \mathrm{X}_{\mathrm{it}}, Z_{i}\right), \mathrm{t}=1, \ldots, \mathrm{q}
$$

\footnotetext{
${ }^{16}$ First order serial correlation is expected in the first-differenced residuals even if the disturbances are serially uncorrelated. When using System GMM, second order correlation is present, therefore we limit our model to using only Difference-GMM.
} 
Where $\mathrm{T}_{\mathrm{i}}=\mathrm{t}$ denotes failure within interval $t, \mathrm{~T}_{\mathrm{i}} \geq \mathrm{t}$ denotes survival up to time $t$ for individual $i, \mathrm{X}_{\mathrm{it}}$ is a vector of time varying covariates including $T R_{i(t-1)}$, and $Z_{i}$ is a vector of time invariant covariates.

The hazard function can also be expressed as a function of time (baseline hazard) combined with a vector of covariates acting multiplicatively on the baseline hazard and shifting it proportionally (Burton, Rigby, and Young 2003). Semi-parametric approaches in duration analysis, such as the Cox model, do not require any assumption on the distribution of the errors, and thus of the baseline hazard. Instead they rank the occurrence of failures and conduct a binary analysis on each observation, exclusively using the ranking of survival times (Cleves et al. 2008). The proportional hazard model, which we will estimate using the Cox model approach, is specified as:

$$
\alpha_{i j}(t)=\alpha_{0}(t) \exp \left(\beta X_{i j}+\gamma Z_{i}+v_{j}\right)
$$

Where $\alpha_{0}(\mathrm{t})$ is the unspecified baseline hazard, $v_{j}$ corresponds to the error term (frailty) of the model, i.e., a latent random effect within groups that enters multiplicatively on the hazard function. Given that in our data we have multiple observations per individual (multiple spells), we can expect that the failing times for each farmer are not independent from each other and thus the standard errors should be adjusted to account for this possible correlation. The option of shared frailty is used to account for this potential correlation, which is measured by $\theta$ and is assumed to have a gamma distribution (Cleves et al. 2008). As we consider time discrete (yearly data), it is likely that more than one observation fails at the same time (tied failures) and as a result the order of failures within this year cannot be established as required for the simple Cox model. Cleves et al. (2008) mention three ways of handling such tied failures, of which we use the Efron's method ${ }^{17}$.

\subsubsection{Potential determinants}

Among the variables potentially explaining the extent of participation as well as the decision to drop out of the export sector, we are particularly interested in the effect of transaction risks. In particular, hold-ups experienced in previous periods might increase the perceived risk of the transaction and thus have a strong negative effect on participation. Transaction risks are captured by the variables: a)

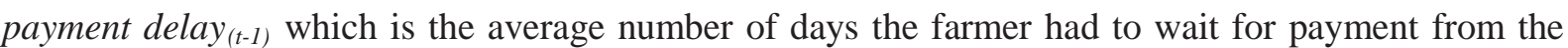
exporter in the previous year, and b) $\log _{-} k g$ rejected $_{(t-1)}$ which represents the total kilograms rejected

\footnotetext{
${ }^{17}$ Efron's method is an approximation to the exact marginal calculation method for tied failures, where all the possible orders of failures within a group failing at the same $t$ are taken into account for the final probability of failure at that specific time $t$. In Efron's method the risk set used as denominator contains all the observations failing at time $t$, but is corrected using probability weights (Cleves et al, 2002).
} 
by the exporting firm in the previous year in $\operatorname{logs}^{18}$. We consider these variables strictly exogenous, which means that feedback from current or past external unobserved shocks has been ruled out.

Regarding other transaction characteristics, the price per kilogram paid by the exporter to the collection center at time $t$ is included in the model (price export market). This value represents a fixed price that is negotiated between the farmers' group and the exporter on an annual basis. In addition, we include a dummy that equals one if during 2012 the average price obtained by the farmer in the local market was below the fixed export market price of 2012. We use this variable as a proxy for low bargaining power in the local market. As we only have farmer-specific local market prices for 2012 and not for the full study period, we implicitly assume that individual bargaining power remained invariable throughout the analyzed time period.

Furthermore, we consider three distinct proxies for social networks and information access. First, we include a dummy variable that equals one if the farmer has family ties with workers of the collection center. Given that family ties play an important role in Latin American rural societies (Carlos and Sellers 1972), farmers may feel more obliged to meet their commitment and deliver their produce to the collection center, if a family member is working there. On the other hand, for the case of Madagascar, Fafchamps and Minten (2001) show that contracts are handled more flexibly among kin and thus deviations from the original agreement are observed more frequently. Second, we follow Moser and Barrett (2006) using the aggregate quantity delivered per village (aggregate village supplies $\left._{(t-1)}\right)$ as a proxy for community behavior and expectations. Moser and Barrett (2006) describe how the pressure to conform to behavioral norms established within a community can affect individual decisions. Therefore, if many village members are active suppliers of the export market and village leaders encourage participation, individual farmers might associate higher social acceptance with that particular marketing channel. In addition, higher levels of aggregate village supplies can also result in better access to information and lower costs of transportation for individual farmers. In the econometric estimation we consider this variable as pre-determined (it may be influenced by past external shocks) and use lagged aggregate village supplies to minimize endogeneity problems resulting from reverse causality. Third, membership in the farmers' group operating the collection center can facilitate access to information, e.g. regarding the conditions of export market participation, and to the services provided by the organization such as access to technical support and credit. In addition, members made monetary contributions to the initial investments of the organization and therefore have a stake in the business, which also makes them more likely to patronize the collection center. It is important to note that farmers became members of the farmers' group when it was founded in 2001, and in the following years no new members were admitted.

\footnotetext{
${ }^{18}$ In the duration model, we do not control for the total amount of broccoli delivered in the previous time period, and therefore, instead of the absolute quantity rejected we include the percentage of produce rejected in the previous time period.
} 
While often unobserved in empirical studies due to the difficulty of measurement, we also include the farmer's attitude towards risk as a potential determinant. This is particularly important in the context of our study, given that the farmer's risk attitude is likely to influence his subjective perception and evaluation of transaction risks. We played an experimental game with real payoffs proposed by Binswanger (1980) to obtain a measure of risk attitude. Six different gambling options were presented to each farmer at the end of the interview, each option with a different partial risk aversion coefficient ranging from extreme risk-averse (if option 1 was preferred) to neutral or negative risk-averse (if option 6 was preferred). Given that many of the interviewed farmers were illiterate, for each of the six options we presented them a picture of the sum of money they could win. The partial risk aversion coefficient was then calculated according to the farmer's choice as explained in Binswanger (1980) and normalized to a scale from 0 (low risk aversion) to 1 (high risk aversion). We expect that more riskaverse farmers prefer the market channel associated with lower risk. Accordingly, risk-averse farmers may be more likely to participate in the export chain offering them a secure market and a secure price. On the other hand, if there is mounting evidence of increasing transaction risks, such as payment delays or product rejections, risk-averse farmers may be the first to drop out of the chain.

To capture poverty, we use a dummy variable that equals one if the household received a governmental cash transfer (cash transfer), which is targeted to the poorest households in the country. Other variables capturing household and farm characteristics are included as controls, such as age, gender and education of the household head, number of household members, lagged farm size, and distance to the collection center in kilometers. In most specifications, we include interaction terms between a dummy variable for the period 2009 - 2012 and our main variables of interest in order to control for the time span after the negative external shock caused by the bankruptcy of the buyer. Long payment delays and payment defaults during this time may have jeopardized the trust of smallholder suppliers, negatively affecting their participation in the value chain. Year and village dummies are also included to control for year-specific macroeconomic effects and shocks as well as village-specific characteristics.

\subsection{Descriptive results}

Descriptive statistics for the covariates included in the models are presented in Table 2.2 as well as in Table A1.1 in the Appendix. Table 2.2 compares the characteristics for the year 2012 of farmers currently supplying the export market (current participants), farmers who dropped out of the export market (former participants) and farmers who have never supplied the export market (nonparticipants). Descriptive results indicate that while most of the household characteristics do not differ significantly between the three groups, current participants have less education but more farming experience than former participants and in particular than non-participants. Geographically, current 
participants are located closer to the collection center and further away from the local market, compared to both former and non-participants. We find no significant difference in the size of owned land (in 2012) between the three categories of farmers; only when taking into account rented and shared plots the total land size of non-participants is slightly bigger than that of current participants (significant at the $10 \%$ level). Yet, current participants are more specialized in terms of the area dedicated to broccoli production. Nevertheless, when looking at the income derived from broccoli production, we find no significant difference between the three groups. Furthermore, income differences, even though slightly lower for current participants, are not significantly different between the groups. According to our proxy for wealth (cash transfer), however, we do find evidence that current participants are significantly poorer than non-participants. Finally, we find significant differences between the groups with respect to social networks. A significantly larger share of current participants is member of the farmers' group and has family ties with workers at the collection center. Compared to non-participants, both current and former participants have a larger number of relatives producing broccoli for the local market and in particular for the export market.

Large differences also exist between the three groups of farmers regarding the characteristics of the market transactions. First of all, we observe that only $22 \%$ of the current participants exclusively sell their broccoli to the export market. The majority of current participants, besides delivering to the export market, also deliver some of their produce to the local market. Yet, when compared to former and non-participants, their income obtained from local market sales is significantly lower, because some of their produce was destined to the export sector.

Table 2-2 Household, farm and transaction characteristics in 2012, by participation status. ${ }^{\text {a }}$

\begin{tabular}{|c|c|c|c|c|c|c|}
\hline \multirow{2}{*}{$\begin{array}{l}\text { Variable } \\
\text { (no. obs) }\end{array}$} & \multirow{2}{*}{$\begin{array}{c}\text { a. Current } \\
\text { part. } \\
88\end{array}$} & \multirow{2}{*}{$\begin{array}{c}\text { b. Former } \\
\text { part. } \\
195\end{array}$} & \multirow{2}{*}{$\begin{array}{c}\text { c. Non- } \\
\text { part. } \\
118\end{array}$} & \multicolumn{3}{|c|}{ Sig. differences } \\
\hline & & & & $a b$ & $b c$ & $a c$ \\
\hline \multicolumn{7}{|l|}{ Household characteristics } \\
\hline Risk aversion & 0.247 & 0.211 & 0.267 & & & \\
\hline HH members & 4.17 & 4.18 & 4.32 & & & \\
\hline $\mathrm{HH}$ head age & 48.35 & 47.23 & 46.58 & & & \\
\hline HH member off-farm & 0.72 & 0.64 & 0.74 & & $*$ & \\
\hline HH head secondary education & 0.19 & 0.23 & 0.35 & $* *$ & $* *$ & $* *$ \\
\hline Farming experience & 10.23 & 9.59 & 8.14 & & $* *$ & $* *$ \\
\hline \multicolumn{7}{|l|}{ Farm characteristics } \\
\hline Distance to collection center $(\mathrm{km})$ & 1.37 & 4.51 & 10.02 & $* * *$ & $* * *$ & $* * *$ \\
\hline Distance to local market (km) & 13.25 & 12.05 & 9.91 & $* * *$ & $* * *$ & $* * *$ \\
\hline Total area (solar) ${ }^{\mathrm{b}}$ & 4.21 & 5.13 & 6.50 & & & $*$ \\
\hline Own area (solar) & 3.73 & 4.3 & 5.07 & & & \\
\hline Broccoli area (solar) & 2.61 & 1.95 & 2.07 & $* *$ & $* *$ & $* * *$ \\
\hline \multicolumn{7}{|l|}{ Wealth related variables } \\
\hline Cash transfer & 0.70 & 0.6 & 0.52 & $*$ & & $* * *$ \\
\hline
\end{tabular}


Chapter 2. Dynamics of smallholder participation in horticultural export chains.

Evidence from Ecuador

\begin{tabular}{lcccccc} 
Total income (USD) & 6412.09 & 7766.7 & 8576.87 & & & $* *$ \\
Total farm income (USD) & 2740.10 & 2777.32 & 3214.68 & & & \\
\hline Social Networks & & & & & & \\
Membership farmers' group & 0.48 & 0.24 & 0.00 & $* * *$ & $* * *$ & $* * *$ \\
Family ties & 0.34 & 0.10 & 0.01 & $* * *$ & $* * *$ & $* * *$ \\
Relatives in local market & 5.17 & 5.42 & 4.02 & & $* * *$ & $* *$ \\
Relatives in export market & 4.0 & 1.64 & 0.43 & $* * *$ & $* * *$ & $* * *$ \\
\hline Characteristics of the transaction & & & & & & \\
& & & & & & \\
Broccoli income total & 1117.91 & 1014.33 & 1101.99 & & & \\
Broccoli income local market & 635.12 & 904.72 & 1067.05 & & & $* *$ \\
Collection center only & 0.22 & 0 & 0 & $* * *$ & & $* *$ \\
Payment delay (local market) & 4.2 & 2.65 & 1.81 & $* * *$ & $*$ & $* * *$ \\
Payment delay (export market) & 38.54 & - & - & & & \\
\% rejection (in export market) & 11.5 & - & - & & &
\end{tabular}

\footnotetext{
${ }^{\mathrm{a}}$ Mean values calculated from survey data. An explanation of each variable can be found in Table A1.1 in the appendix.

${ }^{\mathrm{b}}$ Area is measured in solar. 1 solar $=1700 \mathrm{~m}^{2}$ (approximately)

*Significant at the $10 \%$ level ** Significant at the $5 \%$ level *** Significant at the $1 \%$ level
}

With respect to the transaction risks, we can observe stark differences between the two marketing channels. In the export market farmers had to wait on average 38 days for their payment in 2012, whereas in the local market payment was made on average within two to four days after delivery. Similarly, stringent quality requirements result in relatively high rejection rates in the export sector. On the average, $11.5 \%$ of produce delivered by current participants was rejected in the high-value chain, while in the local market produce rejections are not an issue. In the export market, farmers received a fixed price of $0.25 \mathrm{US} \$ / \mathrm{kg}$ throughout the whole year (of which the collection center kept $0.02 \mathrm{US} \$ / \mathrm{kg}$ to cover their costs), but in the local market farmers faced extremely volatile prices ranging from $0.04 \mathrm{US} \$ / \mathrm{kg}$ to $1.43 \mathrm{US} \$ / \mathrm{kg}$ (mean: $0.40 \mathrm{USD} / \mathrm{kg}$, standard deviation: 0.24 ).

When current and former participants were asked about the problems experienced in the export sector, over $70 \%$ reported payment delays and 30\% mentioned that they were not paid at all, because the exporter defaulted on the payment (see Figure 2.3). Furthermore, around 35\% experienced produce rejections. This reflects the high levels of uncertainty to which farmers in the export sector are exposed. Both delayed/lack of payment as well as produce rejections negatively affect the cash flow and/or income of smallholder farmers, which often do not possess the means and liquidity to compensate such losses. Finally, low prices and high quality requirements were considered a problem by $25 \%$ and $10 \%$ of the current and former participants, respectively. 
Chapter 2. Dynamics of smallholder participation in horticultural export chains.

Figure 2-3 Problems experienced by farmers in the export sector ${ }^{a}$

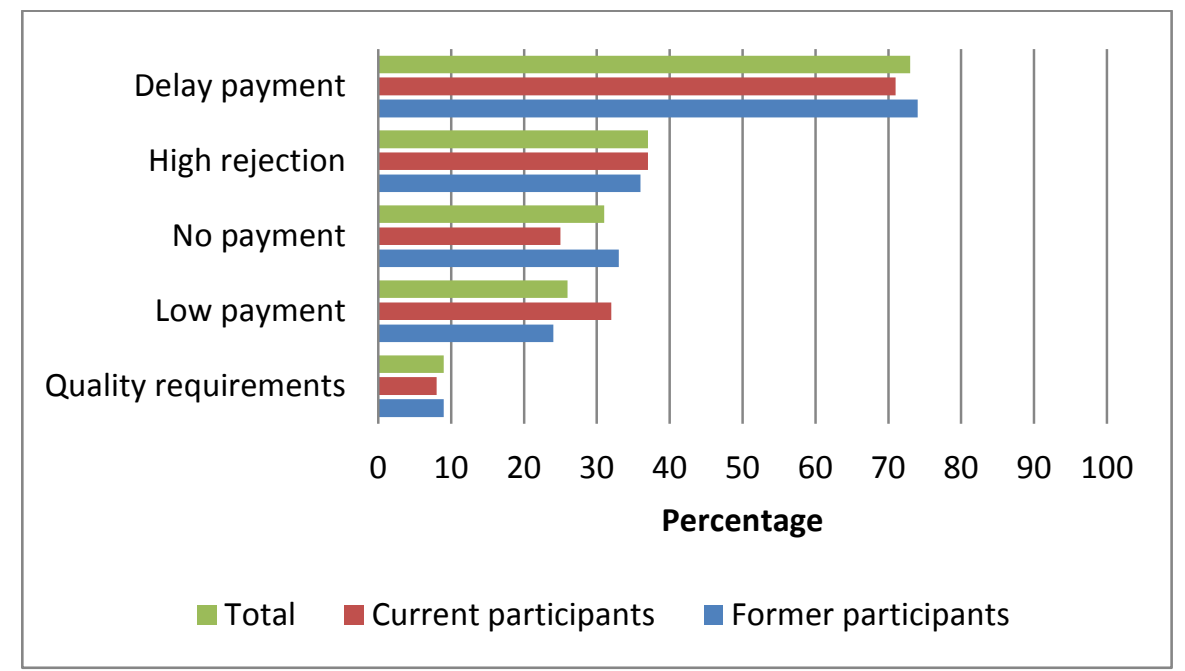

${ }^{a}$ Sub-sample of 283 surveyed farmers who ever delivered broccoli to the export sector.

In spite of the perceived problems, over $60 \%$ of the entire sample (including non-participants) would be willing to produce broccoli for the export market and join a contract scheme, if it was supported by a legal document ${ }^{19}$ (Figure 2.4). The conditions that are critical for them to sign an agreement include secure payment (85\%) and higher prices (50\%). Less than 16\% of the farmers mentioned the provision of inputs, training or credit as a condition to participate in the export market, thus providing some evidence for the existence of functioning factor markets in the area.

Figure 2-4 Farmers's conditions for signing a new contract ${ }^{a}$

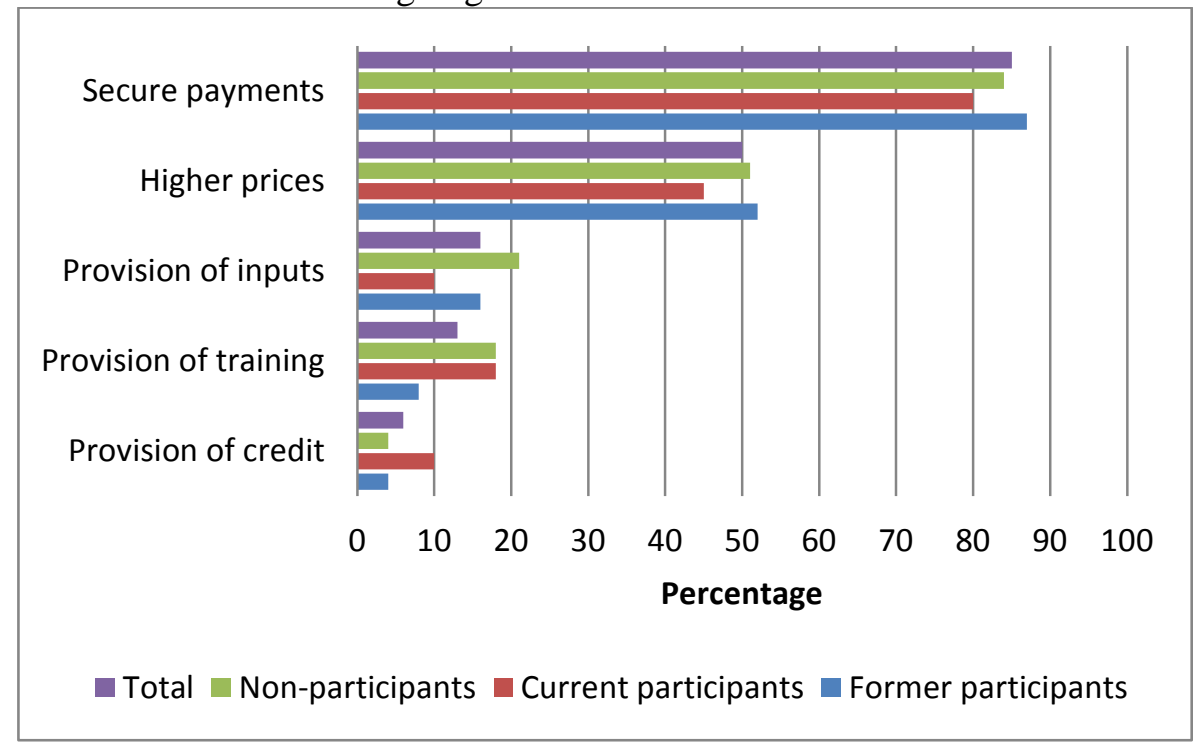

${ }^{a}$ Subsample of 254 farmers willing to sign a new contract.

\footnotetext{
${ }^{19}$ No particular buyer was specified in the question.
} 


\subsection{Econometric results}

When investigating the determinants of the quantities delivered to the export market or the factors influencing the withdrawal from the export chain, those farmers who never participated in the export chain (non-participants) are not considered in the analyses, given that participation is a pre-requisite for the subsequent decision of product allocation and withdrawal from the chain ${ }^{20}$. Nonetheless, we are interested to know whether there are systematic differences between those farmers who at some stage supplied the export market and those farmers who have never done so. To test for potential selection bias, we estimate a Heckman selection model based on the full sample (non-participants, former and current participants). In the first stage, a probit model is used to predict the probability of ever participating in the export market. In the second stage, for those farmers who have ever supplied the export sector the quantity delivered during their first year of participation is predicted. Estimation results are reported in Table A1.3 in the appendix. Rho is not statistically significant, indicating that sample selection is not an issue and farmers who participate in the export sector are not systematically different from those who supply the local market. In the following sections, those farmers who have never entered the export sector are not further regarded in the analyses.

\subsubsection{Extent of participation}

Table 2.3 presents the estimates from the Correlated Random Effects and First-Differenced GMM models on the determinants of the extent of participation. Models (1) and (2) include interaction terms of various potential explanatory variables with the time dummy 2009-2012 to control for the possibility of a structural break induced by the external financial shock. For comparison, columns (3) to (5) report additional model specifications and alternative estimators. Column (3) provides CRE estimates without interaction effects. Comparing results in columns (2) and (3) illustrates the importance of controlling for the structural break that is associated not only with changes in the magnitude but even in the sign of several coefficients before and after the external shock. Accordingly, the data provides strong evidence that supply patterns were adjusted in response to the crisis. Finally, OLS and Fixed Effects estimates are reported in columns (4) and (5).

\footnotetext{
${ }^{20}$ In the model on the extent of participation, non-participants could enter the analysis by setting their amount delivered equal to zero. However, if they never participated in the export chain, they never experienced any transaction risks and accordingly drop out of the analysis due to missing values. Setting their transaction risk values equal zero would be misleading, because it suggests that they experienced no problems, when in reality they simply did not perform any transactions in the export sector.
} 
Chapter 2. Dynamics of smallholder participation in horticultural export chains.

Table 2-3 Results on the exteng of participation in the export sector.

\begin{tabular}{|c|c|c|c|c|c|}
\hline VARIABLES & $\begin{array}{c}\text { (1) } \\
\text { Diff- } \\
\text { GMM } \\
\end{array}$ & $\begin{array}{c}\text { (2) } \\
\text { CRE }\end{array}$ & $\begin{array}{c}\text { (3) } \\
\text { CRE }\end{array}$ & $\begin{array}{c}(4) \\
\text { OLS }\end{array}$ & $\begin{array}{l}\text { (5) } \\
\text { FE }\end{array}$ \\
\hline Kg delivered $_{(\mathrm{t}-1)}$ & $\begin{array}{c}0.504^{* *} \\
(0.225)\end{array}$ & $\begin{array}{c}0.378 * * * \\
(0.0408)\end{array}$ & $\begin{array}{c}0.406 * * * \\
(0.0409)\end{array}$ & $\begin{array}{c}0.554^{* * *} \\
(0.0432)\end{array}$ & $\begin{array}{c}0.224 * * * \\
(0.0507)\end{array}$ \\
\hline \multicolumn{6}{|l|}{ Transaction characteristics } \\
\hline Payment delay $_{(\mathrm{t}-1)}$ & $\begin{array}{c}-9.749 * \\
(5.880)\end{array}$ & $\begin{array}{c}-9.781 * \\
(5.221)\end{array}$ & $\begin{array}{l}-3.267 \\
(2.621)\end{array}$ & $\begin{array}{c}-8.742^{* *} \\
(3.548)\end{array}$ & $\begin{array}{c}-8.868 * \\
(4.884)\end{array}$ \\
\hline Log kg rejected ${ }_{(t-1)}$ & $\begin{array}{c}-2,330 * * * \\
(822.2)\end{array}$ & $\begin{array}{c}-460.3 * \\
(262.5)\end{array}$ & $\begin{array}{c}-1,099 * * * \\
(178.2)\end{array}$ & $\begin{array}{c}109.2 \\
(244.6)\end{array}$ & $\begin{array}{c}221.0 \\
(275.4)\end{array}$ \\
\hline Price export market & $\begin{array}{c}88.38 \\
(518.0)\end{array}$ & $\begin{array}{c}2,349 \\
(1,665)\end{array}$ & $\begin{array}{c}3,263 * * \\
(1,502)\end{array}$ & $\begin{array}{l}452.4 \\
(514.2)\end{array}$ & $\begin{array}{l}-170.4 \\
(411.5)\end{array}$ \\
\hline Low bargaining local market & & $\begin{array}{r}213.8 \\
(425.9) \\
\end{array}$ & $\begin{array}{r}147.3 \\
(243.5) \\
\end{array}$ & & \\
\hline \multicolumn{6}{|l|}{ Social networks } \\
\hline Family ties & $\begin{array}{c}651.5 \\
(1,283)\end{array}$ & $\begin{array}{l}-648.2 \\
(1,225)\end{array}$ & $\begin{array}{l}-1,309 \\
(846.8)\end{array}$ & $\begin{array}{c}1,032 \\
(947.6)\end{array}$ & $\begin{array}{c}228.7 \\
(1,313)\end{array}$ \\
\hline Aggregate village supplies $_{(\mathrm{t}-1)}$ & $\begin{array}{l}2.439 \\
(2.127)\end{array}$ & $\begin{array}{c}0.111 \\
(0.709)\end{array}$ & $\begin{array}{c}1.517 * * * \\
(0.579)\end{array}$ & $\begin{array}{c}0.565 \\
(0.463)\end{array}$ & $\begin{array}{c}1.723^{* * *} \\
(0.647)\end{array}$ \\
\hline Membership farmers'group & & $\begin{array}{c}1,758 * * * \\
(586.5)\end{array}$ & $\begin{array}{c}454.7 \\
(360.2)\end{array}$ & & \\
\hline \multicolumn{6}{|l|}{ Other control variables } \\
\hline Risk aversion & & $\begin{array}{c}643.3 \\
(551.2)\end{array}$ & $\begin{array}{l}-142.1 \\
(301.3)\end{array}$ & & \\
\hline HH members & $\begin{array}{l}225.2 \\
(1,046)\end{array}$ & $\begin{array}{c}-1,664^{* *} \\
(776.5)\end{array}$ & $\begin{array}{c}-1,348^{*} \\
(765.7)\end{array}$ & $\begin{array}{l}-3.644 \\
(90.56)\end{array}$ & $\begin{array}{c}-1,855 * * \\
(780.7)\end{array}$ \\
\hline HH head female & & $\begin{array}{l}-16.97 \\
(482.7)\end{array}$ & $\begin{array}{c}204.0 \\
(359.5)\end{array}$ & & \\
\hline HH head age & $\begin{array}{c}-786.6 * * * \\
(286.7)\end{array}$ & $\begin{array}{l}-895.6 \\
(1,365)\end{array}$ & $\begin{array}{l}-407.7 \\
(1,273)\end{array}$ & $\begin{array}{c}14.24 \\
(12.08)\end{array}$ & $\begin{array}{c}137.8 \\
(223.8)\end{array}$ \\
\hline HH head secondary education & & $\begin{array}{l}-185.3 \\
(325.2)\end{array}$ & $\begin{array}{l}-222.8 \\
(319.9)\end{array}$ & & \\
\hline Distance to collection center & & $\begin{array}{c}7.124 \\
(66.69)\end{array}$ & $\begin{array}{l}-19.47 \\
(69.01)\end{array}$ & & \\
\hline Own $_{\text {area }}^{(t-1)}$ & $\begin{array}{c}731.2 * * \\
(361.2)\end{array}$ & $\begin{array}{c}696.9 * * \\
(277.5)\end{array}$ & $\begin{array}{l}528.0 * \\
(289.0)\end{array}$ & $\begin{array}{c}166.4^{* *} \\
(65.33)\end{array}$ & $\begin{array}{c}665.0 * * \\
(321.0)\end{array}$ \\
\hline Cash transfer & & $\begin{array}{c}-777.0 * * \\
(386.6)\end{array}$ & $\begin{array}{l}-295.1 \\
(223.9)\end{array}$ & & \\
\hline Total years of participation & & $\begin{array}{c}615.7 * * * \\
(85.04) \\
\end{array}$ & $\begin{array}{c}539.3^{* * *} \\
(84.81) \\
\end{array}$ & & \\
\hline \multicolumn{6}{|l|}{ Period 2009 - 2012} \\
\hline 2009-2012 x payment delay $(t-1)$ & $\begin{array}{c}4.400 \\
(6.492)\end{array}$ & $\begin{array}{c}7.495 \\
(5.875)\end{array}$ & & $\begin{array}{l}7.922^{*} \\
(4.148)\end{array}$ & $\begin{array}{c}5.370 \\
(5.253)\end{array}$ \\
\hline $2009-2012$ x log kg rejected $(t-1)$ & $\begin{array}{c}-935.8 * * \\
(430.3)\end{array}$ & $\begin{array}{c}-1,296 * * * \\
(311.0)\end{array}$ & & $\begin{array}{c}-1,042 * * * \\
(258.0)\end{array}$ & $\begin{array}{c}-1,352 * * * \\
(310.8)\end{array}$ \\
\hline 2009-2012 x Low bargaining local market & & $\begin{array}{l}-282.2 \\
(610.7)\end{array}$ & & & \\
\hline 2009-2012 x family ties & $\begin{array}{l}-1,323 \\
(1,750)\end{array}$ & $\begin{array}{l}-553.9 \\
(1,307)\end{array}$ & & $\begin{array}{l}-1,036 \\
(1,080)\end{array}$ & $\begin{array}{c}-2,427^{*} \\
(1,462)\end{array}$ \\
\hline $2009-20012 \mathrm{x}$ aggregate village supplies $(\mathrm{t}-1)$ & $\begin{array}{l}-1.717 \\
(1.108)\end{array}$ & $\begin{array}{c}0.873 \\
(0.587)\end{array}$ & & $\begin{array}{c}-0.827 * \\
(0.489)\end{array}$ & $\begin{array}{c}-0.0818 \\
(0.463)\end{array}$ \\
\hline
\end{tabular}


Chapter 2. Dynamics of smallholder participation in horticultural export chains.

\begin{tabular}{|c|c|c|c|c|c|}
\hline 2009-2012 x membership farmers' group & & $\begin{array}{c}-3,227 * * * \\
(798.1)\end{array}$ & & & \\
\hline 2009-2012 x risk aversion & & $\begin{array}{c}-1,780^{* *} \\
(784.5)\end{array}$ & & & \\
\hline 2009-2012 x HH head female & & $\begin{array}{c}732.8 \\
(615.3)\end{array}$ & & & \\
\hline 2009-2012 x own $\operatorname{area}_{(\mathrm{t}-1)}$ & $\begin{array}{l}-43.39 \\
(142.4)\end{array}$ & $\begin{array}{c}-204.6^{* * *} \\
(71.51)\end{array}$ & & $\begin{array}{l}-61.37 \\
(82.99)\end{array}$ & $\begin{array}{c}-229.2^{* * *} \\
(86.69)\end{array}$ \\
\hline 2009-2012 x cash transfer & & $\begin{array}{l}914.1^{*} \\
(542.7)\end{array}$ & & & \\
\hline Constant & & $\begin{array}{l}-65,257 \\
(49,953)\end{array}$ & $\begin{array}{c}-77,014^{*} \\
(46,588)\end{array}$ & $\begin{array}{c}-7,480 \\
(10,307)\end{array}$ & $\begin{array}{c}9,519 \\
(14,358)\end{array}$ \\
\hline Observations & 1,108 & 1,480 & 1,480 & 1,483 & 1,483 \\
\hline R-squared & & 0.5939 & 0.5717 & 0.498 & 0.430 \\
\hline
\end{tabular}

In the Diff-GMM model (column (1)) we address the endogeneity of the lagged dependent variable $\mathrm{kg}$ delivered $_{(t-1)}$ by using lags two to five as instruments. A Fisher-type unit root test for panel data rules out the existence of random walks in the series used in the model confirming its validity (results are reported in Table A1.4 in the appendix). The Sargan and Hansen tests also show that the instruments used are exogenous to the lagged dependent variable and therefore valid for the estimation (results are reported in Table A1.5 in the appendix). Additionally, we find no autocorrelation of second order in the model using the Arellano-Bond test for autocorrelation ${ }^{21}$. Autocorrelation of first order is expected in first differences because $\Delta \mu_{t}$ and $\Delta \mu_{t-1}$ share a common term (results are reported in Table A1.6 in the appendix). Controlling for potential endogeneity, the Diff-GMM estimates show that the amount of broccoli delivered in the previous period has a significantly positive effect on the amount of broccoli delivered in the current period. The coefficient estimate obtained from the Diff-GMM model lies between the OLS and Fixed Effects estimates, which confirms its consistency. The path dependency or persistence of deliveries reflected in this coefficient is in line with other studies that have reported a strong positive correlation between lagged and current horticultural export volumes (e.g. Schuster and Maertens (2015) for the Peruvian asparagus sector).

Regarding transaction risks, we find - consistently across both models (columns (1) and (2)) - a strongly negative effect of past produce rejections on the extent of participation. According to the CRE model estimates, a one percent increase in the amount rejected in the previous year leads to a decrease in current deliveries of $4.6 \mathrm{~kg}$. This effect is even further exacerbated by the crisis, after which a one percent increase in rejection rate is associated with a decrease in the delivered quantity by $17.6 \mathrm{~kg}$. Once we adequately control for the endogeneity of lagged product deliveries, the Diff-GMM model

\footnotetext{
${ }^{21}$ The existence of autocorrelation of second order would invalidate the use of lags as instruments.
} 
predicts an even stronger effect of product rejections ranging from a reduction in deliveries of $23.3 \mathrm{~kg}$ before the crisis to $32.7 \mathrm{~kg}$ after the crisis. Regarding payment delays, results are also consistent across both models, indicating a negative effect that is statistically significant at the $10 \%$ level. Accordingly, each additional day of payment delay in the previous period decreases current product deliveries by $9.8 \mathrm{~kg}$. The effect of payment delays on product deliveries remains unaltered after the external shock.

The CRE model further allows us to investigate the relationship between potential time-invariant determinants and the extent of participation. First of all, a strong and significantly positive correlation is identified for membership in the farmers' group. On the average, membership increases deliveries by as much as $1758 \mathrm{~kg}$ compared to non-members. This positive effect, however, reverses with the event of the negative external shock to the supply chain. After the crisis, members on the average deliver $1469 \mathrm{~kg}$ less to the collection center than non-members. This may be due to members having better access to information regarding the performance of the organization and thus being more aware of the difficult situation faced by the supply chain and reacting accordingly by reducing their produce allocated to the export market. Besides membership in the farmers' group, the other social network variables (aggregate village supplies ${ }^{22}$ and family ties) do not seem to play an important role in farmers’ product allocation decisions among alternative market outlets.

Finally, we observe that the quantity delivered increases with farm size, and that poor farmers deliver significantly less compared to non-poor households. These relationships are affected, however, by the negative external shock. After the supply chain is struck by the crisis in 2009, farmers with larger farm sizes reduce their produce allocation to the export market, even though the overall effect of farm size remains positive. On the other hand, the difference between poor and non-poor farmers becomes insignificant in the post-crisis period (joint significance of the coefficients on cash transfer and the interaction term: $\mathrm{p}=0.1327)$. Finally, farmers with higher risk aversion respond to the crisis delivering significantly less compared to farmers with low risk aversion in the post-crisis period.

\subsubsection{Dropping out of a high-value chain}

Table 2.4 shows estimation results from the Cox model of proportional hazards analyzing the decision of current and former participants to exit the export market. The coefficients represent the change in the log odds of the outcome variable for a one-unit increase in the independent covariate, holding all other covariates constant. For easier interpretation, the hazard ratios are also provided, which were calculated by exponentiating the coefficients. A negative coefficient implies a negative change in the log odds of the outcome variable, which means a decrease in the hazards of dropping out of the export sector (hazard ratio $<1$ ). On the contrary, a positive coefficient reflects an increase in the log odds of

\footnotetext{
${ }^{22}$ In the Diff-GMM model we instrument for the pre-determined variable Aggregate village supply(t-1) using the lags seven to ten as instruments. Sargan and Hansen test results are reported in the appendix and confirm the validity of the instruments.
} 
Chapter 2. Dynamics of smallholder participation in horticultural export chains.

the outcome variable, meaning an increase in the hazards of dropping out (hazard ratio $>1$ ). The empirical hazard function is visualized in Figure A1 (in the appendix). It represents the conditional probability of dropping out in each time period, given that the farmer did not drop out in the previous time period, but without taking potential multiplicative effects of covariates into account. Figure A1 suggests that the baseline hazard of dropping out increases during the early years of participation stays relatively constant between years five to seven, and then increases sharply after year eight.

Table 2-4 Results on the hazard of dropping out of the export sector.

\begin{tabular}{|c|c|c|c|c|}
\hline \multirow[t]{2}{*}{ VARIABLES } & \multicolumn{2}{|c|}{ (1) } & \multicolumn{2}{|c|}{$(2)$} \\
\hline & Coefficient & $\begin{array}{c}\text { Hazard } \\
\text { ratio }\end{array}$ & Coefficient & $\begin{array}{c}\text { Hazard } \\
\text { ratio }\end{array}$ \\
\hline \multicolumn{5}{|l|}{ Transaction characteristics } \\
\hline Payment delay ${ }_{(\mathrm{t}-1)}$ & $\begin{array}{l}0.0042 * * \\
(0.0021)\end{array}$ & $\begin{array}{r}1.0042 * * \\
(0.0024)\end{array}$ & $\begin{array}{r}0.0032 * * * \\
(0.0011)\end{array}$ & $\begin{array}{r}1.0033^{* * *} \\
(0.0012)\end{array}$ \\
\hline$\%$ rejection $_{(\mathrm{t}-1)}$ & $\begin{array}{c}0.0608 * * \\
(0.0285)\end{array}$ & $\begin{array}{r}1.0627^{* *} \\
(0.033)\end{array}$ & $\begin{array}{c}0.0164 \\
(0.0164)\end{array}$ & $\begin{array}{r}1.0165 \\
(0.016)\end{array}$ \\
\hline Price export market & $\begin{array}{l}-0.507 \\
(0.400)\end{array}$ & $\begin{array}{r}0.6021 \\
(0.236)\end{array}$ & $\begin{array}{l}-0.449 \\
(0.385)\end{array}$ & $\begin{array}{c}0.6384 \\
(0.246)\end{array}$ \\
\hline Low bargaining local market & $\begin{array}{c}-1.401^{* *} \\
(0.706)\end{array}$ & $\begin{array}{r}0.2462 * * \\
(0.179) \\
\end{array}$ & $\begin{array}{c}-0.599 * * \\
(0.293) \\
\end{array}$ & $\begin{array}{r}0.5490 * * \\
(0.133) \\
\end{array}$ \\
\hline \multicolumn{5}{|l|}{ Social networks } \\
\hline Family ties & $\begin{array}{c}1.173 * * \\
(0.494)\end{array}$ & $\begin{array}{r}3.2319 * * \\
(1.680)\end{array}$ & $\begin{array}{c}-0.0512 \\
(0.255)\end{array}$ & $\begin{array}{r}0.9501 \\
(0.22)\end{array}$ \\
\hline Aggregate village supplies $_{(\mathrm{t}-1)}$ & $\begin{array}{r}-0.0001 \\
(0.0003)\end{array}$ & $\begin{array}{r}0.9999 \\
(0.0003)\end{array}$ & $\begin{array}{r}-0.0003 \\
(0.0002)\end{array}$ & $\begin{array}{r}0.9997 \\
(0.0003)\end{array}$ \\
\hline Membership farmers' group & $\begin{array}{c}-2.452 * * * \\
(0.438) \\
\end{array}$ & $\begin{array}{r}0.0861^{* * * *} \\
(0.038) \\
\end{array}$ & $\begin{array}{c}-1.153^{* * *} \\
(0.232) \\
\end{array}$ & $\begin{array}{r}0.3155^{* * *} \\
(0.069) \\
\end{array}$ \\
\hline \multicolumn{5}{|l|}{ Other control variables } \\
\hline Risk aversion & $\begin{array}{l}-0.307 \\
(0.331)\end{array}$ & $\begin{array}{l}0.7356 \\
(0.275)\end{array}$ & $\begin{array}{l}-0.207 \\
(0.203)\end{array}$ & $\begin{array}{l}0.8132 \\
(0.175)\end{array}$ \\
\hline HH members & $\begin{array}{c}0.0178 \\
(0.0466)\end{array}$ & $\begin{array}{l}1.0180 \\
(0.047)\end{array}$ & $\begin{array}{c}0.0195 \\
(0.0488)\end{array}$ & $\begin{array}{l}1.0197 \\
(0.047)\end{array}$ \\
\hline HH head age & $\begin{array}{r}-0.0066 \\
(0.0065)\end{array}$ & $\begin{array}{r}0.9934 \\
(0.0066)\end{array}$ & $\begin{array}{r}-0.0043 \\
(0.0064)\end{array}$ & $\begin{array}{r}0.9956 \\
(0.0066)\end{array}$ \\
\hline HH head secondary education & $\begin{array}{c}-0.0929 \\
(0.177)\end{array}$ & $\begin{array}{r}0.9113 \\
(0.174)\end{array}$ & $\begin{array}{c}-0.0442 \\
(0.174)\end{array}$ & $\begin{array}{r}0.9568 \\
(0.181)\end{array}$ \\
\hline $\mathrm{HH}$ head female & $\begin{array}{c}0.692 * * \\
(0.288)\end{array}$ & $\begin{array}{r}1.9985^{* *} \\
(0.564)\end{array}$ & $\begin{array}{c}0.315 \\
(0.239)\end{array}$ & $\begin{array}{l}1.3708 \\
(0.291)\end{array}$ \\
\hline Distance to collection center & $\begin{array}{c}-0.00439 \\
(0.0282)\end{array}$ & $\begin{array}{l}0.9956 \\
(0.052)\end{array}$ & $\begin{array}{c}-0.00691 \\
(0.0322)\end{array}$ & $\begin{array}{l}0.9931 \\
(0.053)\end{array}$ \\
\hline Own $\operatorname{area}_{(\mathrm{t}-1)}$ & $\begin{array}{c}-0.00687 \\
(0.0132)\end{array}$ & $\begin{array}{r}0.9932 \\
(0.02)\end{array}$ & $\begin{array}{l}-0.0141 \\
(0.0126)\end{array}$ & $\begin{array}{r}0.986 \\
(0.016)\end{array}$ \\
\hline Cash transfer & $\begin{array}{l}0.403^{*} \\
(0.208) \\
\end{array}$ & $\begin{array}{r}1.4969 * \\
(0.337) \\
\end{array}$ & $\begin{array}{c}0.168 \\
(0.131) \\
\end{array}$ & $\begin{array}{l}1.1831 \\
(0.174) \\
\end{array}$ \\
\hline Period 2009 - 2012 & & & & \\
\hline d2009-2012 x days to payment $(\mathrm{t}-1)$ & $\begin{array}{r}-0.00156 \\
(0.0024)\end{array}$ & $\begin{array}{r}0.9984 \\
(0.0027)\end{array}$ & & \\
\hline d2009-2012 x \% rejection $(\mathrm{t}-1)$ & $\begin{array}{l}-0.0554 \\
(0.0362)\end{array}$ & $\begin{array}{l}0.9461 \\
(0.034)\end{array}$ & & \\
\hline d2009-2012 x Low bargaining local market & $\begin{array}{c}1.018 \\
(0.744)\end{array}$ & $\begin{array}{r}2.7673 \\
(2.1358)\end{array}$ & & \\
\hline
\end{tabular}




\begin{tabular}{|c|c|c|c|}
\hline d2009-2012 x family ties & $\begin{array}{c}-1.501^{* * *} \\
(0.528)\end{array}$ & $\begin{array}{r}0.2228^{* * *} \\
(0.129)\end{array}$ & \\
\hline d2009-2012 x aggregate village supplies $(\mathrm{t}-1)$ & $\begin{array}{r}-0.0001 \\
(0.0002)\end{array}$ & $\begin{array}{r}0.9998 \\
(0.0003)\end{array}$ & \\
\hline d2009-2012 x membership farmers' group & $\begin{array}{c}1.787 * * * \\
(0.495)\end{array}$ & $\begin{array}{r}5.9721^{* * *} \\
(3.019)\end{array}$ & \\
\hline d2009-2012 x Risk aversion & $\begin{array}{r}0.111 \\
(0.411)\end{array}$ & $\begin{array}{r}1.1176 \\
(0.5069)\end{array}$ & \\
\hline d2009-2012 x HH head female & $\begin{array}{r}-0.822 * * \\
(0.419)\end{array}$ & $\begin{array}{r}0.4395^{* *} \\
(0.191)\end{array}$ & \\
\hline d2009-2012 x own area $(\mathrm{t}-1)$ & $\begin{array}{r}-0.0181 \\
(0.0259)\end{array}$ & $\begin{array}{r}0.9821 \\
(0.031)\end{array}$ & \\
\hline d2009-2012 x Cash transfer & $\begin{array}{r}-0.392 \\
(0.262)\end{array}$ & $\begin{array}{r}0.6756 \\
(0.185) \\
\end{array}$ & \\
\hline$\theta$ & $1.03 \mathrm{e}-7$ & & $1.03 \mathrm{e}-7$ \\
\hline Observations & 1538 & & 1538 \\
\hline Number of groups & 278 & & 278 \\
\hline Log-likelihood & -1174.67 & & -1188.75 \\
\hline
\end{tabular}

Column (1) in Table 4 provides full results from the Cox model of proportional hazards, including interaction effects and thus allowing for changes in magnitude and size of the coefficients after the structural break induced by the financial crisis. For comparison, we also report results without interaction terms in column (2). As in the extent of participation model, for several variables we observe substantial changes in the effects, both in terms of effect size and direction, after the structural break.

The results of the full model (column (1)) show that the coefficients of the transaction risks variables regarding payment delays and rejections are positive and significant. Both a larger number of days to payment and a higher percentage of rejection in the previous period increase the speed of withdrawal from the export chain. Specifically, for each additional day the farmer had to wait for payment, the individual hazard rate increases by 0.42 percentage points. This can become an important risk factor considering that for the period 2004 - 2009 farmers had to wait for more than 60 days on the average for their payment (see Table A2 in the appendix). Moreover, for each additional percentage point of rejection (in relation to the quantity delivered), the hazard rate of withdrawal increases by 6.27 percentage points. These effects remain unchanged after the supply chain shock. Finally, we find that, everything else held constant, farmers with low bargaining power in the local market tend to drop out of the export market more slowly, which is intuitive given that they have less attractive outside options. On the average, low bargaining power in the local market decreases the hazard rate of withdrawal by 75 percentage points. 
We further find that having a family member who works at the collection center speeds up the process of withdrawal from the export chain, increasing the hazard rate by 223 percentage points. While this is unlike expected, it is likely that the enforcement of the existing agreement is hampered by family ties to the extent that farmers do not fear strong punishment when diverting their product entirely to the local market. Our results also confirm the findings of Fafchamps and Minten (2001), who explain that agreements are handled more flexibly, when actors are related through kinship. However, after the crisis (2009-2012) the effect of family ties reverses, decreasing the overall hazard rate of withdrawal by 28 percentage points ${ }^{23}$. Thus, farmers with family ties, while often pursuing short-term benefits in the period before the crisis, tended to support the collection center during difficult times. This may be a rational strategy, if farmers maximize family level (rather than individual level) utility and therefore seek to prevent the collection center from going bankrupt and loosing income from wage employment at the center.

Membership in the farmers' group has a negative effect on the log odds of dropping out of the export chain, decreasing the hazard rate of withdrawal by almost 91 percentage points, when compared to non-members in normal times. This result can be explained by the fact that members are also the owners of the collection center and thus hold shares of the enterprise. Nonetheless, the negative external shock also significantly affected the members of the association. Overall, after the crisis (2009-2012) the effect of being a member on the speed of withdrawal is still negative, but to a lesser extent. In this period, membership decreases the hazard rate by only 49 percentage points. This provides evidence of how the event of a negative external shock, in this case resulting in the bankruptcy of the main buyer, increases uncertainty in the supply chain and affects the loyalty of small-scale suppliers in the upstream segment of the chain.

Furthermore, the speed of dropping out of the export sector is correlated with household-specific characteristics. We find that poor and female-headed households drop out faster from the export chain. For poor households, the hazard rate of withdrawal is 50 percentage points higher compared to nonpoor households. Similarly, for female-headed households the hazard rate is 100 percentage points higher compared to male-headed households. Interestingly, after the crisis the effect reverses for female-headed households, who now tend to remain longer in the export chain compared to their male counterparts. Compared to male-headed households, the hazard rate of withdrawal is 12 percentage points lower for female-headed households in the period 2009-2012. This marked difference between the two periods is likely to be related to the different transaction costs associated with the two market channels and the perceptions thereof of vulnerable population groups, such as female-headed households. For example, the bankruptcy of the main buyer led to large outstanding debts of the

\footnotetext{
${ }^{23}$ To calculate the effect of a variable in the period 2009-2012 the coefficients before and after this period are added and then exponentiated.
} 
collection center towards farmers. More vulnerable households may be more inclined to stay in the export chain hoping to recover at least some of their payments.

\subsection{Conclusions}

This study combines cross-sectional and panel data to analyze the determinants of smallholder participation in the broccoli export market. We focus on the effects of transaction risks on the extent of participation and on the timing of withdrawal from a high-value chain. While previous studies have investigated the factors influencing participation in high-value markets and contract schemes, we add to the current literature by using longitudinal data, which allows us to identify the threats to the longterm sustainability of smallholder inclusion in high-value export chains controlling for unobserved heterogeneity of the farmers. Given that linking smallholder farmers to high-value markets is considered a promising tool for lifting rural households out of poverty, the identification of such threats is of paramount importance for designing and promoting sustainable value chains for rural development.

Results of our analyses reveal that hold-ups experienced in the export chain substantially increase the uncertainty associated with market transactions in the chain and thus have a negative influence on farmers' participation. In particular, we find that farmers are especially sensitive to product rejections, which reduce the amount delivered to the export market in the following year and increase the risk of dropping out entirely. Delay in payments, although having a smaller effect, can also become an important source of uncertainty, in particular, when farmers are exposed to long payment delays. Our results further show that family ties play an important role in the farmers' decision to participate in or drop out of the export chain, however, the relationship is complex. On the one hand, if farmers have family members working at the collection center, they appear to be less loyal and take advantage of short-term benefits when these can be realized in the local market. On the other hand, after the collection center was affected by the bankruptcy of its main buyer, farmers with family ties proved to be more committed staying with the collection center during difficult economic times. This behavior could be explained, if farmers maximize household welfare, rather than the returns from broccoli sales.

Association membership can increase the extent of participation and slow down withdrawal, but is no guarantee for farmers' loyalty during difficult economic times. In our analysis we find that farmers who are members of the association deliver significantly less in the aftermath of the crisis, possibly because they have better access to information and are more aware of the difficult situation faced by the enterprise. In our case study, members holding a share in the collection center are unlikely to be 
expelled from the farmers' group even when they decide to market their produce elsewhere. Furthermore, members may still derive other benefits from the organization besides having a market outlet for their produce, such as preferential access to credit, training and external support even when they reduce the quantity delivered to their association.

While we find no particular evidence for the exclusion of small-scale farmers from the export sector, we do find that poorer households and female-headed households tend to drop out faster, especially as long as the sector is still prospering. After the sector is struck by the crisis, female-headed households drop out more slowly and larger-scale farmers reduce their supplies to the export sector more drastically than small-scale farmers. This suggests that those farmers, who have better outside options, retire from a crisis-struck sector more immediately, while disadvantaged households may get trapped more easily in less profitable market arrangements.

Based on our results, we derive some policy recommendations aiming to improve the long-term sustainability in high-value chains. As high rejection rates in the export sector have strong economic implications for farmers and thus negatively influence their participation, it is important to increase the transparency regarding the reasons for rejections. Saenger, Torero, and Qaim (2014) e.g. propose the implementation of a third-party control mechanism to increase transparency in the grading process. This could also be useful in the Ecuadorian broccoli sector, where non-transparent product rejections provoke farmers' mistrust in downward actors of the value chain.

Furthermore, it should be a priority to reduce the risk of external shocks caused by the sudden retirement of an export firm and the consequent default in payment borne by farmers. There is an urgent necessity for a stronger legal framework regulating the finances in contract farming and the participation of small farmers' businesses in such schemes. In particular, adequate safeguards could be demanded from export firms to reduce opportunistic behavior and protect small-scale farmers from bearing the consequences of downstream actors' financial problems.

Finally, farmers' businesses and organizations should be placed in a real network environment. Policy attention needs to shift from supporting and regulating particular organizations towards a whole value chain perspective. The debate about smallholder participation in high-value markets needs to graduate from the initial focus on facilitating access to a focus on how to make these business relationships viable and beneficial in the long term. For donors and practitioners this means for example that it is not sufficient to provide incentives for participation, but that more long-term business assistance is needed, for example improving bargaining skills and providing support to conduct legal actions when farmer association are affected by the opportunistic behavior of downstream actors of the value chain. 


\section{References}

Altenburg, Tilman. 2006. “Governance Patterns in Value Chains and Their Development Impact.” The European Journal of Development Research 18 (4): 498-521. doi:10.1080/09578810601070795.

Andersson, Camilla I. M., Christine G. K. Chege, Elizaphan J. O. Rao, and Matin Qaim. 2015. “Following Up on Smallholder Farmers and Supermarkets in Kenya.” American Journal of Agricultural Economics, February, aav006. doi:10.1093/ajae/aav006.

Arellano, Manuel, and Stephen Bond. 1991. "Some Tests of Specification for Panel Data: Monte Carlo Evidence and an Application to Employment Equations.” The Review of Economic Studies 58 (2): 277-97. doi:10.2307/2297968.

Barrett, Christopher B., Maren E. Bachke, Marc F. Bellemare, Hope C. Michelson, Sudha Narayanan, and Thomas F. Walker. 2012. "Smallholder Participation in Contract Farming: Comparative Evidence from Five Countries.” World Development 40 (4): 715-30. doi:10.1016/j.worlddev.2011.09.006.

Bellemare, Marc F. 2012. As You Sow, So Shall You Reap: The Welfare Impacts of Contract Farming. World Development 40(7): 1418-1434.

Berdegué, Julio A., Fernando Balsevich, Luis Flores, and Thomas Reardon. 2005. “Central American Supermarkets' Private Standards of Quality and Safety in Procurement of Fresh Fruits and Vegetables.” Food Policy 30 (3): 254-69. doi:10.1016/j.foodpol.2005.05.003.

Binswanger, Hans P. 1980. “Attitudes Toward Risk: Experimental Measurement in Rural India.” American Journal of Agricultural Economics 62 (3): 395-407. doi:10.2307/1240194.

Bond, Stephen R. 2002. “Dynamic Panel Data Models: A Guide to Micro Data Methods and Practice.” Portuguese Economic Journal 1 (2): 141-62. doi:10.1007/s10258-002-0009-9.

Bond, Stephen R., Anke Hoeffler, and Jonathan R. W. Temple. 2001. GMM Estimation of Empirical Growth Models. SSRN Scholarly Paper ID 290522. Rochester, NY: Social Science Research Network. http://papers.ssrn.com/abstract=290522.

Braun, Joachim Von, David Hotchkiss, and Maarten Dirk Cornelis Immink. 1989. Nontraditional Export Crops in Guatemala: Effects on Production, Income, and Nutrition. Intl Food Policy Res Inst.

Burton, Michael, Dan Rigby, and Trevor Young. 2003. "Modelling the Adoption of Organic Horticultural Technology in the UK Using Duration Analysis.” Australian Journal of Agricultural and Resource Economics 47 (1): 29-54. doi:10.1111/1467-8489.00202.

Carlos, Manuel L., and Lois Sellers. 1972. "Family, Kinship Structure, and Modernization in Latin America.” Latin American Research Review 7 (2): 95-124. 
Carletto, C., Kirk, A., Winters, P.C., Davis, B., 2010. Globalization and Smallholders: The Adoption, Diffusion, and Welfare Impact of Non-Traditional Export Crops in Guatemala. World Dev. 38, 814-827. doi:10.1016/j.worlddev.2010.02.017

Cleves et al.,. 2008. An Introduction to Survival Analysis Using Stata, Second Edition. Third. Stata Press.

Dadi, Leggesse, Michael Burton, and Adam Ozanne. 2004. "Duration Analysis of Technological Adoption in Ethiopian Agriculture.” Journal of Agricultural Economics 55 (3): 613-31. doi:10.1111/j.1477-9552.2004.tb00117.x.

Dolan, C., and J. Humphrey. 2000. "Governance and Trade in Fresh Vegetables: The Impact of UK Supermarkets on the African Horticulture Industry.” Journal of Development Studies 37 (2): 147-76. doi:10.1080/713600072.

Fafchamps, Marcel, and Bart Minten. 2001. "Property Rights in a Flea Market Economy.” Economic Development and Cultural Change 49 (2): 229-67. doi:10.1086/edcc.2001.49.issue-2.

Fahrmeir, Ludwig. 1997. "Discrete failure time models” Sonderforschungsbereich 386. Paper 9. Universität München

FAO Stat 2013. http://193.43.36.221/site/342/default.aspx. Retrieved : 28.04.2013

Gall, Julie Le. 2009. “El Brócoli En Ecuador: La Fiebre Del Oro Verde. Cultivos No Tradicionales, Estrategias Campesinas Y Globalización.” Anuario Americanista Europeo, no. 6: 261-88. Henson, Spencer, Oliver Masakure, and David Boselie. 2005. "Private Food Safety and Quality Standards for Fresh Produce Exporters: The Case of Hortico Agrisystems, Zimbabwe.” Food Policy 30 (4): 371-84. doi:10.1016/j.foodpol.2005.06.002.

Hernández, Ricardo, Thomas Reardon, and Julio Berdegué. 2007. "Supermarkets, Wholesalers, and Tomato Growers in Guatemala.” Agricultural Economics 36 (3): 281-90. doi:10.1111/j.15740862.2007.00206.x.

Hobbs, Jill E., and Linda M. Young. 2000. "Closer Vertical Co-Ordination in Agri-Food Supply Chains: A Conceptual Framework and Some Preliminary Evidence.” Supply Chain Management: An International Journal 5 (3): 131-43. doi:10.1108/13598540010338884.

Holzapfel, Sarah, and Meike Wollni. 2014. "Is GlobalGAP Certification of Small-Scale Farmers Sustainable? Evidence from Thailand.” The Journal of Development Studies 50 (5): 731-47. doi:10.1080/00220388.2013.874558.

Kydd, Jonathan, Andrew Dorward, Jamie Morrison, and Georg Cadisch. 2004. “Agricultural Development and Pro-poor Economic Growth in sub-Saharan Africa: Potential and Policy.” Oxford Development Studies 32 (1): 37-57. doi:10.1080/1360081042000184110.

Maertens, Miet, and Johan F.M. Swinnen. 2009. “Trade, Standards, and Poverty: Evidence from Senegal.” World Development 37 (1): 161-78. doi:10.1016/j.worlddev.2008.04.006. 
Minten, Bart, Lalaina Randrianarison, and Johan F.M. Swinnen. 2009. "Global Retail Chains and Poor Farmers: Evidence from Madagascar.” World Development 37 (11): 1728-41. doi:10.1016/j.worlddev.2008.08.024.

Moser, Christine M., and Christopher B. Barrett. 2006. “The Complex Dynamics of Smallholder Technology Adoption: The Case of SRI in Madagascar.” Agricultural Economics 35 (3): 37388. doi:10.1111/j.1574-0862.2006.00169.x.

National Central Bank, Ecuador (Banco Central del Ecuador) 2013.

http://www.bce.fin.ec/contenido.php?CNT=ARB0000203. Retrieved: 15.04.2013.

Rao, Elizaphan J. O., and Matin Qaim. 2011. “Supermarkets, Farm Household Income, and Poverty: Insights from Kenya.” World Development 39 (5): 784-96. doi:10.1016/j.worlddev.2010.09.005.

Reardon, Thomas, Christopher B. Barrett, Julio A. Berdegué, and Johan F. M. Swinnen. 2009. “Agrifood Industry Transformation and Small Farmers in Developing Countries.” World Development 37 (11): 1717-27. doi:10.1016/j.worlddev.2008.08.023.

Reardon, Thomas, Spencer Henson, and Julio Berdegué. 2007. “'Proactive Fast-Tracking’ Diffusion of Supermarkets in Developing Countries: Implications for Market Institutions and Trade.” Journal of Economic Geography 7 (4): 399-431. doi:10.1093/jeg/lbm007.

Saenger, Christoph, Maximo Torero, and Matin Qaim. 2014. "Impact of Third-Party Contract Enforcement in Agricultural Markets-A Field Experiment in Vietnam.” American Journal of Agricultural Economics, May, aau021. doi:10.1093/ajae/aau021.

Schipmann, Christin, and Matin Qaim. 2010. "Spillovers from Modern Supply Chains to Traditional Markets: Product Innovation and Adoption by Smallholders.” Agricultural Economics 41 (34): 361-71. doi:10.1111/j.1574-0862.2010.00438.x.

Schuster, Monica, and Miet Maertens. 2013. "Do Private Standards Create Exclusive Supply Chains? New Evidence from the Peruvian Asparagus Export Sector.” Food Policy 43 (December): 291-305. doi:10.1016/j.foodpol.2013.10.004.

2015. "The Impact of Private Food Standards on Developing Countries' Export Performance: An Analysis of Asparagus Firms in Peru.” World Development 66 (February): 208-21. doi:10.1016/j.worlddev.2014.08.019.

Williamson, Oliver E. 1979. “Transaction-Cost Economics: The Governance of Contractual Relations.” Journal of Law and Economics 22 (2): 233-61.

Wooldridge, Jeffrey. 2010. “Correlated Random Effects Models with Unbalanced Panels”. Manuscript. Department of Economics. Michigan State University. 


\section{Appendix 1}

Table A1.1. Explanation of variables

\begin{tabular}{|c|c|}
\hline Variable & Specification \\
\hline \% rejection & $\begin{array}{l}\text { Percentage of produce rejected by the exporter; calculated as kg } \\
\text { rejected/kg delivered*100 }\end{array}$ \\
\hline Aggregate village supplies & $\begin{array}{l}\text { Total sum of broccoli supplies delivered to the collection center by } \\
\text { village members; measured in metric tons }\end{array}$ \\
\hline Broccoli area & Total land area cultivated with broccoli in 2012, in solar \\
\hline Broccoli income local market & Income from broccoli sold in the local market in USD for 2012 \\
\hline Broccoli income total & $\begin{array}{l}\text { Total income from broccoli in USD for } 2012 \text { (calculated based on } \\
\text { survey data) }\end{array}$ \\
\hline Cash transfer & $\begin{array}{l}1 \text { if household is eligible for government cash transfer program } \\
\text { targeting poor households }\end{array}$ \\
\hline Collection center only & 1 if farmer sold broccoli exclusively to the collection center in 2012 \\
\hline Distance to collection center & Distance to the collection center in $\mathrm{km}$ \\
\hline Distance to local market & Distance to the nearest local market in $\mathrm{km}$ \\
\hline Family ties & 1 if family member works at the collection center \\
\hline Farming experience & Number of years the household has grown broccoli \\
\hline HH head age & Age of the household head in years \\
\hline HH head female & 1 if household head is female \\
\hline HH head secondary education & 1 if household head has obtained secondary education \\
\hline HH member off-farm & 1 if household head has off-farm employment \\
\hline HH members & Number of household members \\
\hline Kg delivered & Quantity of broccoli delivered to the export market in $\mathrm{kg}$ \\
\hline Kg rejected & Quantity rejected by the exporter in $\mathrm{kg}$ \\
\hline Low bargaining local market & $\begin{array}{l}1 \text { if average price obtained in the local market is lower than export } \\
\text { market price in } 2012\end{array}$ \\
\hline Membership farmers' group & 1 if household is a member of the farmers' group \\
\hline Own area & Total land area owned by the household in 2012, in solar \\
\hline Payment delay & Number of days after delivery until payment was received (in 2012) \\
\hline Price export market & $\begin{array}{l}\text { Price per kilogram paid by the exporter to the collection center in } \\
\text { USD }\end{array}$ \\
\hline Relatives in export market & Number of relatives delivering broccoli to the export market \\
\hline
\end{tabular}


Relatives in local market

Risk aversion

Total area

Total farm income

Total income

Total years of participation
Number of relatives delivering broccoli to the local market Partial risk aversion coefficient calculated according to Binswanger (1980); normalized to a scale from 0 (low risk aversion) to 1 (high risk aversion)

Total land area cultivated by the household in 2012 (owned, rented, and under sharecropping), in solar

Total farm income in 2012 in USD

Total household income in 2012 in USD (incl. farm income, offfarm income, remittances, cash transfers, rents)

Number of years household has participated in the export market

Note: Land area is measured in solar: 1 solar $=$ approx. $1700 \mathrm{~m}^{2}$

Table A1.2. Descriptive statistics for export market transaction variables per year

\begin{tabular}{llrrrrr}
\hline \multirow{2}{*}{ Year } & \multicolumn{1}{c}{ Variable } & Obs & Mean & $\begin{array}{c}\text { Std. } \\
\text { Dev. }\end{array}$ & Min & Max \\
\hline \hline \multirow{2}{*}{2002} & Kg delivered & 112 & 5996.5 & 6056.514 & 127 & 30543 \\
& Kg rejected & 112 & 514.4375 & 471.3525 & 4 & 2511 \\
& \% rejection & 112 & 0.095804 & 0.037142 & 0.02 & 0.2 \\
& Days to payment & 111 & 47.04505 & 13.62577 & 17 & 96 \\
\hline \multirow{2}{*}{2003} & Kg delivered & 166 & 8587.723 & 7437.829 & 280 & 34066 \\
& Kg rejected & 166 & 594.5964 & 497.4679 & 11 & 2587 \\
& \% rejection & 166 & 0.073133 & 0.02071 & 0.03 & 0.14 \\
& Days to payment & 166 & 27.21687 & 14.34345 & 6 & 101 \\
\hline \multirow{2}{*}{2004} & Kg delivered & 164 & 9057.701 & 8087.636 & 160 & 34672 \\
& Kg rejected & 164 & 334.3841 & 328.599 & 2 & 1454 \\
& \% rejection & 164 & 0.037744 & 0.028096 & 0.01 & 0.28 \\
& Days to payment & 164 & 68.52439 & 14.35759 & 23 & 153 \\
\hline \multirow{2}{*}{2005} & Kg delivered & 168 & 9607.327 & 8490.575 & 203 & 34500 \\
& Kg rejected & 167 & 409.6048 & 376.4703 & 8 & 1724 \\
& \% rejection & 168 & 0.042619 & 0.013939 & 0 & 0.14 \\
& Days to payment & 168 & 74.79762 & 12.74323 & 21 & 148 \\
\hline \multirow{2}{*}{2008} & Kg delivered & 150 & 9049.487 & 7728.636 & 284 & 34109 \\
& Kg rejected & 150 & 638.5467 & 608.9711 & 15 & 3064 \\
& \%g rejection & 150 & 0.064867 & 0.024184 & 0.03 & 0.18 \\
& Days to payment & 148 & 68.53378 & 11.45082 & 37 & 115 \\
\hline & Kg delivered & 171 & 10736.37 & 7757.177 & 432 & 34947 \\
& Kg rejected & 171 & 801.0058 & 1601.17 & 11 & 20261 \\
& \% rejection & 171 & 0.070175 & 0.043811 & 0.03 & 0.43 \\
& Days to payment & 168 & 80.32143 & 34.4238 & 34 & 489 \\
\hline & Kg delivered & 176 & 10588.84 & 8275.709 & 478 & 35275 \\
& 176 & 1773.614 & 1932.781 & 21 & 11507 \\
& 176 & 0.06125 & 0.021478 & 0.02 & 0.17 \\
& 176 & 144.8636 & 24.67396 & 66 & 236
\end{tabular}


Chapter 2. Dynamics of smallholder participation in horticultural export chains.

\begin{tabular}{llrrrrr}
\hline \multirow{2}{*}{2009} & Kg delivered & 154 & 6019.455 & 5909.05 & 191 & 28781 \\
& Kg rejected & 152 & 406.9934 & 430.0803 & 11 & 2673 \\
& $\%$ rejection & 153 & 0.066994 & 0.032969 & 0.03 & 0.22 \\
& Days to payment & 120 & 200.575 & 94.74634 & 0 & 388 \\
\hline \multirow{2}{*}{2010} & Kg delivered & 146 & 4495.548 & 3892.135 & 111 & 19194 \\
& Kg rejected & 146 & 389.2877 & 358.2424 & 10 & 1797 \\
& $\%$ rejection & 146 & 0.089795 & 0.044029 & 0.03 & 0.42 \\
& Days to payment & 145 & 49.62069 & 41.68184 & 0 & 367 \\
\hline \multirow{2}{*}{2011} & Kg delivered & 132 & 4799.97 & 4512.431 & 152 & 23891 \\
& Kg rejected & 132 & 592.7121 & 539.3078 & 27 & 2794 \\
& $\%$ rejection & 132 & 0.133182 & 0.062362 & 0.05 & 0.55 \\
& Days to payment & 132 & 52.34848 & 35.7472 & 0 & 217 \\
\hline \multirow{2}{*}{2012} & Kg delivered & 88 & 1999.545 & 1881.352 & 119 & 10232 \\
& Kg rejected & 88 & 229.8636 & 230.6466 & 6 & 1223 \\
& $\%$ rejection & 88 & 0.115 & 0.046312 & 0.01 & 0.23 \\
& Days to payment & 85 & 38.54118 & 26.77354 & 0 & 155 \\
\hline \hline
\end{tabular}

Note: Calculations based on data obtained from the collection center's records. Only the households included in the household survey were used for calculating these values.

Table A1.3. Heckman model estimates of initial export market participation and extent of participation

Variable

Probability of ever Quantity delivered to supplying export export market in first market year $(\mathrm{kg})$
Distance to collection center

Family ties

Aggregate village supplies

Risk aversion

HH members

HH head secondary education

HH head female

Own area

Cash transfer

Membership farmers' group

Price export market

$\begin{array}{cc}-0.110^{* * *} & \\ (0.0132) & 954.7 \\ -0.0379 & (1,748) \\ (0.813) & 0.650 \\ -0.000141 & (0.700) \\ (0.0002) & 291.7 \\ -0.0261 & (948.6) \\ (0.307) & 97.55 \\ -0.183^{* *} & (163.0) \\ (0.0724) & 306.5 \\ -0.182 & (807.1) \\ (0.272) & -1,802^{* *} \\ -0.574 * & (771.6) \\ (0.347) & 163.3 * * \\ 0.0162 * * & (79.12) \\ (0.00744) & -643.8 \\ 0.106 & (623.3) \\ (0.256) & 2,655^{* * *} \\ 7.260^{* * *} & (819.0) \\ (0.837) & 163.4^{* * *} \\ 2.281^{* * *} & (43.56) \\ (0.292) & \end{array}$


Chapter 2. Dynamics of smallholder participation in horticultural export chains.

Rho

$-0.0151$

(0.071)

Constant $-41.15^{* * *}$

(5.341)

\begin{tabular}{lcc}
\hline Observations & 401 & 401 \\
\hline \hline Robus standwd
\end{tabular}

Robust standard errors in parentheses $* * * p<0.01,{ }^{* *} \mathrm{p}<0.05,{ }^{*} \mathrm{p}<0.1$

Wald test for rho: $\mathrm{p}=0.1816$

In the first stage probit model on the decision to ever participate in the export sector, we use the distance to the collection center as exclusion restriction. The coefficient is statistically significant, indicating that farmers located further away from the collection center are less likely to participate in the export chain. Furthermore, female-headed households and larger households (family size) have a lower probability to enter the export sector. On the other hand, land size (owned area), membership in farmers' group and export market price positively influence the decision to participate in the export market. The parameter $\rho$ is not statistically significant indicating that there is no systematic unobserved differences between export sector participants and non-participants.

Table A1.4. Fisher-type unit root test for panel data

Ho: All panels contain unit roots Ha: At least one panel is stationary AR parameter: Panel-specific
Number of panels $=$ Avg. number of periods $=$ Asymptotics: T -> Infinity
283

5.75

\begin{tabular}{lcc}
\hline & Statistic & p-value \\
\hline Kg delivered & & \\
Inverse chi-squared(128) & 205.3834 & 0 \\
Inverse normal & -5.3951 & 0 \\
Inverse logit t(324) & -5.1144 & 0 \\
Modified inv. chi-squared & 4.8365 & 0 \\
& & \\
Kg rejected & & \\
Inverse chi-squared(126) & 261.311 & 0 \\
Inverse normal & -8.0771 & 0 \\
Inverse logit t(319) & -7.7579 & 0 \\
Modified inv. chi-squared & 8.5238 & 0 \\
& & \\
Payment delay & & \\
Inverse chi-squared(128) & 182.1162 & 0.0012 \\
Inverse normal & -4.1785 & 0 \\
Inverse logit t(324) & -3.8992 & 0.0001 \\
Modified inv. chi-squared & 3.3823 & 0.0004 \\
\hline
\end{tabular}


Chapter 2. Dynamics of smallholder participation in horticultural export chains.

\begin{tabular}{llll}
\hline $\begin{array}{l}\text { Sargan test of overid. restrictions } \\
\text { (Not robust, but not weakened by many instruments) }\end{array}$ & Prob> chi2 & $=0.415$ \\
\hline $\begin{array}{l}\text { Hansen test of overid. restrictions } \\
\text { (Robust, but weakened by many instruments.) }\end{array}$ & Prob> chi2 & $=0.164$ \\
\hline
\end{tabular}

Difference in Hansen tests of exogeneity of instruments subsets

\begin{tabular}{|c|c|}
\hline \multicolumn{2}{|c|}{$\operatorname{gmm}_{(\mathrm{kg}}$ delivered $(\mathrm{t}-1)$, collapse $\left.\operatorname{lag}(2 \mathrm{7})\right)$} \\
\hline Hansen test excluding group: & Prob $>$ chi2 $=0.444$ \\
\hline Difference (null H = exogenous): & Prob $>$ chi $2=0.130$ \\
\hline \multicolumn{2}{|l|}{$\begin{array}{l}\text { gmm(aggregate village supplies }(t-1) \text {, } \\
\text { collapse lag(7 10)) }\end{array}$} \\
\hline Hansen test excluding group: & Prob $>$ chi $2=0.695$ \\
\hline Difference (null H = exogenous): & Prob $>$ chi $2=0.041$ \\
\hline
\end{tabular}

Table A1.6. Arellano-Bond test for Autocorrelation

\begin{tabular}{lll}
\hline Arellano-Bond test for AR(1) in first differences & Prob $>$ z & $=0.004$ \\
Arellano-Bond test for AR(2) in first differences & Prob $>$ z & $=0.446$ \\
\hline
\end{tabular}

Figure A1.1. Smoothed hazard estimate for farmer's withdrawal of the export chain.

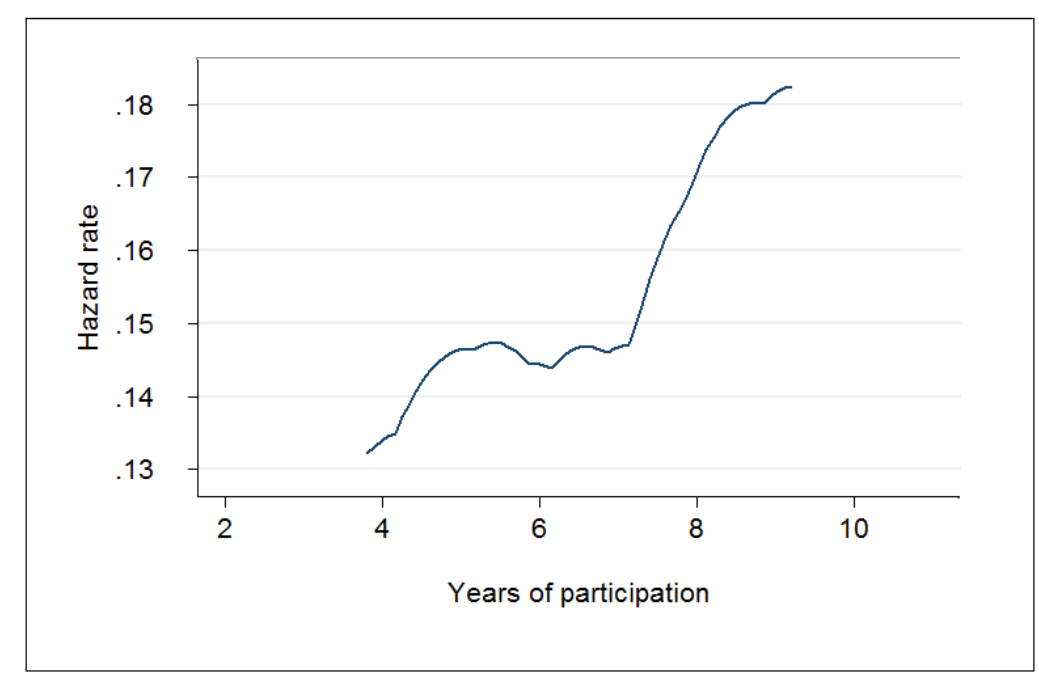

The hazard function is the derivative of the Nelson-Aalen cumulative hazard which is the number of expected failures in the period $(0, t)$ for a subject if failure were a repeatable event. As the cumulative hazard can not be directly diffentiated, the hazard is estimated by smoothing the steps of the cumulative hazard with a kernel smoother. This requires averaging values over a moving window of 
Chapter 2. Dynamics of smallholder participation in horticultural export chains.

data. Near the endpoints, these windows contain insufficient data for accurate estimation, so the estimators contain boundary bias and are not plotted in the graph (Cleves et al. 2002). 


\title{
3. The effect of opportunistic behavior on trust: An experimental approach ${ }^{1}$
}

\begin{abstract}
Linking small farmers to global markets through contract farming has become an important policy recommendation aiming to increase farmers' income and foster rural development. Nevertheless, some of the arrangements involving small farmers have been reported to loose participants or collapse over time. Trust is an informal institution that can discourage opportunism and facilitate the compliance of contracts in a setting with an expensive and weak legal system. Nevertheless, the study of trust has been addressed mostly in lab experiments, but in the agribusiness context it has been addressed only by a few authors in a rather descriptive way

We use a framed field experiment with prior signaling on a sample of 180 small broccoli farmers in the highlands of Ecuador to explore the effect of opportunistic behavior on small farmers' trust. The results reveal that this group of farmers has lower than average trust towards unknown people. Furthermore, we use a signal that mimics the payment of a loan by the B partner as treatment in the predesigned trust game. Results show that a positive signal increases trust, but a negative signal has no effect on it. Reacting slowly to external negative signs can threaten individuals who will not protect themselves towards opportunism. If farmers do not react quickly enough, they might face larger losses and will not be able to stay in business. In addition, if informal norms include weak sanctions, contract farming will be less likely and individuals will prefer the spot market were only one-time exchanges take place.
\end{abstract}

Keywords: small farmers, trust, experiments, delay on payment, signaling.

\subsection{Introduction}

Farmers' inclusion in global markets as food suppliers is perceived as a way not only to increase farm income but also to foster rural development (Barrett et al. 2012; Braun et al. 1989; Hernández et al. 2007). Based on the idea that participation in high value markets can alleviate poverty, linking small farmers to such markets has become an important focus of donors and nongovernmental organizations

\footnotetext{
${ }^{1}$ This chapter is co-authored by Meike Wollni. The authors's contributions are as follows: both authors contributed to the conceptualization and design of the research. CR implemented the game and did the data analysis. Both authors contributed to the interpretation of the results. CR wrote the manuscript and both authors revised it.
} 
(NGOs) in recent years (Altenburg 2006). Simultaneously, contract farming through formal or informal agreements has made this linkage possible by solving the market failures that confront disadvantaged producers ${ }^{2}$. In practice, access to international high-value markets can be beneficial and sustainable only if existing agreements are honored by both buyers and suppliers. Even when governmental and non-governmental organizations facilitate smallholders' inclusion, contract breaches and weak institutions may hold them back and threaten existing relationships among participants and in the communities where they live (Carletto et al. 2010;) . The consequences of opportunistic behavior under weak contract enforcement in developing countries have been addressed by only a few authors. For example, Cungu et al. (2008) find empirical evidence using survey data of a decrease in farmers' monetary investment as a response to delayed payments in Hungary's agricultural sector. Nevertheless, the effect on farmers' trust has not been quantified so far.

Adequate institutions and enforcement mechanisms that deter contract breach are essential for stable business relationships. North (1990) describes institutions as constraints that decrease uncertainties by providing rules of behavior that shape human interaction and facilitate cooperation. Institutions can be either formal, such as a country's political and economic rule or informal such as a country's culture, codes of conduct and norms of behavior. Informal rules govern most of our daily interactions, whereas formal rules influence only a small proportion of our choices; thus, even when formal rules change quickly, it remains difficult to modify informal rules. When the legal system becomes either unreliable or too expensive, these informal mechanisms can become complements that both discourage opportunism and facilitate market transactions (Klein 1996; North 1990; Fafchamps and Minten 2001). This situation is particularly common in rural areas in developing countries, which are often characterized by weak legal systems associated with high transaction costs. In such a context, both trust and informal codes of conduct can provide structures that promote exchange (Cardenas and Carpenter 2008; Fafchamps and Minten 2001; North 1990). Analyzing how these informal codes of conduct are shaped can help us to understand interactions in supply chains involving smallholder farmers.

Trust refers to the expectation of good behavior by others and is seen as a lubricant that both decreases the fear of opportunism and facilitates trade (Arrow 1974; Höhmann et al. 2002; Höhmann and Welter 2002). According to Höhmann and Malieva (2002), the "degree of trust between people and towards existing institutions determines the structure, quality and efficiency of interactions and transactions.” The conditions under which trust is built, sustained or destroyed are important for understanding the existence of institutions and organizations (Torero and Viceisza 2011). Informal codes of conduct and opportunism affect the level of trust and the governance structures that guide trade in rural areas, such as contract farming. Thus, trustworthiness and reciprocity either reward or punish others' behavior

\footnotetext{
${ }^{2}$ For an overview on contract farming refer to Key and Runsten (1999).
} 
(Greig and Bohnet 2008) and in the absence of efficient external enforcement mechanisms, they make contracting possible (Morduch 1999).

The correlation between trust and market development has been extensively studied. Prior studies show that trust has a positive influence on the development of trade; such studies include those of Lyon (2000) for the case of rural Ghana, Höhmann et al. (2002) for Eastern Europe and Fafchamps and Minten (2001) for Madagascar. The effect of market participation on trust has also been analyzed more recently. Siziba and Bulte (2012) conclude that a rapid entrance into markets decreases the level of trust in a society, and Fischer (2008) and Berggren and Jordahl (2006) find that frequent trade experiences under good economic institutions generate trust. In the same field, but using an experimental approach, behavioral economics attempts to quantify the level of individual trust by measuring the actual behavior of people under controlled game settings. In such games, individuals are offered real money as payoffs for the decisions that they make. The trust or investment game designed by Berg et al. (1995) has been used extensively to measure trust and reciprocity based on an investment simulation. The results show that individuals can both trust and reciprocate in anonymous relationships to achieve mutual gains and enhance cooperation (Berg et al. 1995). Using the same game, other studies have found that trust is higher in more homogeneous groups (Bouma et al. 2008), that men trust more than women (Buchan et al., 2008) and that women are more reciprocal than men (Croson and Buchan 1999).

Experimental games are usually run with students in a lab, but studies have shown that their behavior varies significantly when compared to that of individuals operating under different social constraints (Anderson et al. 2012; Henrich et al. 2001). This indicates that such data should be collected directly from the specific populations whose behavior is being investigated. To our knowledge, only a few framed trust experiments have been conducted with farmers in developing countries to study their behavior when facing specific problems, ${ }^{3}$ leaving room for further research to determine possible explanations for their observed decrease in cooperation in the long term. Given the characteristics of small farmers and the high costs of using the legal system in rural areas, informal institutions are extremely important for compliance with and the sustainability of payment agreements. In developing countries in which the rural economy is dominated by such small producers, studying the determinants of trust is important for the design of new programs and interventions that aim to create social capital (of which trust is an important component) and sustainable relationships.

Our main objective in this paper is to explore the effect of opportunistic behavior in the form of delayed payment on small farmers' trust and investment decisions. Farmers exposed to payment delays should decrease their level of trust as a measure of protection. Conversely, a positive signal in

\footnotetext{
${ }^{3}$ Torero and Viceisza (2011) conduct framed trust experiments to analyze the effect of third-party enforcement and possible collusion in Vietnamese dairy farmers' investment decisions.
} 
the form of on-time payment should increase trust and encourage exchange. We use a field-framed trust experiment with prior signaling conducted with a sample of small broccoli farmers linked to different markets in the highlands of Ecuador. The game measures changes in trust by the change in the amount of money sent by the trustor after receiving a signal in the treatment group. Given that some of the invited farmers did not show up to the experiment, we correct for possible selection bias in the analysis that may be introduced if the farmers who participate in our game significantly differ from the rest of the sample.

The article is organized as follows. The next section provides background information on the broccoli supply chain in Ecuador and on the farmers invited to participate in our game. Section three provides a conceptual framework discussing the definition and measurement of trust. Information on the experimental approach and the implementation of the trust game is given in section four. Finally, section five presents and discusses the results, and section six concludes.

\subsection{The broccoli export chain and small farmers in Ecuador}

Broccoli became important as an export crop in the Ecuadorian highlands at the end of the 90s and was considered a promising source of income for small farmers. The inclusion of small farmers in the export chain was promoted by a local NGO, which organized a farmers' group and established a collection center to gather the produce and sell it to an exporting firm. The farmers' group acted as intermediary between the exporter and the small farmers and an agreement specifying the volume, price, quality and payment conditions was made between the farmers' group, the exporter and the suppliers. The business relationship was not free of problems and during the past decade producers and buyers have been exposed to different transaction risks during the marketing process. Suppliers for example have experienced hold ups when the buyer decided to reduce the price, delay the payment or increase the grading criteria. According to the contract, the payment for the delivered produce had to be made within a two-week period but in practice suppliers faced regular delays on their payment. When a payment is not made on time, the buyer is effectively extracting rent from its suppliers by getting access to interest-free loans (Gow and Swinnen 1998). This problem worsened in 2009 when an exporting firm supplied by the collection center went bankrupt and left the area without paying for the received product. Consequently, the farmers' group endured a liquidity crisis, and payments were delayed even longer than usual. Meanwhile, a large percentage of suppliers have abandoned the scheme, and the farmers' collection center faces a broccoli shortage. Figure 3.1 shows the average number of days the farmer had to wait for the payment and the number of suppliers working with the collection center during the past 11 years. 
Figure 3-1Payment delays experienced by broccoli farmers and number of farmers supplying the export chain in the past 11 years..

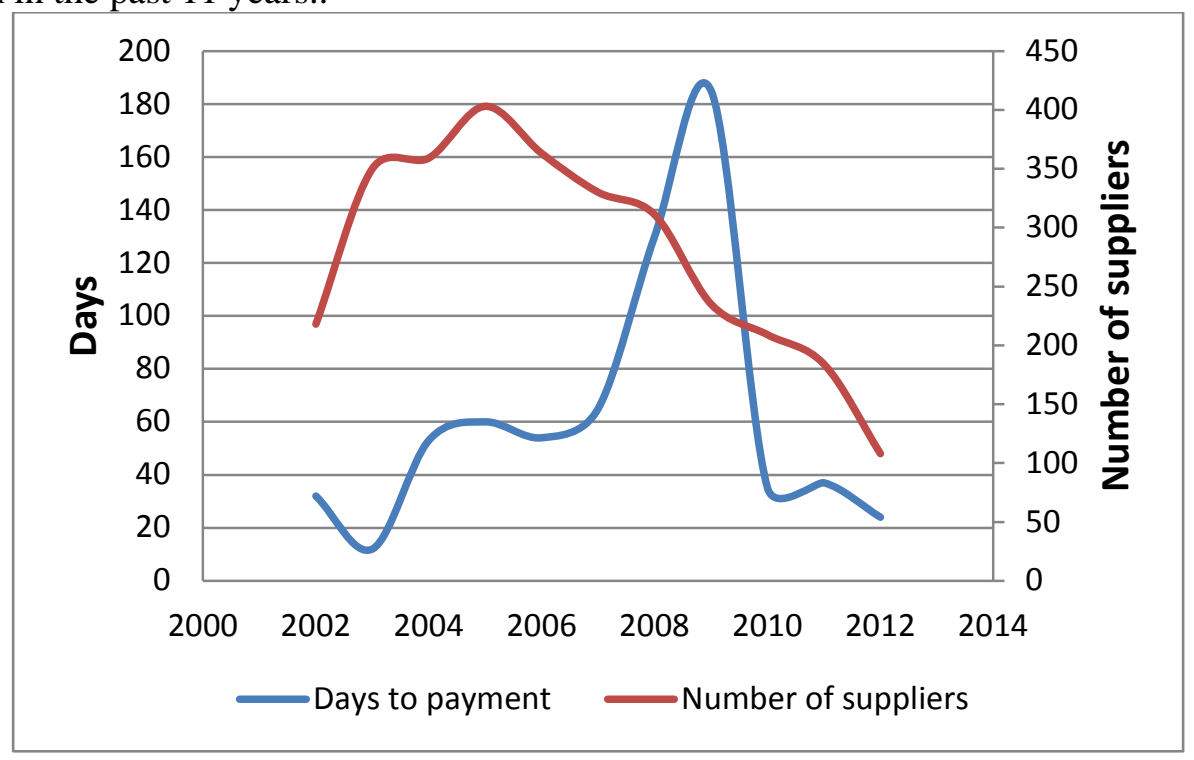

Source: Farmers 'group collection center records.

Several studies mention the importance of trust to facilitate exchange and to construct a flexible and good relation (Cardenas and Carpenter 2008; Fafchamps and Minten 2001; Lyon 2000). However, perceiving the buyer as opportunistic could negatively affect the suppliers' trust. Table 1 describes the level of perceived trust for two marketing channels (i.e. export market and local market) for a sample of broccoli farmers who are currently supplying the export sector (Current suppliers of export market), who dropped out from the export sector (Former suppliers of export market) or who sold their produce only in the local market (Never participated in export market). The level of trust for the local market is higher than the level of trust for the export market for the whole sample of surveyed farmers. The construct for trust depicted in Table3.1 is based on 4 different statements rated by farmers on a five-point Likert scale during a household survey. Based on these statements trust was identified using principal component analysis ${ }^{4}$. All the surveyed farmers show similar levels of trust for buyers in the local market, but trust for the export market differs between the two groups involved in the export market. Farmers who withdrew from the export market show lower levels of trust when compared to farmers who are still participating in the scheme. However, different hold ups experienced (e.g: delay in payment and high rejection) could have had different effects on the way farmers' perceive their buyers. This can also be determined by personal characteristics. Furthermore, the group of former suppliers could have had a lower trust even before joining the export chain. Thus, the measuring of trust and how trust is affected by possible hold ups can be further improved. For this we conducted an artefactual field experiment with a subsample of the same group of farmers in order to quantify general trust and their response to a payment delay.

\footnotetext{
${ }^{4}$ For details on the statements used to build the construct as well as its validity (variance explained, loadings of the components and KMO) refer to the Appendix 2 section A2.1.
} 
Table 3-1Trust towards different marketing channels.

\begin{tabular}{lccccc}
\hline & $\begin{array}{c}\text { Whole } \\
\text { sample }\end{array}$ & $\begin{array}{c}\text { Current } \\
\text { suppliers of } \\
\text { export market } \\
\left(86^{1)}\right.\end{array}$ & $\begin{array}{c}\text { Former } \\
\text { suppliers of } \\
\text { export market } \\
(174)\end{array}$ & $\begin{array}{c}\text { Never } \\
\text { participated in } \\
\text { export market } \\
(113)\end{array}$ & (113) \\
\hline Trust in the export & & & & & $\mathrm{a}$ \\
market & 0.573 & 0.683 & 0.543 & 0.631 & \\
Trust in the local market & 0.650 & 0.633 & 0.669 & \\
& & $* * * \mathrm{~b}$ & & & \\
\hline \hline
\end{tabular}

*Significant at the $10 \%$ level ** Significant at the 5\% level *** Significant at the $1 \%$ level. a: Significant difference in trust expressed for export market by current and former suppliers. b: Significant difference in trust expressed for the export market and for the local market for the whole sample. c: Significant difference in trust expressed for the export market and for the local market by the group of former suppliers. ${ }^{1}$ The number of observations is 74 when measuring trust in the local market for current suppliers

\subsection{Conceptual framework}

\subsubsection{Trust and enforcement mechanisms}

Berggren and Jordahl (2006) classify trust into two categories: particularized and generalized trust. Particularized trust is based on reputation and refers to trusting concrete actors who are known from past interactions, which leads to a decrease in transaction costs and the creation of sustainable relationships. In contrast, generalized trust is linked to social capital and refers to putting trust in unknown people. Different beliefs about others' trustworthiness and the ability to elicit trustworthy behavior are some of the factors that influence a person's willingness to trust (Glaeser et al. 2000). Yamagishi (2001) discusses high and low trustors in society. In the absence of any prior evidence, high trustors have high expectations that people are trustworthy, whereas low trustors expect the opposite. General distrust provides protection to individuals but simultaneously leads them into isolation. By not interacting with others, low trustors miss opportunities to develop their social intelligence, which could make them more vulnerable to opportunistic situations over the long term (Yamagishi 2001). Yamagishi (2001) finds evidence that because of this lack of social interaction, low trustors take more time to decipher signals from others and therefore their response is slower than that of high trustors.

An individual's trustworthiness, which is directly linked to reciprocity, makes a contract possible in the absence of external enforcement mechanisms (Bohnet et al. 2001). Greig and Bohnet (2008) distinguish between balanced and conditional reciprocity. Balanced reciprocity exists when the receiver repays an investment as if it were an interest-free loan. This approach characterizes populations with harsh economic conditions under which individuals must insure themselves against income shocks. Conditional reciprocity, in contrast, occurs when a relationship is seen as a partnership, with both actors profiting. In this case, higher trust is rewarded with higher trustworthiness, thus increasing the efficiency of the transaction. 
Rational choice theory assumes that trust is a product of some system of rewards and penalties that act as incentives for the trustee to fulfill his duties in repeated interactions (Bacharach and Gambetta 2001). Coleman and Coleman (1994) and Calvert (1995) refer to mistrust or the withdrawal of trust as a social sanction imposed on a person who has violated some norm. Nevertheless, it can be the case that a relationship with a partner may be too strong (family or friendship), such that maintaining it becomes more important than sanctioning opportunism. An absence of strong sanctioning can also occur if the affected person wants to avoid the reputation of being difficult to do business with, which could harm his future business relationships (McMillan and Woodruff 2000).

\subsubsection{Measuring trust}

The trust game designed by Berg et al. (1995) has been used extensively to study trust and trustworthiness in an investment setting. In the two-player game, player A is given the choice to send part of his initial endowment to an anonymous partner, B. The amount sent is tripled by the experimenter and delivered to player $\mathrm{B}$, who then must decide how much of the received money he wants to return to player A. Anonymity is preserved during the game and in the original version, no repetitions are played to eliminate potential punishment and long-term strategies such as reputation building. Generalized trust is observed if player A sends part of his endowment to his unknown partner, who may not reciprocate. The ratio of B's response to A's initial decision is referred to as trustworthiness. Player B reciprocates if the amount that he returns is equal to or larger than the original quantity sent by A (Greig and Bohnet 2008).

Signaling can be introduced to the game to reveal the players' intentions. These signals can be used to establish if a partner possesses or lacks trustworthiness qualities (Bacharach and Gambetta 2001). Weele (2012) notes that when introducing signaling to a game, people can behave in a more calculated manner when giving their trust. Using a repeated trust game, McCabe et al. (2003) find evidence that certain players do consider their partners' intentions when making a decision. Therefore, sending a credible signal is expected to guide trustors to make a more rational decision regarding how much to trust someone. We use prior signaling in our experiment to frame possible opportunism when paying back a loan. Thus, a private signal is sent by the B players to their A partners before the trust game is played. The B players are asked to decide whether they want to pay back a loan made by A on time or if they prefer to delay the payment and obtain an additional profit.

\subsection{Experimental approach}

\subsubsection{Instructions for the game and predictions}

The first stage of the game is framed as a loan in which player A must send a fixed portion of his endowment to player B, and B must decide to either repay the loan on time or delay repayment. In the 
second stage, the normal trust game is played after A has learned of his partner's decision with respect to the loan. Neither player is informed that the trust game will be played in the second stage to ensure enough variation in B's decision with respect to the loan. If B was aware of the second stage, he would be more likely to choose to pay the loan on time as a reputation-building strategy. To mimic the opportunity cost of money, a profit is awarded to the player holding the money from the loan. Because providing the loan is mandatory for players $\mathrm{A}$, the profit for the first stage must be shared between the players. During the second stage, the profit corresponding to the loan stays with the person who retains the capital from the loan. According to the rules as conveyed to both players, player A expects payment for the loan once the first stage is complete (if A receives the payment on time, she will also obtain the profit corresponding to the second stage). Nevertheless, B can choose to default on the payment and keep the money to obtain the additional profit. If B chooses this option, he still must send the loan repayment at the end of the second stage.

The game took approximately one hour, and the instructions were read aloud in Spanish and Quichua. To begin, all players (A and B) were given an initial endowment of 5 US dollars (USD), which is a half-day's salary for an agricultural worker in the region. In the first stage, player A has to send a 1 USD loan out of his initial endowment to player B. Player A expects to be paid back in the following move together with some profit. B receives the loan from his partner, plus 0.50 USD profit $\left(P_{1}\right)$. Player B immediately must decide whether to repay the loan on time together with half of the profit, as expected by his partner, or to delay the payment until the end of the second stage and to return only half of the profit for the time being $\left(0.5 \mathrm{P}_{1}\right)$. If $\mathrm{B}$ decides to delay the payment, he obtains an additional profit of 0.25 USD $\left(P_{2}\right)$ for keeping the money during the second stage. If B decides to repay the loan on time, the 0.25 USD $\left(\mathrm{P}_{2}\right)$ goes to player $\mathrm{A}$. The trust game (second stage) starts once player A receives a response from $\mathrm{B}$ in a closed envelope that contains the $0.5 \mathrm{P}_{1}(0.25 \mathrm{USD})$ and additionally either contains or does not contain the 1 USD loan. Now, the trust game starts. Player A must decide how much of the remaining $4 \mathrm{USD}^{5}$ he wants to send to player $\mathrm{B}(X)$. $X$ is tripled by the experimenter, so player B receives $3 X$. Finally, player B sends back whatever amount he wants $(Z)$ in return for his partner's trust. Additionally, if player B delayed the repayment of the loan in the first stage, he must pay the 1 USD loan at the end of the second stage. Figure 2.1 shows a graphic representation of both stages of the game. Monetary payoffs for the control and treatment groups and the English translation of the instructions of the game are shown in the Appendix 2, sections A2.2 and A2.3.

\footnotetext{
${ }^{5}$ Regardless of whether Player A received the 1 USD back, all of the A players in the second stage can only decide to send part of the remaining 4 USD. The control group also received a 5 USD initial endowment, but similarly, they were able to send only up to 4 USD out of the endowment to match the conditions of the A players in the extended version of the game.
} 
Figure 3-2 Graphic representation of the trust game with signaling.

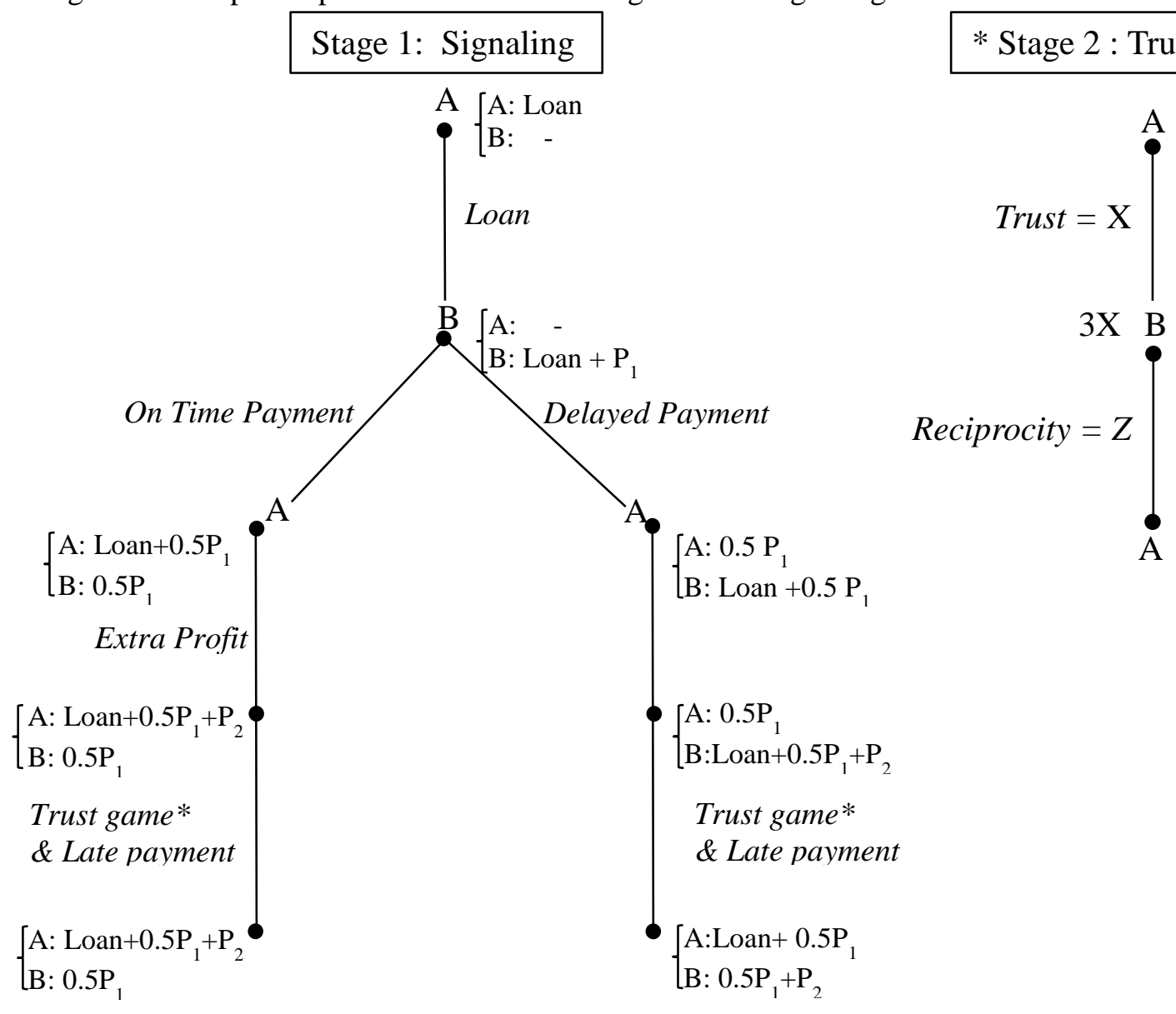

From our game, we make three predictions based on the existing literature. First, if individuals have a strictly increasing utility function for wealth, it is expected that the B players will behave opportunistically in the first move by delaying the payment and keeping the loan during both stages of the game ( $\mathrm{R}_{\mathrm{A}}=0$ for all players). Alternatively, if at least one $\mathrm{B}$ player complies with the rule and repays the loan on time, then we can test how the A players react to this positive signal. Second, as in the original game described by Berg et al. (1995), if the A players infer their partners' dominant strategy of keeping all of the money, they will not cooperate. Therefore, player A will not trust player $B$ because $B$ is expected to send nothing in return. Finally, our third prediction is that social norms acting as private ordering mechanisms that sustain cooperation should modify A's trust according to the signal received from his partner. Thus, Player A should increase his trust when receiving the payment on time ( $X_{T}>X_{C}$ if $\mathrm{R}_{\mathrm{A}}=1$ ) and should decrease his trust to protect himself against a possible negative outcome when not receiving the payment on time $\left(X_{T}<X_{C}\right.$ if $\left.\mathrm{R}_{\mathrm{A}}=0\right)$. 


\subsubsection{Data collection}

A household survey was conducted with a random sample of 401 small broccoli farmers in the highlands of Ecuador between December 2012 and February 2013. Former and active export chain suppliers were selected from a list of producers provided by the farmers' association and were interviewed in 8 different villages. In addition, households in the same eight villages and in a ninth village located in the same province (with the same infrastructure and weather characteristics) that had never participated in the export market were selected through a random walk. A questionnaire was answered by a family member involved in broccoli production and marketing decisions.

A member of one of the 383 interviewed households was invited to participate in the game (there were too few observations on three of the visited villages so as to organize an experimental session). Invitations were made immediately after the survey took place and repeated in the days after through phone calls. The participants were required to be involved in production and marketing decisions for broccoli but were not limited to heads of household. The game was played with the people who voluntarily attended each session after receiving the invitation. Fourteen sessions were played in six villages with 180 small farmers, of whom 51\% participated as export chain suppliers. The trust game with signaling was played in 12 of the sessions, and in the remaining 2 sessions, the trust game alone was played as a control. The final sample comprised 90 observations, ${ }^{6}$ of which 49 observations received a delayed payment, 23 observations received the payment on time and 18 observations played the trust game alone.

\subsubsection{Determinants of trust}

Our primary interest is to analyze the effects of positive and negative signaling on small farmers' trust. To this end, we specified the following outcome or main equation:

(2) $Y_{i}=\gamma^{\prime} Z_{i}+\varepsilon_{i 2}$,

where $Y_{i}$ is the amount of USD sent by player $\mathrm{A}, \mathrm{Z}_{i}$ is a vector of variables influencing trust that include the dummies On time payment $t_{i}$ and Delayed payment ${ }_{i}$ accounting for the signal received from the $\mathrm{B}$ partner, and $\varepsilon_{i 2}$ is the unobserved error term for equation 2. In addition to controlling for the initial signal received at the beginning of the game, $\mathbf{Z} \boldsymbol{i}$ includes other covariates related to the personal characteristics of each trustor such as female, asset index ${ }^{7}$ (as a proxy for household wealth), organization membership and completed primary education (as a proxy for game understanding). We

\footnotetext{
${ }^{6}$ Because of the paired structure of the game.

${ }^{7}$ The asset index was calculated using principal component analysis. For details on the assets used to build the index as well as its validity (variance explained, loadings of the components and KMO) refer to the Appendix 2, section .A2.4.
} 
also include the variable dropout as a control for whether the household had previously participated in the export chain which could influence a farmer's response when confronted with similar situations.

Recent studies (e.g. Frijters et al., 2015; Harrison et al., 2009) suggest that individuals might be more willing to participate in artificial field experiments due to some specific characteristics that differentiate them from the original sample, introducing a sample selection problem. In our experiment, invited farmers' had to decide whether to participate and once they arrived, they were further randomly assigned to two groups: $\mathrm{A}$ and $\mathrm{B}^{8}$. Our interest lies in the A players' decision about how much to trust their partners. A Heckman model corrects for this selection process, in which the level of trust of the non-participants could be different than zero but is unknown. In such an approach, a probit model is used to explain the selection mechanism. The model assumes that both decisions (e.g. the decisions to participate and the decision on how much to trust during the game) have a bivariate distribution that allows both error terms to be correlated. If the errors of both equations are correlated (rho is significant), then unobservables in the first stage also affect the outcome variable in the second stage or outcome equation. In such cases, the Heckman model is appropriate to produce unbiased estimates. The probability of a farmer participating in the game can be estimated using a probit model if the error term is assumed to have a standard normal distribution. Our selection equation is defined as follows:

(1) $P_{i}^{*}=\beta^{\prime} \boldsymbol{X}_{i}+\varepsilon_{i 1}$,

$$
P_{i}=1 \text { if } P_{i}^{*}>0,0 \text { otherwise }
$$

where the binary choice variable $\mathrm{P}_{\mathrm{i}}$ takes the value of 1 if the farmer decided to participate and 0 otherwise, $X_{i}$ is a vector of exogenous variables influencing participation and $\varepsilon_{i 1}$ is the unobserved error term to be minimized. Studies advise using an exclusion restriction in the selection equation to generate credible estimates. This exclusion restriction consists of at least one variable that appears with a non-zero coefficient in the selection equation but not in the equation of interest. Thus, we use number of household $(\mathrm{HH})$ members and Distance to game, which should not have an effect on trust and could affect participation. We expect a positive effect of the number of HH members because the bigger the family, the lower the opportunity costs for one of its members to engage in activities outside the household. Distance to the game is a proxy for a farmer's costs to travel to the location, which should affect participation negatively but should not have any effect on trust.

8 A table showing the Characteristics of players A and B is presented in the Appendix 2, section A2.5. There is no significant difference between both groups 
The correlation between the error terms of both equations $\varepsilon_{\mathrm{i} 1}$ and $\varepsilon_{\mathrm{i} 2}$ is measured by $\rho$ (Rho) which determines whether there is a sample selection problem. If $\rho=0$, then $\varepsilon_{\mathrm{i} 1}$ and $\varepsilon_{\mathrm{i} 2}$ are not correlated, and there is no necessity to correct for sample selection (Wooldridge 2012).

\subsection{Results and discussion}

\subsubsection{Results from the experimental game}

Rational choice theory predicts that player B will behave opportunistically in the first move to maximize his monetary profits. Nevertheless, 23 of the 72 B players who were required to send a signal chose to repay the loan on time and thus to comply with the rules of the game. We can therefore reject our first prediction on the opportunistic behavior expected from all B. Some individuals behaved according to the rules, even though this meant giving up the extra profit they would have earned had they kept the loan for one more period.

The decisions made by Players A and B sorted per group are summarized in Table 3.2. Three different groups are specified according to the treatment: 1) payment on time, 2) payment delayed and 3) control. The results confirm the existence of norms of trust and trustworthiness among smallholders even when no previous interaction has taken place. Generalized trust is quantified by the amount sent by the A players in the control group (1.16 USD, or 30\% of their endowment), which shows the farmers' tendency to trust their unknown partners. The level of general trust in our sample is much lower compared with that found in Berg et al. (1995) for American students (50\% of their endowment) and the values compiled by Cardenas and Carpenter (2008) from different studies (40\% of the initial endowment or higher). However, our trust result is similar to that found by Greig and Bohnet (2008) in the slums of Nairobi (30\% of the initial endowment). According to these authors, this low level of trust is influenced by severe poverty and harsh conditions that create the need for participants to insure themselves against income shocks by keeping as much money as possible.

The percentage returned by B (30\% of the possible amount, or 1.25 USD) in the control group closely matches the results reported by Berg et al. (1995) and by Cardenas and Carpenter (2008) for nonstudents. Regarding trustworthiness, on average, player A is better off when the game is over. Players in the control group receive a slightly higher amount than what was initially sent on average $(\mathrm{Z}-\mathrm{X}=$ 0.083 USD). Only $14 \%$ of the A players ${ }^{9}$ received less money than what they sent, and the rest received at least the same amount or higher. However, the average ratio of return observed $(\mathrm{Z} / \mathrm{X}=$ 1,185 ) is not significantly different than $1 .^{10}$ This result is characteristic of balanced reciprocity, whereby the B players perceive that the money sent by A is an interest-free loan, and the profits should not be shared (Greig and Bohnet 2008). Similar to low trust, balanced reciprocity is present

\footnotetext{
${ }^{9}$ Two A players of the 14 who sent something in the first move.

${ }^{10}$ T-test applied. $\mathrm{P}$ value $=0.2947$.
} 
because the players keep as much money as possible for themselves to protect themselves from external shocks. From a negative perspective, this approach can discourage long-term business relationships.

Table 3-2 Trust and trustworthiness according to the signal received.

\begin{tabular}{|c|c|c|c|c|c|c|}
\hline & \multirow{2}{*}{$\begin{array}{l}\text { 1. Payment on } \\
\text { time } \\
{\text { (Obs: } 23)^{\mathrm{b}}}^{\text {(Obs }}\end{array}$} & \multirow{2}{*}{$\begin{array}{l}\text { 2. Payment } \\
\text { delayed } \\
(\text { Obs: } 49)^{b}\end{array}$} & \multirow{2}{*}{$\begin{array}{l}\text { 3. Control } \\
\text { (Obs: 18) }^{\mathrm{b}} \\
\end{array}$} & \multicolumn{2}{|c|}{$\begin{array}{l}\text { Sig. Differences } \\
\text { (p values) }^{c}\end{array}$} & \multirow[b]{2}{*}{23} \\
\hline & & & & 12 & 13 & \\
\hline \multicolumn{7}{|l|}{ Trust } \\
\hline USD sent by A $(X)$ & $\begin{array}{l}1.565 \\
(0.895)\end{array}$ & $\begin{array}{l}1.122 \\
(0.881)\end{array}$ & $\begin{array}{l}1.167 \\
(1.043)\end{array}$ & $0.043 * *$ & $0.092 *$ & 0.920 \\
\hline$\%$ sent by $\mathrm{A}$ & $\begin{array}{l}0.391 \\
(0.224)\end{array}$ & $\begin{array}{l}0.281 \\
(0.220)\end{array}$ & $\begin{array}{l}0.291 \\
(0.261)\end{array}$ & $0.043 * *$ & $0.092 *$ & 0.920 \\
\hline \multicolumn{7}{|l|}{ Amount returned by $B$} \\
\hline USD sent by B (Z) & $\begin{array}{l}2.413 \\
(1.819)\end{array}$ & $\begin{array}{l}0.776 \\
(1.071)\end{array}$ & $\begin{array}{l}1.250 \\
(1.128)\end{array}$ & $0.000 * * *$ & $0.024 * *$ & $0.047 * *$ \\
\hline \% sent by B $\left(K_{b}\right)$ & $\begin{array}{l}0.479 \\
(0.238)\end{array}$ & $\begin{array}{l}0.190 \\
(0.245)\end{array}$ & $\begin{array}{l}0.307 \\
(0.250)\end{array}$ & $0.000^{* * *}$ & $0.009 * * *$ & $0.0509 *$ \\
\hline $\begin{array}{l}\text { Trustworthiness } \\
\text { Ratio of return }(Z / X)^{\text {a }}\end{array}$ & $\begin{array}{c}1.50 \\
(0.6548) \\
\end{array}$ & $\begin{array}{c}0.735 \\
(0.7592) \\
\end{array}$ & $\begin{array}{c}1.185 \\
(0.6322)\end{array}$ & $0.000 * * *$ & $0.0453 * *$ & $0.0235^{* *}$ \\
\hline
\end{tabular}

Receiving the payment on time is interpreted as a positive signal that increases the level of trust and enhances cooperation. Individuals who were paid on time sent on average a significantly higher amount of their endowment (1.56 USD) compared to the average amount sent by players whose payment was delayed (1.12 USD). When comparing these figures to the control group, players who received a positive signal also trust more than players who received no signal at all ( $\mathrm{p}$ value $=0.092$ ). However, when comparing trust after a negative signal with that of the control group, there is no significant difference $(\mathrm{p}$ value $=0.920)$. In summary, a positive signal sent at the beginning of the relationship has the power to trigger a positive response and to enhance the trust of small farmers, but a negative signal has no effect. We find three possible explanations for this behavior. First, individuals do not have much room to react strongly toward their partner's opportunism by significantly decreasing their trust because their level of general trust is already quite low. Our second explanation follows Yamagishi's theory that generalized distrust provides protection to individuals but also leads them to social isolation and lower levels of social intelligence (Yamagishi 2001). The author finds evidence that low trustors respond more slowly to external information, especially when stimuli are negative. Finally, farmers might not decrease their already-low trust because they do not want to completely sever the relationship. It could be that maintaining a relationship is more important than severely sanctioning opportunism because of other social aspects (kinship or friendship within the members of the community with whom they are playing). 
The average amount returned by B also differs among the three groups. The group of farmers who paid the loan back on time returned an average of 2.41 USD (50\% of what they received) compared to the farmers who behaved opportunistically, and in the second stage they returned on average only 0.77 USD (19\% of what they received). The trustworthiness shown by the B players is clearly linked to their first decision about when to pay their counterpart. Players who behaved according to the rules also showed a higher degree of trustworthiness and reciprocity later on by sharing part of their profits with their counterparts. B players who kept the money for themselves also behaved selfishly later, and most of the time they made their counterparts worse off: on average, their partners received $26.5 \%$ less than what they had sent.

\subsubsection{Determinants of trust considering sample selection}

To determine the factors influencing trust we use a Heckman selection model to control for possible self-selection of participants. In Table 3.3 we present the results for both stages: participation and trust.

Table 3-3 Heckman model for trust.

\begin{tabular}{|c|c|c|}
\hline VARIABLES & $\begin{array}{l}\text { 1. Participation } \\
\text { Coef. }\end{array}$ & $\begin{array}{c}\text { 2. Trust } \\
\text { USD sent by A }\end{array}$ \\
\hline \multicolumn{3}{|l|}{ Treatment $^{a}$} \\
\hline Received payment on time $\left(\mathrm{R}_{\mathrm{A}}=1\right)$ & & $\begin{array}{c}0.574 * * \\
(0.247)\end{array}$ \\
\hline Received delayed payment $\left(\mathrm{R}_{\mathrm{A}}=0\right)$ & & $\begin{array}{l}0.057 \\
(0.219)\end{array}$ \\
\hline \multicolumn{3}{|l|}{ Control variables } \\
\hline Female & & $\begin{array}{c}-0.435 * * * \\
(0.151)\end{array}$ \\
\hline Completed primary education & & $\begin{array}{l}0.061 \\
(0.167)\end{array}$ \\
\hline Distance to main market & $\begin{array}{l}0.024 \\
(0.025)\end{array}$ & $\begin{array}{l}0.068 \\
(0.041)\end{array}$ \\
\hline Asset index & $\begin{array}{l}-0.071 \\
(0.047)\end{array}$ & $\begin{array}{l}-0.051 \\
(0.074)\end{array}$ \\
\hline Organization membership & $\begin{array}{l}0.269^{*} \\
(0.147)\end{array}$ & $\begin{array}{c}0.832^{* * *} \\
(0.238)\end{array}$ \\
\hline Dropout from export chain & $\begin{array}{c}-0.0273 \\
(0.142)\end{array}$ & $\begin{array}{l}-0.158 \\
(0.227)\end{array}$ \\
\hline HH members & $\begin{array}{l}0.0568 * \\
(0.0334)\end{array}$ & \\
\hline Distance to game location & $\begin{array}{l}-0.172 \\
(0.112)\end{array}$ & \\
\hline Constant & $\begin{array}{c}-0.988^{* * *} \\
(0.195) \\
\end{array}$ & $\begin{array}{c}-1.724^{* *} \\
(0.585) \\
\end{array}$ \\
\hline Rho & & $\begin{array}{c}0.968^{* * *} \\
(0.025)^{\mathrm{b}}\end{array}$ \\
\hline Observations & 383 & 88 \\
\hline
\end{tabular}


The rho estimate indicates a positive correlation between the error terms of both equations, and the Wald test indicates that this correlation is highly significant. Therefore, some unobserved factors positively influence participation and trust. This result confirms a selection problem and the adequacy of the Heckman model to analyze our data and correct for the positive bias that our estimates would otherwise have.

The results of the Participation equation show that farmers who decided to participate in our sessions have specific characteristics that differentiate them from the entire sample of invited farmers. Farmers who are members of an organization and those with more household members were more likely to participate. Although wealth negatively affects participation, as expected, it is not statistically significant. Members of an organization hold regular meetings in which it is common for outsiders to organize different activities such as technical training or the diffusion of information. Therefore, these farmers could be more willing to participate in a meeting organized by scholars. Moreover, we had the support of the farmers' group in conducting the survey, and the group might have encouraged its members to participate in the game. It is also not surprising that wealthier farmers were less likely to participate. One of the variables in our exclusion restriction is also significant. Having an additional member of the household increases the likelihood that one of the household's members has time to participate in our game. When this variable is divided into household members over 15 and household members under 15, the results (see the Appendix 2, section A2.6.) show that having one household member older than 15 significantly increases the probability of participating in the game, which supports the idea that an additional household member alleviates the burden of household work, thus allowing another member to participate in external activities.

After controlling for selection bias and other characteristics, we still find that a positive signal modifies the trust of an individual toward one's partner, thus allowing us to accept $\mathrm{H}_{4}$. However, a negative signal does not have an effect on trust; therefore, we cannot reject our last null hypothesis. Holding all other variables constant, a small farmer who receives a loan repayment on time sends on average 0.57 USD more than one who has not received any signal from his partner. Conversely, a person whose payment was delayed sends on average the same amount of money as in the control group ( $p$ value: 0.785 ). Low trustors can take longer to react to external stimuli because of their reluctance to engage in social interactions, a situation that represents a problem when eliciting the trustworthiness of others. Additionally, females in our sample send an average of 0.43 USD less than males. This result confirms previous findings by Buchan et al. (2008) that females trust less than males. Additionally, the amount sent by members of an organization is an average of 0.83 USD higher than the amount sent by non-members. Our players do not know their partners' identities, but because members of the same village often belong to the same organization, increased trust may be encouraged. Finally, it is interesting that even though former participants in the export value chain showed a negative coefficient for trust, this result is not statistically significant. 


\subsection{Conclusions}

Care must be taken when drawing conclusions from experimental data because the individuals who participate in experimental games could systematically differ from the originally invited population. Recruiting participants is easier with the support of a local organization, but their members might have specific characteristics that differentiate them from the general population. Therefore, selection bias should be accounted for when using game data derived from a subsample of the population for whom we wish to draw our conclusions.

Our findings show a low level of generalized trust towards unknown people. This result could be the effect of the business conditions to which the farmers had been exposed, which include extremely volatile prices in the local market and high uncertainties due to quality (rejections) and price (payment delay) in the export market. This paper's primary contribution is the study of farmers' behavior when exposed to previous signaling from a partner. In such cases, the level of trust partly varied according to the type of signal. Behaving according to the rules and sending an on-time payment increased the amount of trust received in the game. Thus, we can conclude that positive signaling enhances trust and promotes norms of cooperation. However, farmers whose partners behaved opportunistically showed similar levels of trust as those who had no information at all. We should keep in mind that the reason for this lack of response could be a low capacity for eliciting others' trustworthiness. Farmers already protect themselves at the beginning of any business relationship by showing mistrust toward an unknown partner and if they receive a negative signal, they may be unable to react promptly, so they choose to maintain the relationship at a low level. Nevertheless, if not reacting in the face of opportunism is an informal norm in the region, agreements would be considered flexible because not fulfilling them would have no visible consequences. Reacting slowly to external signs, particularly when such signs are negative can threaten livelihoods of farmers. If small farmers cannot react quickly enough, they might face large losses by the time they decide to sanction such behavior. In addition, according to Williamson (1993), if informal rules include weak sanctions, then an action depending on a reciprocal sense of responsibility will be less likely. Therefore, individuals may prefer the spot market, in which immediate exchanges take place, rather than some signed or verbal agreement in which both actors must act reciprocally and responsible during a prolonged period and in which they are exposed to hold ups.

The low levels of trust toward unknowns and the existing norms that reward good behavior also suggest the need to send a strong positive signal at the beginning of any relationship to achieve cooperation. Now that technology facilitates the exchange of information on reputation, a database containing information about the reputation of possible partners can be established and distributed by the authorities to increase the initial level of trust. Additionally, adequate safeguards to ensure contract 
compliance should be demanded from larger players as a sign of their willingness to engage in longterm relationships.

This study represents an initial approach that attempts to disentangle the internal norms that govern smallholder behavior. There is extensive room to expand the topic of signaling and trust using farmers as the subjects of study. We analyzed the response to a single signal, but it remains unknown whether repeated positive signals produce an added effect on trust or whether farmers' responses cease to change at some point. Similarly, it would be interesting to see whether farmers change their behavior when faced with repeated negative signals. Finally, the signaling used was a delayed payment, which the farmers might not find very serious. There is a chance that farmers may react differently to other possible problems, such as high rejection rates. 


\section{References}

Altenburg, T., 2006. Governance Patterns in Value Chains and their Development Impact. Eur. J. Dev. Res. 18, 498-521. doi:10.1080/09578810601070795

Anderson, J., Burks, S.V., Carpenter, J., Götte, L., Maurer, K., Nosenzo, D., Potter, R., Rocha, K., Rustichini, A., 2012. Self-selection and variations in the laboratory measurement of otherregarding preferences across subject pools: evidence from one college student and two adult samples. Exp. Econ. 16, 170-189. doi:10.1007/s10683-012-9327-7

Arrow, K., 1974. The Limits of Organization.

Bacharach, M., Gambetta, D. 2001. Trust in Signs. In: Trust in Society. Ed. Cook, K. Russell Sage Foundation Series on Trust.

Barrett, C.B., Bachke, M.E., Bellemare, M.F., Michelson, H.C., Narayanan, S., Walker, T.F., 2012. Smallholder Participation in Contract Farming: Comparative Evidence from Five Countries. World Dev. 40, 715-730. doi:10.1016/j.worlddev.2011.09.006

Berggren, N., Jordahl, H., 2006. Free to Trust: Economic Freedom and Social Capital. Kyklos 59, 141-169. doi:10.1111/j.1467-6435.2006.00324.x

Berg, J., Dickhaut, J., McCabe, K., 1995. Trust, Reciprocity, and Social History. Games Econ. Behav. 10, 122-142. doi:10.1006/game.1995.1027

Bohnet, I., Frey, B.S., Huck, S., 2001. More Order with Less Law: On Contract Enforcement, Trust, and Crowding. Am. Polit. Sci. Rev. null, 131-144. doi:10.1017/S0003055401000211

Bouma, J., Bulte, E., van Soest, D., 2008. Trust and cooperation: Social capital and community resource management. J. Environ. Econ. Manag. 56, 155-166. doi:10.1016/j.jeem.2008.03.004

Braun, J.V., Hotchkiss, D., Immink, M.D.C., 1989. Nontraditional Export Crops in Guatemala: Effects on Production, Income, and Nutrition. Intl Food Policy Res Inst.

Buchan, N.R., Croson, R.T.A., Solnick, S., 2008. Trust and gender: An examination of behavior and beliefs in the Investment Game. J. Econ. Behav. Organ. 68, 466-476. doi:10.1016/j.jebo.2007.10.006

Calvert, R. 1995. The rational choice theory of social institutions: cooperation, coordination, and communication. In: Modern Poitical Economy: Old Topics, New Directions. Ed. Banks, J., Hanushek, E. Cambridge University Press.

Cardenas, J.C., Carpenter, J., 2008. Behavioural Development Economics: Lessons from Field Labs in the Developing World. J. Dev. Stud. 44, 311-338. doi:10.1080/00220380701848327

Carletto, C., Kirk, A., Winters, P.C., Davis, B., 2010. Globalization and Smallholders: The Adoption, Diffusion, and Welfare Impact of Non-Traditional Export Crops in Guatemala. World Dev. 38, 814-827. doi:10.1016/j.worlddev.2010.02.017 
Chemnitz, C., 2007. The Compliance Decision with Food Quality Standards on Primary Producer Level. A Case Study of the EUREPGAP Standard in the Moroccan Tomato Sector. Presented at the I Mediterranean Conference of Agro-Food Social Scientist, Barcelona, Spain.

Coleman, J.S., Coleman, J.S., 1994. Foundations of Social Theory. Harvard University Press.

Croson, R., Buchan, N., 1999. Gender and Culture: International Experimental Evidence from Trust Games. Am. Econ. Rev. 89, 386-391.

Cungu, A., Gow, H., Swinnen, J.F.M., Vranken, L., 2008. Investment with weak contract enforcement: evidence from Hungary during transition. Eur. Rev. Agric. Econ. 35, 75-91. doi:10.1093/erae/jbn001

Fafchamps, M., Minten, B., 2001. Property Rights in a Flea Market Economy. Econ. Dev. Cult. Change 49, 229-267. doi:10.1086/edcc.2001.49.issue-2

Fischer, J.A.V., 2008. Is competition good for trust? Cross-country evidence using micro-data. Econ. Lett. 100, 56-59. doi:10.1016/j.econlet.2007.11.001

Frijters, P., Kong, T.S., Liu, E.M., 2015. Who is coming to the artefactual field experiment? Participation bias among Chinese rural migrants. J. Econ. Behav. Organ. 114, 62-74. doi:10.1016/j.jebo.2015.03.006

Glaeser, E.L., Laibson, D.I., Scheinkman, J.A., Soutter, C.L., 2000. Measuring Trust. Q. J. Econ. 115, 811-846.

Gow, H.R., Swinnen, J.F.M., 1998. Up- and downstream restructuring, foreign direct investment, and hold-up problems in agricultural transition. Eur. Rev. Agric. Econ. 25, 331-350. doi:10.1093/erae/25.3.331

Greig, F., Bohnet, I., 2008. Is There Reciprocity in a Reciprocal-Exchange Economy? Evidence of Gendered Norms from a Slum in Nairobi, Kenya. Econ. Inq. 46, 77-83. doi:10.1111/j.14657295.2007.00081.x

Harrison, G.W., Lau, M.I., Elisabet Rutström, E., 2009. Risk attitudes, randomization to treatment, and self-selection into experiments. J. Econ. Behav. Organ., Field Experiments in Economics 70, 498-507. doi:10.1016/j.jebo.2008.02.011

Henrich, J., Boyd, R., Bowles, S., Camerer, C., Fehr, E., Gintis, H., McElreath, R., 2001. In Search of Homo Economicus: Behavioral Experiments in 15 Small-Scale Societies. Am. Econ. Rev. 91, 73-78.

Hernández, R., Reardon, T., Berdegué, J., 2007. Supermarkets, wholesalers, and tomato growers in Guatemala. Agric. Econ. 36, 281-290. doi:10.1111/j.1574-0862.2007.00206.x

Höhmann, H., Kautonen, T., Lageman, B., Welter, F., 2002. Entrepreneurial strategies and trust: a position paper. In. Entrepremeurial Strategies and Trust. Structure and Evolution of Entrepreneurial Behavioural Patterns in East and West European Environments - Concepts and considerations. Bremen. 
Höhmann, H.-H., Welter, F., 2002. Entrepreneurial strategies and trust. Structure and Evolution of Entrepreneurial Behavioural Patterns in East and West European Environments - Concepts and considerations. Bremen Forschungsstelle Osteur.

Höhmann, H.-H., Malieva, E. 2002. Trust as a Basic Antrhopological Category . In. Entrepremeurial Strategies and Trust. Structure and Evolution of Entrepreneurial Behavioural Patterns in East and West European Environments - Concepts and considerations. Bremen.

Key, Nigel, and David Runsten. 1999. “Contract Farming, Smallholders, and Rural Development in Latin America: The Organization of Agroprocessing Firms and the Scale of Outgrower Production.” World Development 27 (2): 381-401.

Klein, B., 1996. Why Hold-Ups Occur: The Self-Enforcing Range of Contractual Relationships. Econ. Inq. 34, 444-463. doi:10.1111/j.1465-7295.1996.tb01388.x

Lyon, F., 2000. Trust, Networks and Norms: The Creation of Social Capital in Agricultural Economies in Ghana. World Dev. 28, 663-681. doi:10.1016/S0305-750X(99)00146-1

McCabe, K.A., Rigdon, M.L., Smith, V.L., 2003. Positive reciprocity and intentions in trust games. J. Econ. Behav. Organ. 52, 267-275. doi:10.1016/S0167-2681(03)00003-9

McMillan, J., Woodruff, C., 2000. Private Order under Dysfunctional Public Order. Mich. Law Rev. 98, 2421-2458. doi:10.2307/1290349

Morduch, J., 1999. The Microfinance Promise. J. Econ. Lit. 37, 1569-1614.

North, D.C., 1990. Institutions, Institutional Change and Economic Performance. Cambridge University Press.

Siziba, S., Bulte, E., 2012. Does market participation promote generalized trust? Experimental evidence from Southern Africa. Econ. Lett. 117, 156-160. doi:10.1016/j.econlet.2012.05.003

Torero, M., Viceisza, A., 2011. Potential Collusion and Trust Evidence from a Field Experiment in Vietnam.

Weele, J. van der, 2012. The Signaling Power of Sanctions in Social Dilemmas. J. Law Econ. Organ. 28, 103-126. doi:10.1093/jleo/ewp039

Williamson, O.E., 1993. Calculativeness, Trust, and Economic Organization. J. Law Econ. 36, 453486.

Wooldridge, J., 2012. Introductory Econometrics: A Modern Approach. Cengage Learning. Yamagishi, Y., 2001. Trust as a form of social Intelligence. In: Trust in Society. Ed. Cook, K. Russell Sage Foundation Series on Trust. 


\section{Appendix 2}

\section{A2.1: Principal component analysis for construction of Trust variables.}

Table A2.1: Statements used for construct Trust.

\begin{tabular}{lll}
\hline \multicolumn{1}{c}{ Construct } & $\begin{array}{c}\text { Cronbach's } \\
\text { Alpha }\end{array}$ & \\
\hline Trust in Export market & 0.832 & $\begin{array}{l}\text { I think that I can trust on my buyer in the export market } \\
\text { to fulfill his promises } \\
\text { In general, I think that my buyer in the export market has } \\
\text { been honest with me }\end{array}$ \\
& $\begin{array}{l}\text { I would recommend my buyer in the export market to } \\
\text { my friends and family who grow broccoli }\end{array}$ \\
& $\begin{array}{l}\text { I think that my buyer in the export market has been } \\
\text { trustful during the time I have dealt with him }\end{array}$ \\
\hline Trust in Local market & $\begin{array}{l}\text { I think that I can trust on my buyer in the local market to } \\
\text { fulfill his promises }\end{array}$ \\
& $\begin{array}{l}\text { In general, I think that my buyer in the local market has } \\
\text { been honest with me }\end{array}$ \\
& $\begin{array}{l}\text { I would recommend my buyer in the local market to my } \\
\text { friends and family who grow broccoli }\end{array}$ \\
& $\begin{array}{l}\text { I think that my buyer in the local market has been trustful } \\
\text { during the time I have dealt with him }\end{array}$ \\
\hline
\end{tabular}

Table A2.2: Principal components for Trust

\begin{tabular}{|c|c|c|c|c|}
\hline Component & Eigenvalue & Difference & Proportion & Comulative \\
\hline \multicolumn{5}{|c|}{ Trust in Export market } \\
\hline Comp1 & 2.68677 & 2.06259 & 0.6717 & 0.6717 \\
\hline Comp2 & .624182 & .272973 & 0.1560 & 0.8277 \\
\hline Comp3 & .351209 & .0133747 & 0.0878 & 0.9155 \\
\hline Comp4 & .337835 & & 0.0845 & 1.0000 \\
\hline \multicolumn{5}{|c|}{ Trust in Local market } \\
\hline Comp1 & 2.44337 & 1.71933 & 0.6108 & 0.6108 \\
\hline Comp2 & .72404 & .210389 & 0.1810 & 0.7919 \\
\hline Comp3 & .51365 & .19471 & 0.1284 & 0.9203 \\
\hline Comp4 & .31894 & & 0.0797 & 1.0000 \\
\hline
\end{tabular}


Table A2.3: Factor Loadings for Component 1 (rotation = varimax).

\begin{tabular}{lrr}
\hline Variable & $\begin{array}{c}\text { Trust in } \\
\text { export market }\end{array}$ & $\begin{array}{c}\text { Trust in } \\
\text { local market }\end{array}$ \\
\hline \hline Statement 1 & 0.5085 & 0.4954 \\
Statement 2 & 0.5244 & 0.5618 \\
Statement 3 & 0.4341 & 0.4178 \\
Statement 4 & 0.5272 & 0.5143 \\
\hline \hline
\end{tabular}

Table A2.4: Kaiser-Meyer-Ohlin measure of sampling adequacy.

\begin{tabular}{lcc}
\hline Variable & $\begin{array}{c}\text { KMO for trust in } \\
\text { export market }\end{array}$ & $\begin{array}{c}\text { KMO for trust } \\
\text { in local market }\end{array}$ \\
\hline \hline Statement 1 & 0.7844 & 0.7459 \\
Statement 2 & 0.7894 & 0.6857 \\
Statement 3 & 0.8588 & 0.8355 \\
Statement 4 & 0.7822 & 0.7798 \\
\hline Overall & $\mathbf{0 . 7 9 7 1}$ & $\mathbf{0 . 7 4 4 8}$ \\
\hline \hline
\end{tabular}

\section{A2.2. Monetary payoffs for the control and treatment groups}

Control Group (Berg et al., 1995)

Player A: $\pi_{A}=1 U S D+\left[4 U S D-X c+Z_{C}\right]$

Player B: $\pi_{B}=5 U S D+3 X C-Z_{C}$

\section{Treatment Group ${ }^{11}$}

Player A: $\pi_{A}=\frac{P_{1}}{2}+R_{A} P_{2}+\left[1 U S D+4 U S D-X_{T}+Z_{C}\right]$

Player B: $\pi_{B}=\frac{P_{1}}{2}+\left(1-R_{A}\right) P_{2}+\left[5 U S D+3 X_{T}-Z_{C}\right]$

Where:

$\pi_{A}, \pi_{B}=$ Profit for player A and player B, respectively

$X c, X_{T} \in\{0,1,2,3,4\}:$ Amount sent by player $\mathrm{A}=$ "trust"

$k_{b} ; k_{b c}$ : Percentage returned by player $\mathrm{B}$ of the total quantity received

$Z \in\{0,1, \ldots, 12\}$ : Total amount sent by player B. 
$\mathrm{Z} / \mathrm{X}=$ Trustworthiness (ratio of return to $\mathrm{A}$ )

$\mathrm{P}_{1}, \mathrm{P}_{2}$ : Profits from loan during the first and second stage, respectively.

$\mathrm{R}_{\mathrm{A}}$ : Dummy for player A receiving payment on time ( $1=$ Yes; $0=$ No)

\section{A2.3. Instructions of the game translated to English}

\section{PLAYER A}

For this game you have a partner in the room next door with whom you will play following the instructions we will read out loud. Your partner does not know your name and you will not get to know his/her name either. All decisions will be anonymous. Please do not make any comments with the other players in this room. If you do this, you will not be able to continue playing the game.

To begin with, we will give you and your partner in the other room 5 dollars each for coming to the game.

[Distribute envelopes containing 5 bills of 1 dollar]

\section{1}

To start, you have to give a loan of 1 dollar of the 5 dollars you got to your partner. This dollar will produce a profit of 0,50 cents that will be split between you and your partner. So for the 1 dollar loan you will get a 0,25 cent profit and your partner will also get a 0,25 cent profit. At the end of this stage, your partner MUST pay you the 1 dollar back plus the 0,25 cents of the profit. It is important that you get this payment on time. Now, please put 1 of the 5 dollars you got inside the blue envelope.

[Collect blue envelopes]

[Wait for response of player B]

\section{2}

Your partner MUST pay you the dollar you sent him/her as a loan plus the 0,25 cents that are your share of the profit. This means that you MUST receive 1 dollar with 0,25 cents inside the yellow envelope that was sent to you by your partner.

[Distribute yellow envelopes coming from player B]

Please open the yellow envelope and look inside. You will find 1 dollar if your partner PAID YOU ON TIME for the loan, plus the 0,25 cents of profit. If your partner decided to NOT SEND THE 
PAYMENT ON TIME and keep YOUR 1 dollar for longer, then your envelope will have only 0,25 cents, which is your part of the profit.

Now, If your partner PAID YOU ON TIME, that means if you got your 1 euro back already, you will get an additional profit for having your money with you. But if you did not find a dollar in the envelope then your partner DID NOT PAY YOU YET, and the additional profit will go to your partner and not to you.

The people who received the PAYMENT for the 1 dollar ON TIME, will get 0,25 cents as additional profit. However, if your partner DID NOT GIVE YOU THE DOLLAR BACK YET, you will get NO additional profit.

[Distribute white envelopes which contain 0,25 cents if the player got the payment on time or which are empty if the player did not get the payment on time]

3

\section{START SECOND STAGE OF THE GAME}

Now we will start the second stage of the game. During this second part, you are still playing with the same partner you have been playing so far. You all must have at least 4 dollars left. Now, you have to decide how much of this 4 DOLLARS you want to send to your partner. The amount you send to your partner will be multiplied by three by us and then the total amount will be delivered to your partner. Your partner will receive this money and afterwards should decide how much he wants to send back to you.

For example, if you send your partner 1 dollar of the 4 dollars you have left, we will multiply this by 3 and give your partner 3 dollars. Then, he/she HAS TO decide how much of these 3 dollars he/she wants to send back or share with you. IF you decide to send your partner 2 dollars, we will give your partner 6 dollars and he/she will have to decide how much of these 6 dollars he/she wants to send back to you.

There are no wrong decisions. You can send to your partner 0, 1, 2, 3 or 4 dollars. Depending on how far you trust that your partner will send you a fair amount back. Please take your decision and put the money on the white envelope in front of you.

[Collect white envelopes]

4

[Distribute the envelopes coming from B players] 
Please open the envelopes your partners have sent you. The white envelop has the money that your partner sent you back. The yellow envelope MUST have 1 dollar of the initial loan if you were not paid before. If you were already paid, this envelope is going to be empty.

\section{END OF THE GAME}

\section{PLAYER B}

For this game you have a partner in the room next door with whom you will play following the instructions we will read out loud. Your partner does not know your name and you will not get to know his/her name either. All decisions will be anonymous. Please do not make any comments with the other players in this room. If you do this, you will not be able to continue playing the game.

To begin with, we will give you and your partner in the other room 5 dollars each for coming to the game.

[Distribute envelopes containing 5 bills of 1 dollar]

1

Your partner sent you 1 dollar as a loan out of the 5 dollars he got. This dollar generates a profit of 0,50 cents. You must share this profit with your partner and additionally PAY HIM/HER the 1 dollar back.

[Distribute blue envelopes containing 1 dollar and white envelopes containing two coins of 0,25 cents] Inside the blue envelope you will find 1 dollar sent by your partner which you MUST immediately pay back. Inside the white envelope you will find the 0,50 cents profit coming from this loan which you must share with your partner. Please take this money out of the envelopes.

Now, please take the yellow envelope placed in front of you and put inside the 0,25 cents that are your partners' share of the profit.

Now you must decide if you want to pay the 1 dollar loan made by your partner ON TIME as HE/SHE IS EXPECTING IT. IF you decide to send the 1 dollar back ON TIME to his/her OWNER, your partner will get an additional profit of 0,25 cents but you will not receive any additional profit. BUT, if you decide to KEEP the 1 dollar for longer, I will give you an additional 0,25 cents profit to you, but your partner (the owner of the DOLLAR) will not receive anything. Please make your decision and close the yellow envelope.

[collect yellow envelope]

Now we will distribute the additional profit if you decided to keep the 1 dollar for longer. 
[Distribute white envelopes which contain 0,25 additional cents for the players who kept the loan or which is empty for the ones who paid the loan on time]

[Wait for white envelopes coming from A players]

\section{START SECOND STAGE OF THE GAME}

Do you remember that at the beginning of this game you and your partners received 5 dollars each. Now, your partner has decided to send you part of his 4 dollars as an investment. What they decided to send you I have multiplied by three and is the amount that you will receive now. Once you get this additional money, you have to decide how much you want to send back and share with your partner. For example, if your partner sent you 1 dollar of his 4 remaining dollars I multiplied this by 3 and you will receive 3 dollars now. In a following move you have to decide how much of the 3 additional dollars you just received you want to share with your partner. Another example: if your partner sent you 2 dollars, you will get 6 dollars inside the new envelope and you have to decide how much of this money you want to share with your partner. If your partner sent you 3 dollars, you will receive 9 dollars and you have to decide how much of these you want to send back to your partner. Finally, if your partner sent you 4 dollars, you will receive 12 dollars and you have to decide how much of these 12 dollars you want to send back to your partner. The money that you do not send back to your partner will be yours.

[Distribute white envelopes that comes from A partners]

Please take the money out of the envelope and count it, but do not talk to your neighbor.

Now you have to decide how much of what you just got you want to share with your partner. Put this amount of money again inside the white envelope. There are no wrong decisions. This means that you can send back any amount you think is better, from 0 to everything you got. Close the envelope.

Now, please put inside the yellow envelope in front of you the 1 dollar that your partner sent you as a loan at the very beginning of the game if you did not paid on time. If you already paid this dollar before, let the envelope empty and close it. 


\section{A2.4: Principal component analysis for construction of the Asset Index}

Table A2.5. Principal components for Asset Index

Number of Obs: 401 (Original survey participants).

\begin{tabular}{lrrrr}
\hline Component & Eigenvalue & Difference & Proportion & Comulative \\
\hline \hline Comp1 & 2.78363 & 1.55347 & 0.232 & 0.232 \\
Comp2 & 1.23016 & 0.154495 & 0.1025 & 0.3345 \\
Comp3 & 1.07566 & 0.057864 & 0.0896 & 0.4241 \\
Comp4 & 1.0178 & 0.124076 & 0.0848 & 0.5089 \\
Comp5 & 0.893723 & 0.0220651 & 0.0745 & 0.5834 \\
Comp6 & 0.871658 & 0.00361226 & 0.0726 & 0.6561 \\
Comp7 & 0.868045 & 0.10822 & 0.0723 & 0.7284 \\
Comp8 & 0.759826 & 0.0338496 & 0.0633 & 0.7917 \\
Comp9 & 0.725976 & 0.0246856 & 0.0605 & 0.8522 \\
Comp10 & 0.701291 & 0.146155 & 0.0584 & 0.9106 \\
Comp11 & 0.555136 & 0.0380417 & 0.0463 & 0.9569 \\
Comp12 & 0.517094 & & 0.0431 & 1 \\
\hline \hline
\end{tabular}

Table A2.6. Factor Loadings for Component 1 (rotation = varimax).

\begin{tabular}{lr}
\hline Variable & Component 1 \\
\hline \hline Pickup & 0.311 \\
Truck & 0.0038 \\
Car & 0.0764 \\
Tractor & 0.032 \\
Pc & 0.3948 \\
Refrigerator & 0.3925 \\
HH floor & 0.4186 \\
HH roof & 0.2541 \\
HH aspect & 0.2708 \\
HH bathroom & 0.3697 \\
USD clothes & 0.2852 \\
Extra house & 0.2355 \\
\hline \hline
\end{tabular}

Table A2.7. Kaiser-Meyer-Ohlin measure of sampling adequacy.

\begin{tabular}{lc}
\hline \multicolumn{1}{c}{ Variable } & KMO \\
\hline \hline Pickup & 0.8211 \\
Truck & 0.7008 \\
Car & 0.7324 \\
Tractor & 0.7567 \\
Pc & 0.7722 \\
refrigerator & 0.8265 \\
HH floor & 0.7941
\end{tabular}




\begin{tabular}{lr} 
HH roof & 0.6595 \\
HH aspect & 0.7842 \\
HH bathroom & 0.8042 \\
USD clothes & 0.8382 \\
Extra house & 0.716 \\
\hline Overall & $\mathbf{0 . 7 8 5 1}$ \\
\hline \hline
\end{tabular}

\section{A2.5. Characteristics of players A and B}

Table A2.8. Descriptive statistics for player A and B

\begin{tabular}{lccc}
\hline & & & \\
& Players A & Players B & p value \\
\hline \hline Female & 0.523 & 0.494 & 0.708 \\
Asset Index & -0.235 & -0.423 & 0.441 \\
Organization membership & 0.455 & 0.494 & 0.601 \\
Complete primary education & 0.705 & 0.632 & 0.312 \\
Dropout from export chain & 0.477 & 0.540 & 0.408 \\
Distance to main market & 12.192 & 12.167 & 0.952 \\
HH members & 4.375 & 4.080 & 0.228 \\
Distance to game location & 0.578 & 0.645 & 0.418 \\
\hline \hline
\end{tabular}

\section{A2.6: Other models explaining participation and trust.}

Table A2.9 Heckman model with two different variables showing the composition of the household in the selection equation.

\begin{tabular}{|c|c|c|}
\hline VARIABLES & $\begin{array}{c}1 . \\
\text { Participation } \\
\text { Coef. }\end{array}$ & $\begin{array}{l}\text { 2. Trust } \\
\text { USD sent by } \\
\text { A } \\
\end{array}$ \\
\hline \multicolumn{3}{|l|}{ Treatment $^{a}$} \\
\hline Received payment on time $\left(\mathrm{R}_{\mathrm{A}}=1\right)$ & & $\begin{array}{l}0.496 * * \\
0.244\end{array}$ \\
\hline Received payment delayed $\left(\mathrm{R}_{\mathrm{A}}=0\right)$ & & $\begin{array}{l}-0.021 \\
0.220\end{array}$ \\
\hline \multicolumn{3}{|l|}{ Control variables } \\
\hline Female & & $\begin{array}{l}-0.408^{* * * *} \\
0.151\end{array}$ \\
\hline Complete primary education & & $\begin{array}{l}0.096 \\
0.174\end{array}$ \\
\hline Distance to main market & $\begin{array}{l}0.022 \\
0.025\end{array}$ & $\begin{array}{l}0.061 \\
0.041\end{array}$ \\
\hline Asset Index & $\begin{array}{l}-0.079 * \\
0.046\end{array}$ & $\begin{array}{l}-0.039 \\
0.071\end{array}$ \\
\hline Organization membership & $\begin{array}{l}0.264^{*} \\
0.147\end{array}$ & $\begin{array}{l}0.793^{* * *} \\
0.230\end{array}$ \\
\hline Dropout from export chain & $\begin{array}{l}-0.018 \\
0.143\end{array}$ & $\begin{array}{l}-0.182 \\
0.222\end{array}$ \\
\hline HH members over 15 & $\begin{array}{l}0.076^{* *} \\
0.036\end{array}$ & \\
\hline HH members under 15 & -0.1892628 & \\
\hline
\end{tabular}




\begin{tabular}{llc} 
& 0.138 & \\
Distance to game location & -0.182967 & \\
& 0.113 & \\
Constant & $-1.301^{* * *}$ & $-1.501^{* * *}$ \\
& 0.355 & 0.699 \\
\hline \hline Rho & & $0.961^{* * *}$ \\
& & $(0.025)^{\mathrm{b}}$ \\
Observations & 383 & 88 \\
\hline
\end{tabular}




\title{
4. Inclusive and beneficial? Governance in global food value chains in Costa Rica ${ }^{1}$
}

\begin{abstract}
Global agri-food systems have undergone a rapid transformation towards closer vertical coordination and more stringent food quality and safety regulation. Contractual arrangements can provide farmers in developing countries with a safeguard and thus potentially support investments into farm-level upgrading and standard adoption. We use original survey data from pineapple growers in Costa Rica to analyze the determinants of contract choice and the dynamics of standard adoption. Furthermore, we evaluate the effects of different market arrangements on pineapple revenues, transaction risks and relational capital. Our analysis reveals that while contracts represent an important catalyst for farmlevel upgrading, major transaction risks in the supply chain remain unresolved. In particular, farmers in formal contract schemes face high rejection rates and long payment delays. Verbal agreements appear to be the best option that brings higher income, low transaction risks and higher relational capital in the form of trust and loyalty towards the buyer.
\end{abstract}

Keywords: contract farming, pineapple production, vertical coordination, standard adoption

\subsection{Introduction}

In recent years, global agri-food systems have undergone a rapid transformation towards higher concentration, closer vertical coordination, and more stringent food quality and safety standards (Maertens and Swinnen, 2009; Reardon et al., 2009; Swinnen and Maertens, 2007). This has been driven in part by an increasing world demand for certified products with attributes related to safety, high quality and social or environmental responsibility (Humphrey and Memedovic, 2006). In particular, current exports from developing countries to the EU or US markets need to comply with increasingly complex regulations (Dolan and Humphrey 2000; Henson et al. 2005). In response, modern management tools, such as standards and governance structures that allow closer coordination between lead firms and their suppliers, are more and more widely used in global value chains (Barrett et al., 2012). These market developments offer both opportunities as well as threats to smallholder farmers in developing countries. Many experts emphasize that participation in emerging high-value markets can support farmers in upgrading their production systems and improving their incomes by facilitating access to information and more profitable markets. On the other hand, stringent food safety

\footnotetext{
${ }^{1}$ This chapter is co-authored by Meike Wollni, Fernando Saenz, Jean-Francois Le Coq. The authors's contributions are as follows: CR and MW contributed to the conceptualization and design of the research. CR implemented the survey. MW and CR contributed to the data analysis and interpretation of the results. MW wrote the manuscript and all authors revised it.
} 
requirements can also pose barriers to the participation in high-value markets. Acquiring the technical know-how and financial resources to adapt the production process to the new requirements can be challenging and potentially marginalize smaller and resource-poor farmers (Henson et al. 2005; Key and Runsten 1999; Reardon et al. 2009).

In the past, the definition and implementation of food safety standards was mostly in the domain of public institutions and regulators. However, over recent years, there has been a shift towards private standards that define minimum requirements for produce to enter a specific supply chain (Dolan and Humphrey, 2000; Maertens and Swinnen, 2009). Some of the private standards have become quasimandatory, such as the GlobalGAP standard, which has been adopted by a large number of retail chains in major EU markets.

With a shift in the standard setting authority from public to private, the question arises who will support farm-level adjustments to the new standard requirements. Public extension services in developing countries often lack the capacities and specialized knowledge to prepare farmers for upgrading and compliance with private standards. This can partly be attributed to the dualistic market structure with low food safety and quality requirements in traditional markets and high requirements in modern domestic and export markets resulting in a food safety and quality gap at the producer level. Public extension services have so far mostly served traditional markets and are usually not equipped to support farmers in overcoming the food safety and quality gap between traditional and modern markets. Furthermore, in addition to limited access to extension services and specialized technical assistance, smallholder farmers in developing countries are often constrained by other market failures, including missing or imperfect credit, insurance and input markets (Key and Runsten, 1999). In response to this, there has been a surge in contract schemes and new institutional arrangements including public-private partnerships that have evolved to solve the missing markets problem and to provide the necessary support structures to help farmers adjust to the new market requirements (Kersting and Wollni, 2012).

Contract schemes vary from rather informal, trust-based agreements to written, legally enforceable contracts. Also, the intensity of vertical coordination varies from case to case. Simple marketing agreements only specify the quantity and time of delivery as well as a fixed or variable pricing scheme. Production contracts involve much closer vertical interaction where buyers may provide inputs or perform specific on-farm tasks during the production cycle. Previous studies have investigated the effects of contract farming on smallholder farmers. Several authors find that contractual arrangements can help small-scale farmers to participate in and benefit from high-value markets with high standard requirements (Miyata et al. 2009; Minten et al. 2009; Bellemare 2012; Narayanan 2014; Maertens and Swinnen 2009). Contract farming can provide farmers with a safe market outlet thus reducing the risks associated with relationship-specific investments (Dries and Swinnen, 2004). However, contract farming has also been associated with potential threats. Several studies claim that contracts can increase tensions within the household or community, increase 
farmers' dependence on one or few cash crops and lock them into an unbalanced relationship (Chemnitz et al. 2007; Cungu et al. 2008; Echanove and Steffen 2005; Key and Runsten 1999; Narayanan 2014)

In this paper we investigate the role of formal and informal private-sector contract schemes for farmlevel upgrading and marketing performance in high-value chains. In a first step, we analyze the determinants of participation in formal and informal contract schemes. In a second step, we look at the effects of contract schemes on standard adoption. Finally, we investigate whether farmers benefit from participation in contract schemes in terms of higher net revenues and more sustainable supply chain relationships. We address these questions in the context of a case study carried out with exportoriented small and medium-scale pineapple farmers in Costa Rica. The Costa Rican pineapple sector represents a typical agricultural high-value chain dominated by vertically integrated international agribusinesses with a strong export orientation, which is increasingly regulated by private standards that set product and process requirements. The paper is structured as follows. In the next chapter we provide some background on the Costa Rican pineapple sector and describe the food standards that are of relevance for the export market. In chapter three we introduce the data and methodology used in the study. Chapter four to six present and discuss results and chapter seven concludes.

\subsection{Governance in the Costa Rican pineapple sector.}

\subsubsection{Coordination and regulatory system}

Since the introduction of pineapple as an export crop in Costa Rica, the sector has expanded rapidly (Vagneron et al. 2009), and nowadays, Costa Rica is the largest exporter of fresh pineapple in the world. Between 2000 and 2009, pineapple production more than doubled, increasing from 0.9 million tons to 1.9 million tons (FAO Stat 2011). A major part of the production is destined for the export market, which amounted to 1.5 million tons of pineapples in 2008 (FAO Stat 2011). The main destination markets of Costa Rican pineapple exports are Europe (approx. 52\%) and the U.S. (approx. 48\%) (CANAPEP 2011). Due to trade agreements (Caribbean Basin Initiative and the Generalized System of Preferences), exporters do not incur entry tariffs to access these markets (Ingwersen 2012; MACMAP 2015). Both European and U.S. markets, however, are demanding in terms of sanitary and phyto-sanitary standards and public food safety regulations. Furthermore, the importance of private food safety and quality standards has been increasing in these markets over recent years.

The most important food safety and quality standard in the Costa Rican pineapple sector is the GlobalGAP standard, a private collective farm-gate standard developed by the European Retailer Association. The GlobalGAP standard represents a set of rules defining good agricultural practices, especially related to food safety, environmental protection, pesticide use, handling of waste, and workers' health, safety, and welfare (FoodPLUS and GTZ, 2008). While being a voluntary standard, 
GlobalGAP is becoming quasi-mandatory in some countries, e.g. the UK and Scandinavia, because major retailers demand it as a prerequisite (Poisot, 2007). The main purpose of the GlobalGAP standard is the harmonization and codification of information along the supply chain, i.e., it is used as a coordination mechanism and not as a marketing tool. Therefore, it is not associated with a price premium at the consumer level. Still, in some cases buyers may pay higher prices for GlobalGAP certified products at the producer level to provide incentives to farmers to comply with GlobalGAP regulations (Kersting and Wollni, 2012).

Besides food safety and quality standards, sustainability standards have gained in importance during recent years. In the Costa Rican pineapple sector, organic certification and the Rainforest Alliance standard are of particular relevance. The Rainforest Alliance standard, which was developed by the Sustainable Agriculture Network - a coalition of various environmental NGOs, is a voluntary process standard focusing on sustainable production systems (Rain Forest Alliance 2011). Certification with this standard entitles farmers to use the Rainforest Alliance label on their products as a marketing tool to inform consumers about the sustainability of their product. Currently, markets are still limited and there is no secure price premium, however, farmers might benefit in terms of securing access to a potentially growing market (Giovannucci and Ponte, 2005).

Similarly, the organic standard is a voluntary process standard that can be used as a signal to consumers who are willing to pay a price premium for organically produced products. The International Federation of Organic Agriculture Movements (IFOAM) has developed basic guidelines that serve as a reference for national and private agencies to develop more specific organic standards. During the past decade, the organic market segment has experienced considerable growth rates in US and EU markets (Hughner et al., 2007). In response to this, many countries have implemented public standards to regulate the organic sector (Giovannucci and Ponte 2005). Certification with organic standards can be associated with high implementation costs, especially due to long transition periods from conventional to organic production systems (Coulibaly and Liu, 2006). This exposes farmers to major uncertainties regarding future prices of organic produce, given that the price premium is not fixed but depends on market conditions.

The Costa Rican pineapple sector consists of approximately 170 exporters, 72 packing facilities and 1300 producers (CANAPEP 2011). Many exporters are vertically integrated into the processing and production stages, thus disposing of their own packing plants and production units. The majority of the production destined to export markets originates from such vertically integrated production units that are owned by international and national private firms. Only 5 to $10 \%$ of the total export volume is produced by small and medium-scale farmers (MAG 2007; Vagneron et al. 2009 ). The vast majority of these smallholders, approximately $98 \%$, are located in the Huetar Norte region, where around $50 \%$ of the pineapple destined for export markets is grown (MAG 2007, CANAPEP 2011). The other two pineapple growing regions, namely the Atlantic (33\% of export production) and the Pacific (17\% of export production) regions (CANAPEP 2011), are dominated by large-scale integrated production 
units. Small-scale farmers usually deliver their produce directly to exporters, who impose strict standards in terms of volumes, product safety and quality (Vagneron et al. 2009). To close the gap between the quality and food safety of produce delivered by small and medium scale pineapple growers and the quality and safety requirements of international markets, several exporters have engaged in formal or informal contracts with growers.

\subsubsection{Transaction risks and asset-specific investments}

According to transaction costs theory, asset-specific investments will not occur in a highly uncertain environment without safeguards (Williamson, 1979). Asset-specific investments entail sunk costs that cannot be recovered, if the envisioned market exchange fails (Chavas, 1994; Johnson and Pasour, 1981). Producers who make asset-specific investments are thus locked into a specific market relationship and exposed to potential opportunistic behavior (Klein, 1996; Williamson, 1979). Buyers can for example reduce the producers' return on the investment by increasing their quality grading criteria, reducing prices or delaying payment. Having made a relationship-specific investment, the producer finds himself in a disadvantageous bargaining position vis-à-vis the buyer (Klein 1996). Anticipating this threat, producers will be reluctant to make asset-specific investments resulting in hold-ups, i.e. profitable investments are foregone as a result of coordination failure (Williamson 1984, Slangen et al. 2008).

In the pineapple sector, producers face multiple risks at different stages of the production and marketing process ranging from weather, yield and price risk to potential opportunistic behavior of buyers. In particular, pineapple cultivation requires considerable upfront investments into the establishment of the plot, which are estimated to figure around 9000 US\$ per hectare (CANAPEP 2011). The majority of farmers take out a loan to finance this initial investment, which leaves them at risk of credit default if their harvest is damaged or prices are low. Once the pineapple is ripe, farmers face multiple risks throughout the marketing process (see Figure 1). First of all, it is important for them to find a buyer at the time of harvest, because the quality of ready-to-ship pineapples quickly deteriorates in the field. That is, at that point, farmers do not have much flexibility to wait and search for a better market option. At the time of harvest, farmers perform a first grading in order to decide how much of their produce they deliver to the exporter and how much is sent to the processing industry. In the processing industry, quality requirements are substantially lower, and so are prices. Farmers therefore try to maximize the amount delivered to the exporter, while at the same time taking transportation costs into account. Exporters will reject any produce that does not fulfill their quality standards and send it back to farmers, who then usually deliver it to a processing firm. Farmers bear the full costs of transportation including the return of the rejected produce. They thus have an incentive to grade their produce as accurately as possible. In the packaging plant, exporters perform a second grading, where grades 5 to 7 are the preferred grades and grades 8 and higher command lower 
prices $^{2}$. Given that farmers do not assist in the process, the grading process often lacks transparency and is potentially subject to opportunistic behavior on the side of the buyer.

Based on our survey data collected from pineapple producers in Costa Rica, we estimated that overall in 2010 only $41 \%$ of the pineapples planted for the export market reached their destination, whereas $59 \%$ were lost or re-directed to the processing industry (which is associated with significantly lower prices). Figure 4.1 reports the percentages of pineapples at each stage that where subject to qualityrelated transaction risk. Finally, farmers face considerable price risk, which partly stems from seasonal variation and partly from variability in the grading process. During the production season 2010, grades 5 to 7 obtained an average price of 30 US-cents/kg, ranging between 18 and 35 US-cents/kg, whereas grades 8 and higher obtained a fixed price of 12 US-cents $/ \mathrm{kg}$.

Figure 4-1 Transaction risks faced by producers in the pineapple chain.

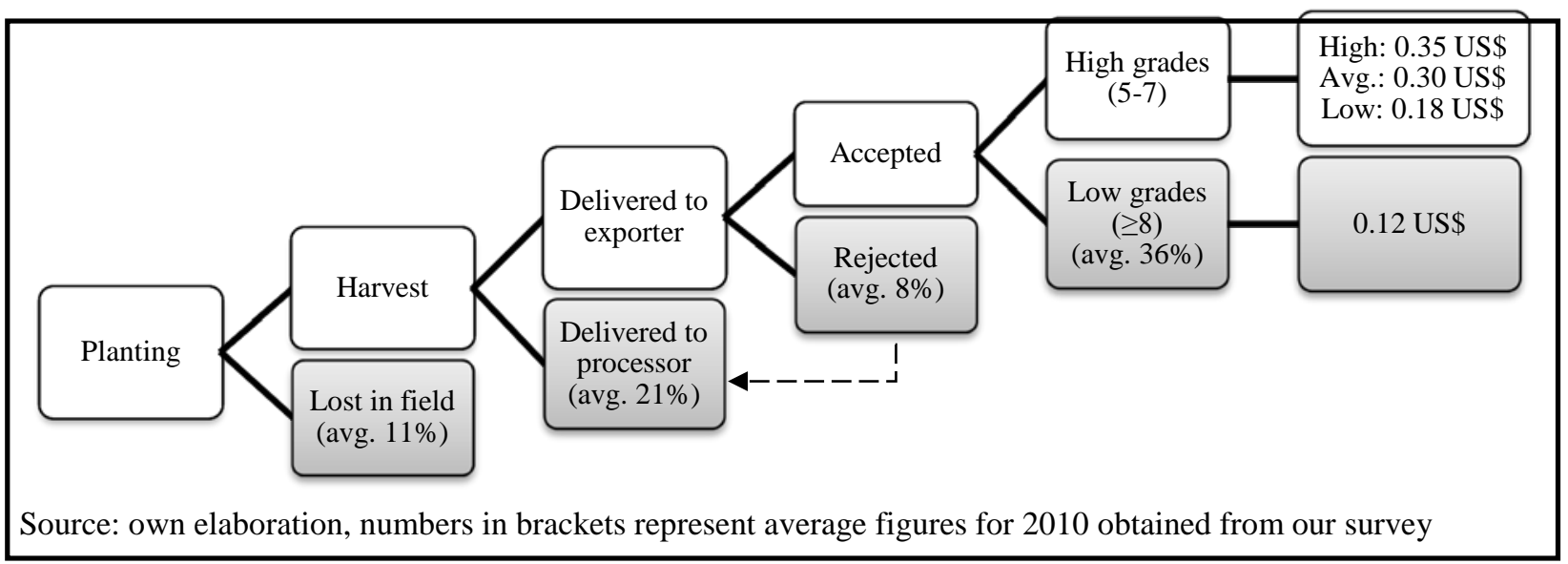

As outlined above, according to transaction costs theory producers will make more asset-specific investments, if they have a safeguard for their investment. That is, producers are more likely to invest into expanding their pineapple production area, if they have a safe and reliable market outlet. Similarly, farmers will also be more likely to invest into upgrading their production process and adopting food standards, if they have a market outlet they can rely on and where they may receive a price premium for certified produce. Contractual agreements between buyers and producers can represent such a safeguard, as long as they credibly reduce the risk that buyers behave opportunistically once producers have made an asset-specific investment and thus locked themselves into the market relationship.

\footnotetext{
${ }^{2}$ Grades 5 to 7 are the grades demanded in international markets. Grades 8 to 12 correspond to smaller pineapples that are mostly used for processing.
} 


\subsection{Empirical data and methods}

\subsubsection{Survey data}

Pineapple production in Costa Rica takes place along the Atlantic and Caribbean coasts and in the northern part of the country, the Huetar Norte region. While the coastal production areas are characterized by large-scale vertically integrated production units, the Huetar Norte region is structurally more diverse. In this area, production units of different sizes and different forms of vertical coordination co-exist. Overall, the Huetar Norte region accounts for $50 \%$ of the national pineapple production and for $98 \%$ of the small and medium-scale pineapple producers in the country (MAG 2007).

The analysis is based on original survey data that was collected in Pital and Guatuso, which are two main pineapple production areas in the Huetar Norte region in northern Costa Rica. The survey was implemented from November 2010 to January 2011. Prior to the household survey comprehensive information about pineapple farming was collected from CANAPEP, the national pineapple organization, as well as from local associations involved in the pineapple sector. Eventually, because no comprehensive and unbiased lists of pineapple farmers could be obtained, pineapple farmers were selected randomly through a random walk approach. For that purpose central locations were identified in the settlements and a direction was randomly determined. In that direction, households were chosen for interviews based on a certain interval, which was determined depending on the size of the settlement (in order to make sure to reach the outer boundaries of the settlement). Households qualified for the interview, if they could be considered small-scale producers of pineapple, i.e., with a pineapple area of less than 50 hectares $^{3}$. If a household was not eligible or available for the interview, it was replaced with the neighboring household until a suitable household was found. Density of pineapple growers is very high in the selected research areas, which are economically dominated by pineapple cultivation. Overall, our sample consists of 173 households, of which two households had to be excluded due to incomplete data. The interview was conducted face-to-face with an adult household member involved in pineapple production. We used a standardized questionnaire to collect data on pineapple production and marketing, standard adoption, as well as on socio-economic household variables.

\subsubsection{Methodology to analyze contract choice}

In a first step, we aim to identify the determinants of contract choice. Farmers can choose between three alternative marketing arrangements to sell their pineapple. Firstly, they can sell in the open spot

\footnotetext{
${ }^{3}$ In our definition of small-scale farmers we follow CANAPEP, which classifies farmers cultivating pineapple on less than 50 ha as small-scale. In our sample, farmers cultivate on the average 5.9 ha, including owned as well as rented land. While size varies from a quarter hectare to $45 \mathrm{ha}, 80 \%$ of the farmers in our sample grow pineapple on less than ten hectares.
} 
market, i.e., without any prior marketing agreement. Secondly, they can engage in an informal agreement with a buyer, which entails that at the time of planting, they verbally pre-determine the terms of exchange to be followed at the time of harvest. Thirdly, they can enter a formal agreement with a buyer, which implies the signing of a written and legally binding contract. The individual decision to choose a particular market arrangement is modeled in a random utility framework. For farmer $i$ with $J$ choices, the utility of choice $j$ can be expressed as

$U_{i j}=X_{i j} \beta+\varepsilon_{i j}$

The farmer will choose a particular market arrangement, when the utility of that arrangement is larger than the utilities associated with all other alternatives, i.e., $U_{i j}>U_{i k}$ for all $k \neq j$. The choice of farmer $i$ is indicated by a random variable $Y_{i}$. Furthermore, the disturbances are assumed to be i.i.d. and follow a Gumbel distribution giving rise to the multinomial logit model (Greene 2003). In our case, where farmers can choose between three market arrangements, we obtain the following specification:

$\operatorname{Prob}\left(Y_{i}=j \mid X_{i}\right)=\frac{e^{\beta_{j} X_{i}}}{1+\sum_{k=1}^{2} e^{\beta_{k} X_{i}}}$

In our model, utility depends on $X_{i}$, which includes individual-specific characteristics that vary across producers, but are constant across market arrangements. We include several variables related to human capital, specialization, social capital, and accessibility that are likely to influence the probability of a farmer to participate in a particular market arrangement. These variables affect both the ability and preferences of the farmers to engage in contract schemes as well as the interest of buyers to engage with that particular farmer (depending on the transaction costs associated with dealing with the farmer). In general, farmers with better access to resources (land, quantity and quality of human capital) are expected to have better chances to obtain a contractual agreement (Key and Runsten 1999, (Barrett et al., 2012)). Similarly, farmers with better access to information (education, experience, social networks, geographic proximity) are expected to be better informed about contract options and to have better access to potential buyers (Barrett et al., 2012; Reardon et al., 2009). Finally, transaction costs matter in the decision to engage in a contract. Market search and contract negotiation costs are to a large extent fixed costs, which makes contract farming more attractive to larger and more specialized farms (Barrett, 2008). Due to the same reason, these farms are also often preferred by buyers (Reardon et al., 2009) Key and Runsten 1999, Reardon et al. 2009). On the other hand, small-scale farmer usually have less outside options, which can make a given contract offer relatively more attractive to them (Key and Runsten 1999). 


\subsubsection{Methodology to analyze standard adoption}

In a second step, we are interested to explore in how far the choice of a certain market arrangement speeds up or slows down the upgrading process. The underlying hypothesis is that vertical coordination provides a safeguard to farmers and therefore induces farm-level investments. We use a duration model to estimate the effects of participation in formal and informal contracts on the time it takes the farmers to adopt a standard. Duration models estimate the probability that a farmer switches from non-adoption to adoption, given that the farmer has not yet adopted the standard. This probability is reflected by the hazard function, which resembles the continuous time version of a sequence of conditional probabilities (Burton et al., 2003). The proportional hazard model is specified as

$\lambda(t ; Z(t))=e^{Z(t) \beta} \lambda_{0}(t)$

where $t$ is the time period and $\beta$ is a vector of parameters to be estimated. The individual hazard rate is a function of the baseline hazard $\lambda_{0}(t)$ and a vector of variables $Z(t)$ that shift the hazard multiplicatively. The baseline hazard can be described by different distributional forms, which vary with respect to the assumed course of adoption (Wooldridge 2002). If $T$ has a Weibull distribution, the hazard function is

$\lambda_{0}(t) \equiv \alpha t^{\alpha-1}$

In this specification, if $\alpha>1$ the hazard rate is monotonically increasing, i.e., it exhibits positive duration dependence implying that the probability of adoption increases the longer the farmer is in the sector. On the other hand, if $\alpha<1$ the hazard rate is monotonically decreasing (Wooldridge 2002).

In our analysis we include all 171 households of which 86 adopted a standard over the observed time period. The remaining 85 households are non-adopters and are treated in the analysis as right-censored observations, i.e., they might adopt the standard at a later point in time. The analyzed adoption spell starts at $\mathrm{t}=2002$ or later for those individuals who entered the pineapple sector after 2002. The vector $Z(t)$ includes both time-variant and time-invariant covariates. Most importantly, we include two dummy variables on the type of market agreement (one for participation in verbal and one for participation in formal contracts) that vary over the observed time spell. Additionally, we include time-variant information on membership in pineapple producer groups. Time-invariant variables include information on human capital, specialization, social capital and accessibility ${ }^{4}$. In general, we expect the variables assumed to influence contract choice also to play a role in standard adoption. Standard adoption is also associated with substantial fixed costs related to initial investments and

\footnotetext{
${ }^{4}$ We do not include variables related to the experience in the sector because the length a farmer has been in the sector and its effect on the probability to adopt is implicitly included in the baseline hazard.
} 
transaction costs (Kersting and Wollni 2012). Farmers with more human capital, stronger specialization, more social capital and better accessibility are therefore hypothesized to be more likely to adopt a standard (Asfaw et al., 2010; Kersting and Wollni, 2012; Reardon et al., 2009).

\subsubsection{Methodology to analyze the impacts of contract choice}

Finally, we are interested in estimating unbiased treatment effects of participation in two treatments participation in formal and informal contract schemes - on various outcome variables. Given that we cannot observe the same contract farmers without contractual arrangements, we need to construct a valid counterfactual in order to derive the average treatment effect on the treated (ATT). This is achieved by matching treatment households on observable characteristics with households from the control group (i.e., farmers without contractual arrangement). In our case, we have two mutually exclusive treatments, defined as $C_{i}=1$ if farmers have a verbal agreement and $C_{i}=2$ if farmers have a formal contract, and a control group of farmers without marketing agreement $\left(C_{i}=0\right)$. While most of the literature deals with estimating the ATT for a single treatment, the methodology can be extended to the case of multiple treatments (see e.g. (Chiputwa et al., 2015), (Lechner, 2002), Maertens and Swinnen 2009). Given that there is a large number of potentially relevant covariates, matching directly on the covariates is not practical. Alternatively, a one-dimensional indicator, the propensity score, is constructed reflecting the conditional probability of being in the treatment group (Rosenbaum and Rubin 1983). Based on the propensity score the ATT can then be estimated as follows (Becker and Ichino 2002):

$$
\begin{aligned}
& \tau_{v}=E\left\{E\left[Y_{1 i} \mid C_{i}=1, p\left(X_{i}\right)\right]-E\left[Y_{0 i} \mid C_{i}=0, p\left(X_{i}\right)\right] \mid C_{i}=1\right\} \\
& \tau_{f}=E\left\{E\left[Y_{2 i} \mid C_{i}=2, p\left(X_{i}\right)\right]-E\left[Y_{0 i} \mid C_{i}=0, p\left(X_{i}\right)\right] \mid C_{i}=2\right\}
\end{aligned}
$$

where $Y_{1 i}, Y_{2 i}$ and $Y_{0 i}$ are vectors of outcome variables with and without treatment, respectively, and $X_{i}$ is a vector of covariates used to obtain the propensity score. We use the multinomial logit model specified above to estimate the propensity score. With this specification, we achieve balancing for all of the included covariates. We use nearest neighbor matching to identify suitable comparison households for the treatment group. Based on this algorithm, each treatment household is matched with the three nearest neighbors in terms of propensity score distances (with replacement) (Caliendo and Kopeinig, 2008). Moreover, only households in the common support region are included in the calculation of the ATT (see Tables A1 and A2 in the appendix). Common support is satisfied when the propensity score of the treated units is no higher than the maximum or lower than the minimum score of the control units (Becker and Ichino 2002). 
Propensity score matching is based on the conditional independence assumption (CIA) which sustains that - conditional on observed factors - treatment assignment is independent of subsequent outcomes (Lechner, 2002). If there are unobserved factors that affect treatment assignment and the outcome variable simultaneously, such hidden bias may adversely affect the robustness of the matching estimators (Becker and Caliendo, 2007). It is therefore useful to determine how sensitive the estimates are to unobserved factors influencing the selection process. This can be done by calculating Rosenbaum bounds as proposed by Becker and Caliendo (2007) and (DiPrete and Gangl, 2004). The procedure takes the difference in the response variable between treatment and control cases and calculates Wilcoxon signed-ranks tests that give upper and lower bound estimates of significance levels at given levels of hidden bias (Becker and Caliendo 2007).

We consider several outcome variables to represent different dimensions of the marketing relationship. First of all, we look at net pineapple revenue both in total and per hectare terms. We expect that farmers in contractual relationships make more informed investment decisions resulting in higher monetary benefits derived from pineapple cultivation (Bellemare 2012, Michelson et al. 2012). Furthermore, we consider several variables related to transaction risks including rejection rate, quality, price and terms of payment. Given the coordination function of contractual agreements, we expect contract participation to have a positive impact on the terms of the exchange. On the other hand, high levels of product rejections have been reported to be a common problem in formal contract schemes in developing countries (Barrett et al. 2012). Finally, we compare relational capital across the different marketing arrangements including trust and loyalty. Such informal institutions can provide important enforcement mechanisms that facilitate market exchange, especially in environments characterized by weak formal institutions (e.g. Poulton et al. 2010). Previous research has concluded that trust is generated through exchange performed under good institutions (Fischer 2008, Berggren and Jordahl 2006). On the contrary, we expect that if farmers are exposed to extensive transaction risks over prolonged time periods, their levels of trust and loyalty towards the downstream actors of the value chain are negatively affected.

\subsection{Contract choice}

\subsection{Characteristics of marketing arrangements}

With respect to the contractual arrangements, we find that $32 \%$ of the farmers in our sample have a verbal agreement and $42 \%$ have a written agreement with their buyer. The remaining $26 \%$ of the farmers have no agreement prior to selling their fruit. In general, input provision is not very common in the Costa Rican pineapple sector. Table 1 shows that through only 3.6\% of the verbal agreements and $1.4 \%$ of the written agreements, farmers received inputs from their buyer. Overall, input markets function well in the research area, so that access to inputs does not represent a major constraint to pineapple producers. In contrast, the extent of credit and extension provision varies significantly 
between the different marketing arrangements. In the case of written agreements, $55 \%$ of farmers received credit and 90\% received extension from their buyers. Credit and extension provision is substantially lower in the context of verbal agreements, but still significantly more common than in open spot market transactions. Furthermore, the majority of verbal and written agreements contain some specification of the volumes to be delivered, while the price is fixed very rarely in either type of agreement. In open spot market transactions, by definition no agreements between producer and exporter are made. However, Table 4.1 shows that in 33\% of the spot market transactions producer and buyer agree on a volume just before the produce is physically delivered to the processor's plant. Given that farmers have to bear the cost of transportation of the fruit to the firm, such consultation can help to reduce their marketing risk to some extent.

Table 4-1 Description of market arrangements in the pineapple sector.

\begin{tabular}{lcrrrrrr} 
& \multicolumn{2}{c}{ No agreement } & \multicolumn{2}{c}{ Verbal agreement } & \multicolumn{2}{c}{ Signed contract } \\
& \multicolumn{2}{c}{ Ne45 } & \multicolumn{2}{c}{ N=55 } & \multicolumn{2}{c}{ N=71 } \\
& Mean & Std. dev. & Mean & Std. dev. & Mean & Std. dev. \\
\hline Buyer provides inputs & 0.000 & 0.000 & 0.036 & 0.189 & 0.014 & 0.119 & \\
Buyer provides credit & 0.067 & 0.252 & 0.218 & 0.417 & 0.549 & 0.501 & $* * * a, c$ \\
Buyer provides extension & 0.067 & 0.252 & 0.491 & 0.505 & 0.901 & $0.300 * * * a, b, c$ \\
Agreed on volume & 0.333 & 0.477 & 0.873 & 0.336 & 0.958 & $0.203 * * * a, b$ \\
Agreed on price & 0.000 & 0.000 & 0.109 & 0.315 & 0.113 & $0.318 * a$ & $*$ \\
\hline
\end{tabular}

$* * *$ [*] significant at $1 \%[10 \%]$ probability of error; $\mathrm{a}=$ significant difference between signed contract and no agreement; $b=$ significant difference between verbal agreement and no agreement; $c=$ significant difference between signed contract and verbal agreement.

\subsubsection{Determinants of contract choice}

Results of the multinomial logit model on contract choice are presented in Table 4.2. The first column provides results on the determinants of choosing a verbal agreement as opposed to no prior agreement. We find that younger farmers and those with better access to labor and land resources, i.e. having more male family members and larger pineapple areas, are more likely to choose a verbal agreement instead of selling in the spot market. Furthermore, membership in a pineapple producer organization is positively associated with engaging in verbal agreements.

Next, we report results from the second column in Table 2, which refers to the choice of formal agreements as opposed to no prior agreement. We find that farmers involved in formal contract schemes tend to be more educated and more specialized, i.e. they have less nonfarm activities and larger pineapple areas. The lack of nonfarm activities may also reflect a larger need for access to credit, which is often obtained through formal contractual arrangements (see Table 1). Furthermore, membership in farmer groups and in social organizations increases the likelihood of a farmer to engage in formal contracts, pointing to the importance of social networks to gain access to formal contract schemes. In line with this, if the farmer has known the buyer for a longer time, they are more likely to engage in a formal contractual relationship. On the other hand, holding all else constant, 
farmers with more experience in the pineapple sector are less likely to engage in a formal contractual relationship. This may be due to the fact that farmers with less experience need more technical assistance, which is often provided by buyers through formal contract schemes. Inclusion of a squared term shows that this relationship is non-linear, pointing to a u-shaped relationship between experience in the pineapple sector and the likelihood to participate in a formal contract.

Comparing farmers engaged in formal contracts with those engaged in verbal agreements, we find that farmers in formal contracts are significantly more educated, but less experienced in the pineapple sector. This again indicates that farmers with long-term experience in the sector are less dependent on the support offered by formal contract schemes. On the other hand, all other factors held constant, the longer the farmer has know the buyer, the more likely they are to engage in a formal contract. Finally, membership in producer organizations and in social groups both increase the farmers' likelihood to engage in a formal contract as compared to a verbal contract.

Table 4-2 Results of multinomial logit model on contract choice.

\begin{tabular}{|c|c|c|c|c|c|c|c|c|c|}
\hline & \multicolumn{2}{|c|}{$\begin{array}{l}\text { Verbal versus } \\
\text { none }\end{array}$} & \multirow[b]{2}{*}{$\operatorname{sig}$} & \multicolumn{2}{|c|}{$\begin{array}{c}\text { Formal versus } \\
\text { none }\end{array}$} & \multirow[b]{2}{*}{ sig } & \multicolumn{2}{|c|}{$\begin{array}{c}\text { Formal versus } \\
\text { verbal }\end{array}$} & \multirow[b]{2}{*}{ sig } \\
\hline & RRR & std err & & RRR & std err & & RRR & std err & \\
\hline Secondary school & 0.439 & 0.345 & & 3.296 & 2.282 & $*$ & 7.498 & 5.472 & $* * *$ \\
\hline Age & 0.940 & 0.020 & $* * *$ & 0.964 & 0.022 & & 1.025 & 0.022 & \\
\hline Number of female adults & 1.337 & 0.518 & & 1.716 & 0.728 & & 1.283 & 0.467 & \\
\hline Number of male adults & 1.763 & 0.531 & $*$ & 1.132 & 0.353 & & 0.642 & 0.175 & \\
\hline Land size (lagged) & 1.064 & 0.037 & $*$ & 1.072 & 0.037 & $* *$ & 1.008 & 0.011 & \\
\hline Farm is main business & 2.676 & 1.999 & & 3.506 & 2.779 & & 1.310 & 0.998 & \\
\hline Nonfarm activities & 0.737 & 0.373 & & 0.365 & 0.207 & $*$ & 0.495 & 0.246 & \\
\hline $\begin{array}{l}\text { Member in pineapple group } \\
\text { (lagged) }\end{array}$ & 4.365 & 3.811 & $*$ & 14.570 & 12.320 & $* * *$ & 3.338 & 1.694 & $* *$ \\
\hline Member in social group & 0.294 & 0.360 & & 3.739 & 2.955 & $*$ & 12.701 & 15.477 & $* *$ \\
\hline Distance to road & 1.013 & 0.044 & & 0.985 & 0.052 & & 0.973 & 0.040 & \\
\hline Known buyer (in years) & 1.012 & 0.009 & & 1.038 & 0.011 & $* * *$ & 1.025 & 0.009 & $* * *$ \\
\hline Experience & 1.012 & 0.095 & & 0.746 & 0.076 & $* * *$ & 0.737 & 0.069 & $* * *$ \\
\hline Experience squared & 1.000 & 0.003 & & 1.007 & 0.003 & $* *$ & 1.007 & 0.003 & $* * *$ \\
\hline
\end{tabular}

\subsection{Vertical coordination and upgrading}

\subsubsection{Investments into pineapple cultivation}

As described before, farmers who have a contractual agreement with a buyer dispose of a safeguard and are therefore expected to invest more extensively in upgrading their pineapple production processes. Figure 4.2 depicts the expansion of land devoted to pineapple cultivation by farmers engaged in the three different types of market arrangements. The black bar indicates the average size 
of pineapple area owned by farmers when they entered the sector. According to one-way analysis-ofvariance and Bonferroni multiple comparison tests, the average size does not differ significantly between the three groups. Subsequently, however, farmers with verbal and formal agreements substantially expanded their pineapple area as compared to farmers who exchange their pineapples through open market transactions. As indicated by the grey and white bars, this applies to both the owned pineapple area as well as the total pineapple area including both rented and own land. According to the graphical depiction, farmers with formal contracts expanded their pineapple area more so than farmers with verbal contracts, however, the differences between these two groups are not statistically significant.

Figure 4-2 Average pineapple area by type of market arrangement

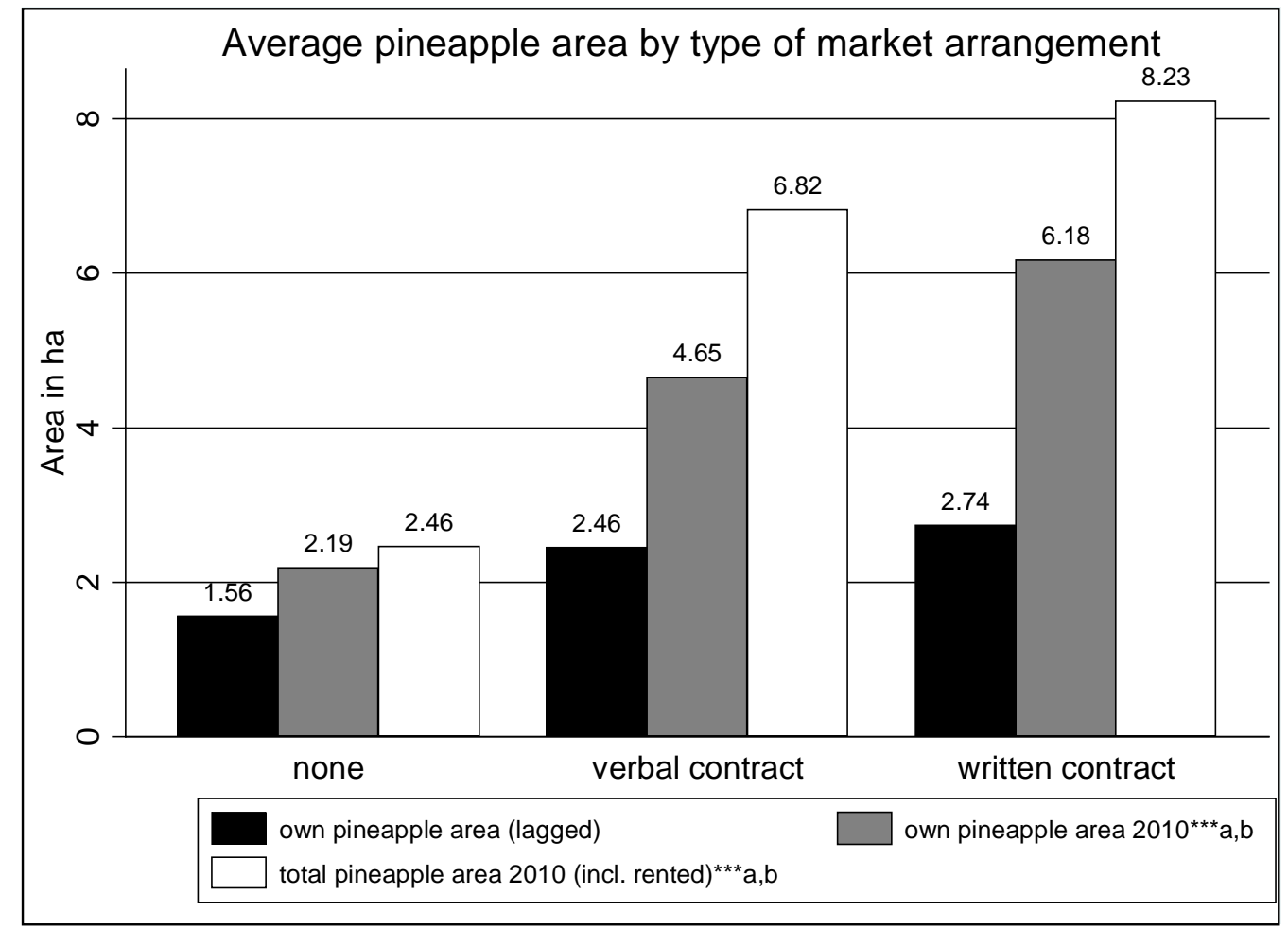

*** significant at $1 \%$ probability of error; a=significant difference between signed contract and no agreement; $\mathrm{b}=$ significant difference between verbal agreement and no agreement.

Besides the expansion of land under pineapple cultivation, implementation of food safety and sustainability standards represents a substantial asset-specific investment. Standard adoption is associated with considerable up-front investments that only pay off for the farmer, if better market opportunities can be realized as a result. Presumably, farmers who have a contractual relationship with their buyer can be more secure about their future market outlet, and will therefore be more likely to invest in standard implementation. Table 4.3 shows the relationship between vertical coordination and standard adoption. 
Figure 4-3Vertical coordination and standard adoption.

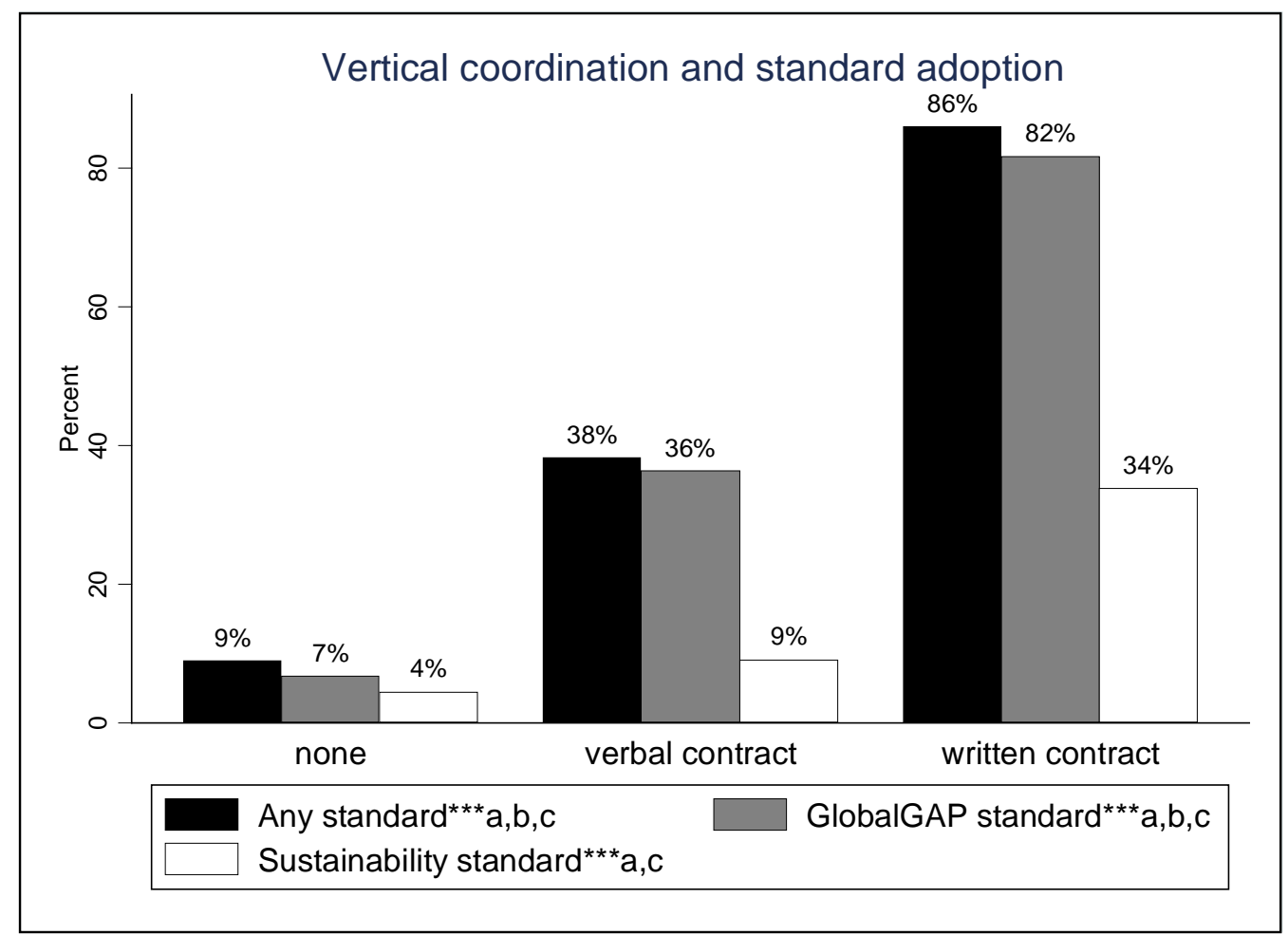

Sustainability standard refers to Rainforest Alliance and/or Organic standard; *** significant at $1 \%$ probability of error; a=significant difference between signed contract and no agreement; $b=$ significant difference between verbal agreement and no agreement; c=significant difference between signed contract and verbal agreement.

Among farmers engaged in a formal contractual arrangement standard adoption is very common: 82\% have implemented GlobalGAP and 34\% are certified with a sustainability standard. In contrast, only $38 \%$ of farmers holding a verbal agreement and $9 \%$ of farmers holding no agreement have adopted a standard to upgrade their production process.

\subsubsection{Dynamics of standard adoption}

Table 4.3 reports coefficient estimates and hazard ratios of the duration analysis. As outlined above, we use the Weibull distributional form to model the baseline hazard, where the shape of the hazard function is estimated with $\alpha$. In our model, $\alpha$ is significantly larger than one indicating that the hazard rate is monotonically increasing. Given that the choice of the functional form is an empirical matter, we tested different distributional forms for the hazard function and chose the Weibull distribution based on the Akaike information criterion (Cleves et al. 2008). Our results are, however, consistent across different specifications.

The coefficients are interpreted as effects on the hazard rate of adoption. A positive coefficient has a positive impact on the hazard rate, that is, it speeds up the adoption process and vice versa. Table 4.3 also shows hazard ratios calculated from the coefficients. A ratio bigger/smaller than one speeds up/slows down the adoption process; subtracting one from the hazard ratio results in the marginal effect of the variable on the hazard rate of adoption. The estimates show that participation in both 
formal and informal contracts has a significant and positive effect, thus reducing the time spell to standard adoption. A verbal contract increases the hazard rate of adoption by $266 \%$ and a formal contract by $572 \%$. These results confirm that contract schemes can act as an important catalyst for farm-level upgrading.

Furthermore, we find that organized and more socially connected farmers adopt earlier. Membership in a pineapple producer organization increases the hazard rate of standard adoption by $139 \%$ and membership in a social group by $151 \%$. In addition, we find that farm size speeds up the adoption process. This indicates that as expected there are scale economies associated with standard adoption; however, the marginal effect of each additional hectare of land is very small. Finally, remoteness slows down the adoption process. For each additional kilometer that farmers are located away from the road the hazard rate of adoption decreases by $4 \%$.

Table 4-3 Results of the duration analysis.

\begin{tabular}{|c|c|c|c|c|c|}
\hline & Coefficient & Robust Std. Err. & Hazard Ratio & Robust Std. Err. & \\
\hline Signed contract (time variant) & 1.905 & 0.315 & 6.720 & 2.118 & **** \\
\hline Verbal agreement (time variant) & 1.296 & 0.305 & 3.655 & 1.113 & $* * *$ \\
\hline Secondary school & 0.098 & 0.291 & 1.103 & 0.320 & \\
\hline Age & 0.008 & 0.009 & 1.008 & 0.009 & \\
\hline Number of female adults & -0.140 & 0.187 & 0.869 & 0.163 & \\
\hline Number of male adults & -0.002 & 0.116 & 0.998 & 0.116 & \\
\hline Land size (lagged) & 0.006 & 0.002 & 1.006 & 0.002 & $* * *$ \\
\hline Farm is main business & 0.524 & 0.343 & 1.689 & 0.578 & \\
\hline Nonfarm activities & 0.153 & 0.254 & 1.166 & 0.296 & \\
\hline $\begin{array}{l}\text { Member in pineapple group (time } \\
\text { variant) }\end{array}$ & 0.871 & 0.274 & 2.389 & 0.655 & $* * *$ \\
\hline Member in social group & 0.919 & 0.426 & 2.508 & 1.067 & ** \\
\hline Distance to road & -0.038 & 0.020 & 0.963 & 0.019 & $*$ \\
\hline Known buyer (in years) & -0.002 & 0.004 & 0.998 & 0.004 & \\
\hline Constant & -4.695 & 0.681 & & & $* * *$ \\
\hline$/ \mathrm{ln} \_\mathrm{p}$ & 0.233 & 0.078 & & & $* * *$ \\
\hline $\mathrm{P}$ & 1.262 & 0.098 & & & \\
\hline $1 / \mathrm{p}$ & 0.792 & 0.062 & & & \\
\hline \multicolumn{6}{|l|}{ AIC $=317,8$} \\
\hline \multicolumn{6}{|l|}{ Log pseudolikelihood $=-143.918$} \\
\hline \multicolumn{6}{|l|}{ Wald $\operatorname{chi}^{2}(13)=171.20^{* * *}$} \\
\hline \multicolumn{6}{|l|}{ No. of obs. $/$ Time at risk $=924$} \\
\hline \multicolumn{6}{|l|}{ No. of subjects $=171$} \\
\hline No. of failures $=94$ & & & & & \\
\hline
\end{tabular}

Figure4. 4 presents a graphical illustration of the survival probabilities by market arrangement. For each time interval, the survival probability is calculated as the number of non-adopters (i.e., the number of farmers at start minus the number of adopters) divided by the number of farmers at start. To obtain the cumulative probability of survival until any particular time we multiply all the probabilities of survival of the preceding time intervals. For example, the probability of a farmer not adopting a 
standard after two years equals the probability of non-adoption in the first year multiplied by the probability of non-adoption in the second year given that the farmer did not adopt during the first year. From the graph we can see that after nine years farmers who sell in the open spot market have a much higher cumulative survival probability, i.e., a much higher probability to remain without standard, compared to farmers with formal and verbal agreements.

Figure 4-4 Kaplan-Meier survival estimates by type of agreement.

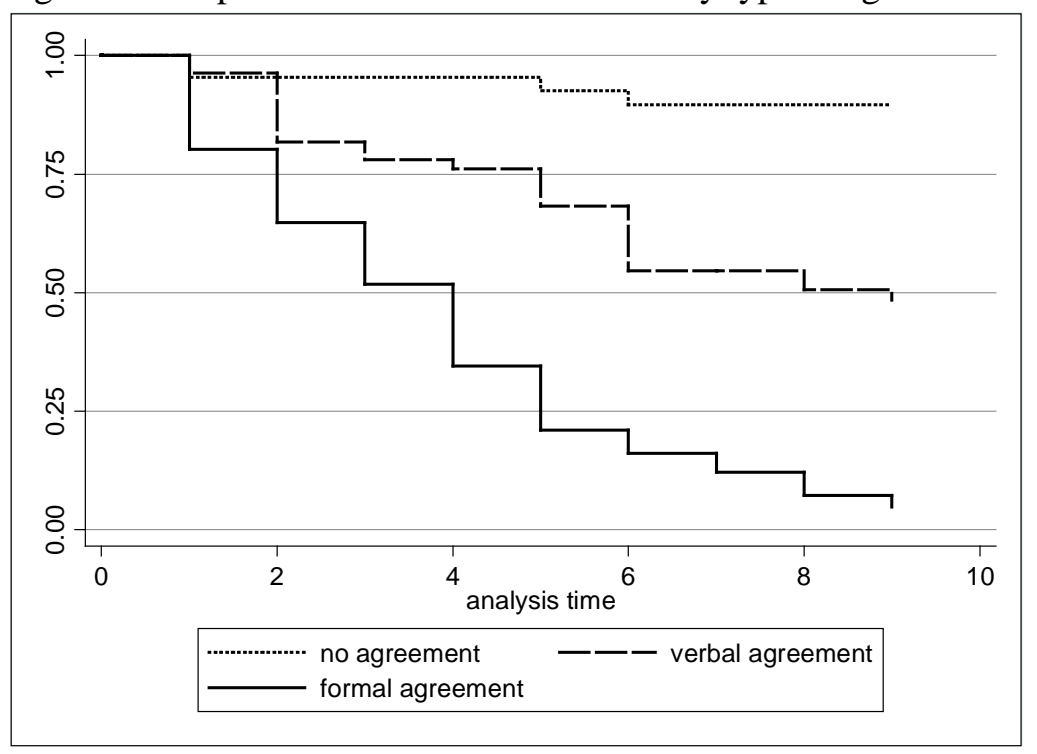

\subsection{Sustainability of marketing relationships}

While formal and informal contracts facilitate upgrading and standard adoption, eventually it is of interest not only whether these investments take place, but also in how far they result in higher net revenues and better market access for farmers. We therefore use propensity score matching to compare various outcome measures across producers engaged in different forms of vertical coordination. Table 4.4 gives an overview of the outcome measures and reports the mean values and standard deviations of unmatched cases by market arrangement. We consider three different categories of outcome measures: overall net revenues derived from pineapple cultivation, transaction risks, and relational capital that describe different dimensions of the quality of the marketing relationship from the perspective of producers. Figures A3.1 and A3.2 in the Appendix 3 show the propensity score distributions for the three possible comparisons as well as the regions of common support. 
Table 4-4Description of outcome variables (unmatched cases).

\begin{tabular}{|c|c|c|c|c|c|c|c|}
\hline & $\begin{array}{r}\text { Signed } \\
\text { contract } \\
\text { Mean } \\
\mathrm{N}=71\end{array}$ & Std.dev & $\begin{array}{c}\text { Verbal } \\
\text { agreement } \\
\text { Mean } \\
N=55\end{array}$ & Std.dev & $\begin{array}{c}\text { No } \\
\text { agreement } \\
\text { Mean } \\
\mathrm{N}=45\end{array}$ & Std.dev & \\
\hline \multicolumn{8}{|l|}{ Net revenues } \\
\hline $\begin{array}{l}\text { Net revenue from } \\
\text { pineapple }\end{array}$ & 18124.10 & 24219.93 & 17913.45 & 20919.24 & 6979.08 & 11806.11 & $* * * a, b$ \\
\hline Net revenue per ha & 2417.01 & 3668.57 & 3245.88 & 5951.04 & 4744.76 & 9406.94 & \\
\hline \multicolumn{8}{|l|}{ Transaction risks } \\
\hline Pineapple rejections (\%) & 0.112 & 0.217 & 0.066 & 0.081 & 0.045 & 0.060 & $* * a$ \\
\hline Informed about reason & 0.535 & 0.502 & 0.709 & 0.458 & 0.400 & 0.495 & $* * * b$ \\
\hline $\begin{array}{l}\text { Percentage graded as high } \\
\text { quality (grade } 5-7 \text { ) }\end{array}$ & 0.659 & 0.163 & 0.642 & 0.137 & 0.601 & 0.107 & $* a$ \\
\hline $\begin{array}{l}\text { Average price received for } \\
\text { high-quality fruit (in US\$) }\end{array}$ & 0.301 & 0.040 & 0.298 & 0.026 & 0.310 & 0.075 & \\
\hline $\begin{array}{l}\text { Days to payment } \\
\text { according to agreement }\end{array}$ & 25.535 & 7.454 & 17.945 & 6.267 & 15.756 & 13.837 & $* * * a, \mathrm{c}$ \\
\hline Days to payment in reality & 48.930 & 40.197 & 30.400 & 36.705 & 26.156 & 32.269 & $* * * a, c$ \\
\hline \multicolumn{8}{|l|}{ Relational capital } \\
\hline Trust & -0.167 & 1.010 & 0.290 & 0.905 & -0.094 & 0.956 & $* * \mathrm{c}$ \\
\hline Loyalty & 0.150 & 0.856 & 0.053 & 1.197 & -0.314 & 0.816 & \\
\hline
\end{tabular}

$* * *(* *)[*]$ significant at $1 \%(5 \%)[10 \%]$ probability of error; a=significant difference between signed contract and no agreement; $b=$ significant difference between verbal agreement and no agreement; $c=$ significant difference between signed contract and verbal agreement.

\subsubsection{Impacts on pineapple revenues}

Table 4.5 presents unbiased average treatment effects for farmers with formal and informal marketing agreements. The first and second rows of Table 4.5 compare farmers with informal contracts and farmers with formal contracts to farmers selling their produce without any prior marketing agreement, respectively. The last row compares farmers with formal contracts to those with informal agreements. The results show that compared to farmers selling in the spot market, farmers with both formal and informal contracts obtain significantly higher annual net revenues from pineapple cultivation. Producers with formal contracts gain on average 11096 US\$ more than producers without prior agreement, whereas a verbal agreement increases net revenue by 11092 US\$. However, net revenues per hectare are not significantly different between farmers with and without contracts, indicating that the positive income effects are mainly due to larger areas cultivated by contract farmers. Comparing total and per hectare net revenue between formal and informal contract schemes, we do not find a significant difference. 
Table 4-5 Impact on outcome variables (matched cases).

\begin{tabular}{|c|c|c|c|c|c|c|c|c|c|}
\hline & \multicolumn{3}{|c|}{ Verbal vs. none } & \multicolumn{3}{|c|}{ Signed vs. none } & \multicolumn{3}{|c|}{ Signed vs. verbal } \\
\hline & ATT & & $\Gamma$ & ATT & & $\Gamma$ & ATT & & $\Gamma$ \\
\hline \multicolumn{10}{|l|}{ Net revenues } \\
\hline Net revenue from pineapple & 11092 & $* * *$ & 2.4 & 11096 & $* * *$ & 1.5 & -7980 & & \\
\hline Net revenue per ha & -543 & & & -927.2 & & & -3382 & & \\
\hline \multicolumn{10}{|l|}{ Transaction risks } \\
\hline Pineapple rejections (\%) & 0.025 & & & 0.084 & $* *$ & 1.5 & 0.041 & & \\
\hline $\begin{array}{l}\text { Informed about reason } \\
\text { Percentage graded as high quality (grade }\end{array}$ & 0.231 & & & -0.098 & & & -0.141 & & \\
\hline $5-7)$ & 0.047 & & & 0.087 & $* *$ & 1.9 & 0.033 & & \\
\hline $\begin{array}{l}\text { Average price received for high-quality } \\
\text { fruit (in US\$) }\end{array}$ & -0.034 & $*$ & 3 & 0.004 & & & -0.001 & & \\
\hline Days to payment according to agreement & -0.442 & & & 5.852 & $*$ & 3.5 & 4.391 & $* *$ & 2.4 \\
\hline Days to payment in reality & -19.865 & & & 21.9 & $* *$ & 1.8 & 15.266 & & \\
\hline \multicolumn{10}{|l|}{ Relational capital } \\
\hline Trust & 0.685 & $* *$ & 2.1 & -0.057 & & & -0.38 & & \\
\hline Loyalty & 0.753 & $* * *$ & 1.7 & 0.493 & $*$ & 5 & 0.128 & & \\
\hline Matched cases (common support) & $52 / 45$ & & & $61 / 45$ & & & $64 / 55$ & & \\
\hline
\end{tabular}

Source: own elaboration; ${ }^{* * *}(* *)[*]$ significant at $1 \%(5 \%)[10 \%]$ probability of error.

\subsubsection{Impacts on transaction risks}

As described before, producers in the pineapple sector face multiple risks along the different marketing stages. We expect contractual relationships between buyers and producers to improve coordination and thereby reduce uncertainties in the supply chain. This should be reflected in lower rejection rates, higher quality grades, and better prices for farmers participating in contract schemes. Table 4.5 compares transaction risks across different market arrangements. While one would expect that closer vertical coordination leads to more efficient transmission of relevant information regarding product requirements along the value chain and thereby reduce rejection rates, we find that rejection rates are higher in formal contract schemes compared to spot market transactions. Results also indicate that information flows do not necessarily work better in market transactions with closer vertical coordination. In fact we find no significant difference regarding the availability of information about product rejections between the different coordination mechanisms. A potential explanation for higher rejection rates in formal contract schemes is that buyers use quality-related arguments for rejections as an excuse to avoid their purchase obligations during times of limited demand in international markets (empirical evidence supporting this claim is provided in Suzuki et al. 2011). This would also explain limited information flows about the reasons underlying product rejections. 
This is also supported by the finding that, despite higher rejection rates, overall, farmers with formal contracts achieve high quality grades (grades 5 to 7) for a larger percentage of their pineapples. As shown before, farmers often can access extension and credit through the contracts, which we find reflected in higher quality output. Beyond this positive effect on product quality, other tangible benefits of formal contracts seem to be limited. With respect to the price obtained for high quality pineapples, we do not find a significant effect for farmers with formal agreements compared to farmers with verbal or no agreements. In addition, farmers with a formal contract face significantly longer payment periods and on top of that suffer from significantly longer payment delays. Altogether, the results indicate that major risks such as high rejection rates and long payment delays are not resolved, but rather aggravated in formal contract schemes. Between informal agreements and the spot market differences in transaction risks are less pronounced. The only significant difference concerns average prices obtained for high-quality pineapple, which is significantly lower with informal agreements (significant at 10\% level). While this may be unlike expected, it may be due to some form of risk sharing between buyer and seller in informal market arrangements that we cannot capture in our cross-sectional data.

\subsubsection{Implications for relational capital}

The sustainability of the supply chain relationship is not only reflected in tangible benefits, but also depends on the relational capital build between producer and buyer. Two important aspects of relational capital include a trustful relationship and loyalty, which are important for the relationship to persist in the long-term. During the interviews, farmers were asked to rate different statements regarding trust and loyalty with their main buyer on a five-point Likert scale. Based on these statements two constructs were identified using principal component analysis. A description of these two constructs is provided in Table 4.6. The derived constructs have a mean value of zero and a standard deviation of one. Accordingly, higher values of the construct indicate higher levels of trust and loyalty.

Table 4-6 Description of constructs.

\begin{tabular}{|c|c|c|c|}
\hline Construct & $\begin{array}{l}\text { Cronbach's } \\
\text { Alpha }\end{array}$ & Item & Load \\
\hline \multirow[t]{4}{*}{ Trust } & 0.856 & $\begin{array}{l}\text { I think that my buyer has been trustful during the time I } \\
\text { have dealt with him }\end{array}$ & 0.833 \\
\hline & & $\begin{array}{l}\text { I will not say negative comments about my buyer to my } \\
\text { friends and family }\end{array}$ & 0.818 \\
\hline & & $\begin{array}{l}\text { I would recommend my buyer to my friends and family } \\
\text { who grow pineapple }\end{array}$ & 0.811 \\
\hline & & $\begin{array}{l}\text { In general, I think that my buyer has been honest with } \\
\text { me }\end{array}$ & 0.737 \\
\hline
\end{tabular}




\begin{tabular}{|c|c|c|c|}
\hline \multirow[t]{3}{*}{ Loyalty } & 0.606 & $\begin{array}{l}\text { If my buyer would lower the price he pays for the } \\
\text { product, I would still work with him }\end{array}$ & 0.763 \\
\hline & & $\begin{array}{l}\text { I would not switch to another buyer even if he offers me } \\
\text { a better price for my product }\end{array}$ & 0.743 \\
\hline & & $\begin{array}{l}\text { As long as I live here and harvest pineapple, I do not feel } \\
\text { the need to look for another buyer }\end{array}$ & 0.663 \\
\hline
\end{tabular}

Source: own elaboration

The comparison of relational capital across different market arrangements is presented in Table 4.5. Results show that relational capital figures most strongly in verbal agreements. Producers' trust in and loyalty to their buyers is significantly higher in verbal market arrangements compared to spot market transactions. This confirms the importance of informal enforcement mechanisms, such as trust and reciprocity, for market exchange based on informal agreements. In formal contracts, farmers display lower levels of trust, which are comparable to the level of trust in open spot market transactions. Several farmers indicated that this is due to the long payment delays and high rejection rates that they have experienced in the past. On the other hand, loyalty within formal relationships is significantly higher than in open spot market transactions, mostly due to the legally binding character of the written agreement preventing farmers from switching buyers in the short run. In contrast, in the open spot market farmers normally choose the buyer offering the best prices at the time of harvest.

\subsubsection{Sensitivity analysis}

As a robustness check we estimate Rosenbaum bounds $(\Gamma)$ for all significant ATTs in Table 4.5. The Rosenbaum bound measures how large the difference in unobserved factors influencing treatment assignment would have to be, in order to turn the estimated ATT insignificant. A low level of $\Gamma$ does not necessarily mean that unobserved heterogeneity exists and that there is no treatment effect; $\Gamma$ merely pictures the worst-case scenario, at which the confidence interval for the ATT would include zero (Becker and Caliendo 2007). Rosenbaum bounds are shown in Table 4.5 and range from 1.5 to 5. This implies that farmers would have to differ in their unobserved characteristics by a factor of at least $1.5(50 \%)$ to 5 (400\%) in order for the ATTs to become insignificant. Based on these results, we can be relatively confident that the estimates obtained from propensity score matching are robust to hidden bias.

\subsection{Conclusions}

Previous studies have documented the emergence of private contract schemes that aim at supporting farm-level adaptation (e.g. Le Coq et al. 2010). Most studies focusing on a particular outgrower scheme have been optimistic about the ability of these private-sector initiatives to support small-scale farmers in their upgrading process. In this study, taking into account verbal and written contracts 
between pineapple producers and several downstream buyers, we find that contracts can act as an important catalyst for standard implementation and that contract farmers derive higher net revenues from pineapple production. Yet, we believe that some caution is warranted given that major uncertainties faced by farmers in the supply chain are not resolved.

In order to build sustainable value chains that are beneficial to both farmers and buyers in the longterm, transaction risks need to be managed more efficiently at the different stages of the supply chain. In particular, long payment delays and high rejection rates reduce farmers' trust in the marketing relationship. Anecdotal evidence from the Costa Rican pineapple sector reveals that disadoption rates of standards are high among small and medium-scale producers due to the fact that farmers do not perceive a strong benefit in terms of market access (high rejection rates) or monetary compensation (no price premiums, long payment delays). In our case study, informal agreements seem to fare better compared to formal contract schemes in terms of generating fair exchange conditions for producers. Further research is needed that looks into the long-term sustainability of private-sector contract schemes and standard adoption. Future research should also extend to other actors of the value chain, such as the exporter - importer relationship, to evaluate the transaction risks faced at the downstream stages of the value chain. 


\section{References}

Asfaw, Solomon, Dagmar Mithöfer, and Hermann Waibel. 2010. “What Impact Are EU Supermarket Standards Having on Developing Countries' Export of High-Value Horticultural Products? Evidence From Kenya.” Journal of International Food \& Agribusiness Marketing 22 (3-4): 252-76. doi:10.1080/08974431003641398.

Barrett, Christopher B. 2008. "Smallholder Market Participation: Concepts and Evidence from Eastern and Southern Africa.” Food Policy 33 (4): 299-317. doi:10.1016/j.foodpol.2007.10.005.

Barrett, Christopher B., Maren E. Bachke, Marc F. Bellemare, Hope C. Michelson, Sudha Narayanan, and Thomas F. Walker. 2012. "Smallholder Participation in Contract Farming: Comparative Evidence from Five Countries.” World Development 40 (4): 715-30. doi:10.1016/j.worlddev.2011.09.006.

Becker, Sascha O., and Marco Caliendo. 2007. "Mhbounds - Sensitivity Analysis for Average Treatment Effects.” SSRN Scholarly Paper ID 958699. Rochester, NY: Social Science Research Network. http://papers.ssrn.com/abstract=958699.

Becker, S.O., Ichino, A. (2002): Estimation of average treatment effects based on propensity scores. The Stata Journal 2(4): 358-377

Bellemare, Marc F. 2012. "As You Sow, So Shall You Reap: The Welfare Impacts of Contract Farming.” World Development 40 (7): 1418-34. doi:10.1016/j.worlddev.2011.12.008.

Berggren, Niclas, and Henrik Jordahl. 2006. "Free to Trust: Economic Freedom and Social Capital.” Kyklos 59 (2): 141-69. doi:10.1111/j.1467-6435.2006.00324.x.

Burton, M, Rigby, D., Young, T. (2003): Modelling the adoption of organic horticultural technology in the UK using duration analysis. Australian Journal of Agricultural and Resource Economics 47(1): 29-54.

CANAPEP (2011): Estadísticas de exportaciones, http://www.canapep.com/canapep/estadisticas , retrieved in April 2011

Caliendo, Marco, and Sabine Kopeinig. 2008. "Some Practical Guidance for the Implementation of Propensity Score Matching.” Journal of Economic Surveys 22 (1): 31-72. doi:10.1111/j.14676419.2007.00527.x.

Chavas, Jean-Paul. 1994. "Production and Investment Decisions Under Sunk Cost and Temporal Uncertainty.” American Journal of Agricultural Economics 76 (1): 114-27. doi:10.2307/1243926.

Chemnitz, Christine, Harald Grethe, and Ulrich Kleinwechter. 2007. "Quality Standards for Food Products: A Particular Burden for Small Producers in Developing Countries?” 83/2007. Working Paper, Wirtschafts- und Sozialwissenschaften an der LandwirtschaftlichGärtnerischen Fakultät, Humboldt-Universität zu Berlin. http://www.econstor.eu/handle/10419/96464.

Chiputwa, Brian, David J. Spielman, and Matin Qaim. 2015. "Food Standards, Certification, and Poverty among Coffee Farmers in Uganda.” World Development 66 (February): 400-412. doi:10.1016/j.worlddev.2014.09.006.

Cleves et al.,. 2008. An Introduction to Survival Analysis Using Stata, Second Edition. Third. Stata Press.

Coulibaly, A. L., and P. Liu. 2006. "Regulations, Standards and Certification for Agricultural Exports. A Practical Manual for Producers and Exporters in East Africa.” http://agris.fao.org/agrissearch/search.do?recordID=XF2007431465.

Cungu, Azeta, Hamish Gow, Johan F. M. Swinnen, and Liesbet Vranken. 2008. "Investment with Weak Contract Enforcement: Evidence from Hungary during Transition.” European Review of Agricultural Economics 35 (1): 75-91. doi:10.1093/erae/jbn001. 
DiPrete, Thomas A., and Markus Gangl. 2004. “Assessing Bias in the Estimation of Causal Effects: Rosenbaum Bounds on Matching Estimators and Instrumental Variables Estimation with Imperfect Instruments.” Sociological Methodology 34 (1): 271-310. doi:10.1111/j.00811750.2004.00154.x.

Dolan, C., and J. Humphrey. 2000. "Governance and Trade in Fresh Vegetables: The Impact of UK Supermarkets on the African Horticulture Industry.” Journal of Development Studies 37 (2): 147-76. doi:10.1080/713600072.

Dries, Liesbeth, and Johan F. M. Swinnen. 2004. "Foreign Direct Investment, Vertical Integration, and Local Suppliers: Evidence from the Polish Dairy Sector.” World Development 32 (9): 152544. doi:10.1016/j.worlddev.2004.05.004.

FAO Stat. 2011. The agricultural trade domain: imports and exports for pineapple, 2008, http://faostat.fao.org/site/342/default.aspx , retrieved in April 2011

Echanove, F, and C Steffen. 2005. "Agribusiness and Farmers in Mexico: The Importance of Contractual Relations” 171 (2): 166-76. doi:10.1111/j.1475-4959.2005.00157.x.

Fischer, Justina A. V. 2008. "Is Competition Good for Trust? Cross-Country Evidence Using MicroData.” Economics Letters 100 (1): 56-59. doi:10.1016/j.econlet.2007.11.001.

FoodPLUS and GTZ, 2008. GLOBALG.A.P. Smallholder Manual. Introduction to the EUREPGAP Standards for Fruit and Vegetables and Farmer Group Certification. Eschborn, Germany.

Giovannucci, Daniele, and Stefano Ponte. 2005. "Standards as a New Form of Social Contract? Sustainability Initiatives in the Coffee Industry.” Food Policy, Private Agri-food Standards: Implications for Food Policy and Agri-food Systems, 30 (3): 284-301. doi:10.1016/j.foodpol.2005.05.007.

Greene, W.H. (2003): Econometric analysis. Fifth Edition. Upper Saddle River, NJ: Prentice Hall.

Henson, Spencer, Oliver Masakure, and David Boselie. 2005. "Private Food Safety and Quality Standards for Fresh Produce Exporters: The Case of Hortico Agrisystems, Zimbabwe.” Food Policy 30 (4): 371-84. doi:10.1016/j.foodpol.2005.06.002.

Hughner, Renée Shaw, Pierre McDonagh, Andrea Prothero, Clifford J. Shultz, and Julie Stanton. 2007. "Who Are Organic Food Consumers? A Compilation and Review of Why People Purchase Organic Food.” Journal of Consumer Behaviour 6 (2-3): 94-110. doi:10.1002/cb.210.

Humphrey, and Memedovic. 2006. "Global Value Chains in the Agrifood Sector.” http://agris.fao.org/agris-search/search.do?recordID=GB2013202293.

Ingwersen, Wesley W. 2012. "Life Cycle Assessment of Fresh Pineapple from Costa Rica.” Journal of Cleaner Production 35 (November): 152-63. doi:10.1016/j.jclepro.2012.05.035.

Johnson, Marc A., and E. C. Pasour. 1981. "An Opportunity Cost View of Fixed Asset Theory and the Overproduction Trap.” American Journal of Agricultural Economics 63 (1): 1-7. doi:10.2307/1239806.

Kersting, Sarah, and Meike Wollni. 2012. "New Institutional Arrangements and Standard Adoption: Evidence from Small-Scale Fruit and Vegetable Farmers in Thailand.” Food Policy 37 (4): 452-62. doi:10.1016/j.foodpol.2012.04.005.

Key, Nigel, and David Runsten. 1999. “Contract Farming, Smallholders, and Rural Development in Latin America: The Organization of Agroprocessing Firms and the Scale of Outgrower Production.” World Development 27 (2): 381-401. doi:10.1016/S0305-750X(98)00144-2.

Klein, Benjamin. 1996. "Why Hold-Ups Occur: The Self-Enforcing Range of Contractual Relationships.” Economic Inquiry 34 (3): 444-63. doi:10.1111/j.1465-7295.1996.tb01388.x.

Lechner, Michael. 2002. "Program Heterogeneity and Propensity Score Matching: An Application to the Evaluation of Active Labor Market Policies.” Review of Economics and Statistics 84 (2): 205-20. doi:10.1162/003465302317411488. 
Le Coq, Faure G, and Saenz F. 2010. "Las Organizaciones de Produtores Y Las Modalidades de Prestación de Los Servicios Agrícolas.” Revista Centroamericana de Ciencias Sociales. http://agris.fao.org/agris-search/search.do?recordID=FR2013103028.

MAG 2007. Caracterización y plan de acción para el desarrollo de la agrocadenade piña en la región Huetar Norte. Ministerio de Agricultura y Ganadería, Dirección Regional Huetar Norte, Spet. 2007

MACMAP. 2015. Market Access Map: Improving transparency in international trade and market access. http://www.macmap.org/ Retrieved in April 2015

Maertens, Miet, and Johan F.M. Swinnen. 2009. "Trade, Standards, and Poverty: Evidence from Senegal.” World Development 37 (1): 161-78. doi:10.1016/j.worlddev.2008.04.006.

Michelson, Hope, Thomas Reardon, and Francisco Perez. 2012. "Small Farmers and Big Retail: Trade-Offs of Supplying Supermarkets in Nicaragua.” World Development 40 (2): 342-54. doi:10.1016/j.worlddev.2011.07.013.

Minten, Bart, Lalaina Randrianarison, and Johan F.M. Swinnen. 2009. “Global Retail Chains and Poor Farmers: Evidence from Madagascar.” World Development 37 (11): 1728-41. doi:10.1016/j.worlddev.2008.08.024.

Miyata, Sachiko, Nicholas Minot, and Dinghuan Hu. 2009. "Impact of Contract Farming on Income: Linking Small Farmers, Packers, and Supermarkets in China.” World Development 37 (11): 1781-90. doi:10.1016/j.worlddev.2008.08.025.

Narayanan, Sudha. 2014. "Profits from Participation in High Value Agriculture: Evidence of Heterogeneous Benefits in Contract Farming Schemes in Southern India.” Food Policy 44 (February): 142-57. doi:10.1016/j.foodpol.2013.10.010.

Poisot, A.-S. 2007. "Summary Analysis of Codes, Guidelines, and Standards Related to Good Agricultural Practices. Background Paper for the FAO Expert Consultation on a Good Agricultural Practice Approach, Rome, Italy, 10-12 November 2003.” FAO GAP Working Papers Series (FAO). http://agris.fao.org/agris-search/search.do?recordID=XF2008434563.

Poulton, Colin, Andrew Dorward, and Jonathan Kydd. 2010. "The Future of Small Farms: New Directions for Services, Institutions, and Intermediation.” World Development, The Future of Small Farms Including Special Section: Impact Assessment of Policy-Oriented International Agricultural Research (pp. 1453-1526), 38 (10): 1413-28. doi:10.1016/j.worlddev.2009.06.009.

Rain Forest Alliance. 2011. About us. http://www.rainforest-alliance.org/about. Retrieved on 12.04.2011

Reardon, Thomas, Christopher B. Barrett, Julio A. Berdegué, and Johan F. M. Swinnen. 2009. "Agrifood Industry Transformation and Small Farmers in Developing Countries." World Development 37 (11): 1717-27. doi:10.1016/j.worlddev.2008.08.023.

Rosenbaum, P.R., Rubin, D.B. (1983): The central role of the propensity score in observational studies for causal effects. Biometrika 70: 41-55.

Slangen, L.H.G., Loucks, L.A., Slangen, A.H.L. (2008): Institutional economics and economic organization theory - an integrated approach. The Netherlands: Wageningen Academic Publishers

Suzuki, A., L.S. Jarvis, R.J. Sexton (2011): Partial Vertical Integration, Risk Shifting, and Product Rejection in the High-Value Export Supply Chain: The Ghana Pineapple Sector. World Development 39(9), 1611-1623

Swinnen, Johan F. M., and Miet Maertens. 2007. "Globalization, Privatization, and Vertical Coordination in Food Value Chains in Developing and Transition Countries.” Agricultural Economics 37: 89-102. doi:10.1111/j.1574-0862.2007.00237.x. 
Vagneron, Isabelle, Guy Faure, and Denis Loeillet. 2009. "Is There a Pilot in the Chain? Identifying the Key Drivers of Change in the Fresh Pineapple Sector.” Food Policy 34 (5): 437-46. doi:10.1016/j.foodpol.2009.05.001.

Williamson, Oliver E. 1979. "Transaction-Cost Economics: The Governance of Contractual Relations.” Journal of Law and Economics 22 (2): 233-61.

Williamson, O.E. (1984): The economics of governance: framework and implications. Journal of Institutional and Theoretical Economics 140: 195-223.

Wooldridge, J.M. (2002): Econometric analysis of cross section and panel data. Cambridge, MA: The MIT Press. 


\section{Appendix 3}

Figure A3.1. Propensity score distribution and common support for farmers with and without agreements
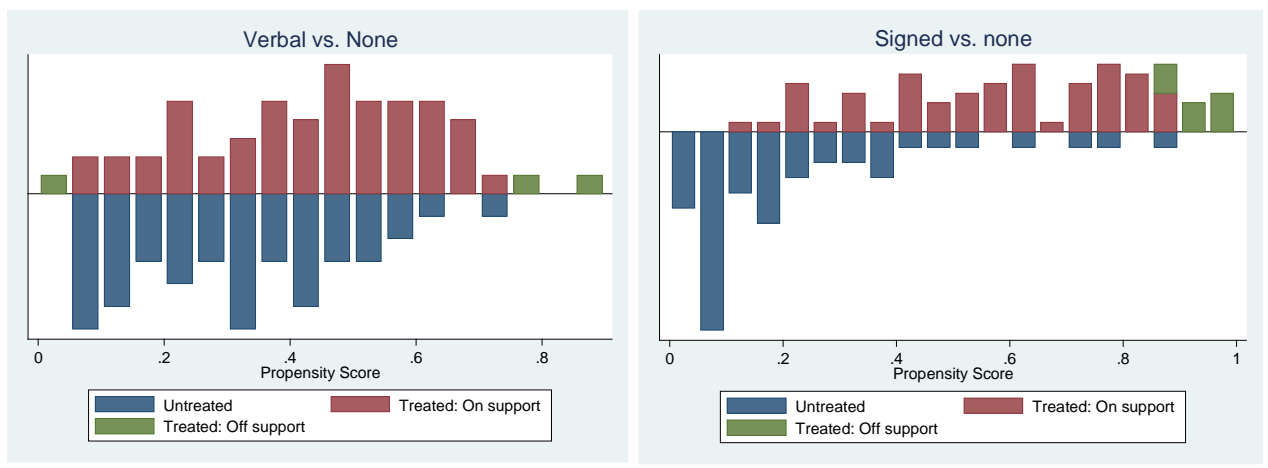

Figure A3.2. Propensity score distribution and common support for farmers with different agreements.

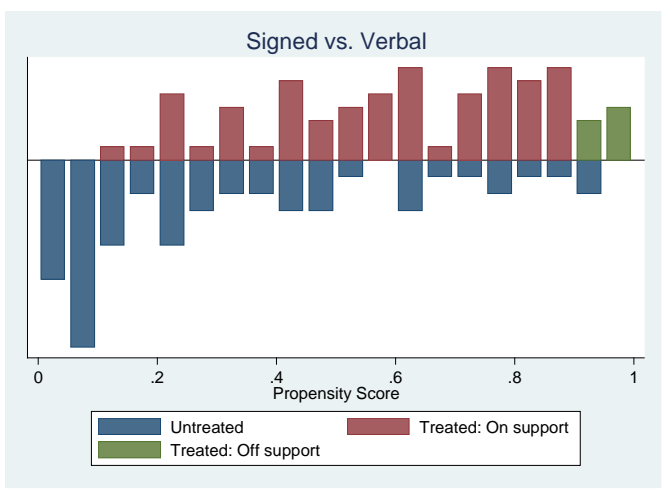




\section{Concluding remarks}

\subsection{Synopsis}

During the past decades, attention has been drawn to promoting agricultural growth in developing countries in order to increase the income of the rural poor and reduce world poverty. Within this context, supporting small farmers has become a priority. At the same time, the agrifood sector has undergone an important modernization process which involves the proliferation of new and tighter standards, a higher degree of concentration at the wholesale, processing and retail level and a shift from spot market transactions to vertical coordination. These changes have brought new opportunities but also new challenges for policymakers in charge of facilitating smallholder participation into modern food markets. Actions so far have managed to solve many problems in the rural sector: contract farming, external intervention and farmers' organizations have efficiently solved market failures and facilitated access to inputs, credits or technical support. Research has focused mainly on exclusion problems and welfare effects of participants, but long term analysis is still missing. High value chains supplied by smallholders have appeared unstable and several of them have collapsed over time. Small agricultural producers could be threatened by high concentration on the buyer side, and farmers are facing severe hold ups which threaten their participation. External support aiming to support small farmers is still clearly needed, but adequate measures need to be identified and put in practice in order to mitigate the dangers of participation and ensure that the possible benefits reach the targeted population.

In order to contribute to the missing literature, I analyzed the implications of high transaction risks in the form of experienced hold ups for small farmers' participation in an horticultural export chain. In a second phase, I analyzed different marketing arrangements, their influence on the dynamics of standard adoption and the implications for smallholders. First, I used a panel data set from a group of small Ecuadorian broccoli suppliers to empirically analyze the effects of delay of payment and high rejections on their extent of participation and withdrawal decisions from an export chain. From a subsample of this group of farmers, I further collected experimental data using an artefactual field experiment to measure the effect of opportunistic behavior on farmers' trust. Finally I used a crosssection data set from Costa Rican pineapple farmers to study the determinants of the type of market arrangement they adopted, how these arrangements influenced standard adoption and their consequences for income, transaction risks and relational capital (e.g. trust and loyalty). In contrast to many findings on small farmers' successful inclusion in high value markets, I found that the sustainability of these chains is threated by hold ups exerted by the buyer which increase transaction 
uncertainties and deteriorate the relationship with the producer. Moreover, the level of trust shown by both groups is low which further threatens cooperation and sustainability of the existing arrangements.

Chapter 2 focused on the effect of transaction risks and external negative shocks on the extent of participation and on withdrawal decisions from a farmers' collection center supplying the export market. The availability of longitudinal data for the analysis allowed me to control for the unobserved heterogeneity of farmers and for multiple periods of participation. Also, Difference GMM allowed me to properly analyze the dynamics of participation by correcting for the endogeneity of the lag dependent variable ( $\mathrm{kg}$ delivered by the farmer) and the predetermined covariate aggregated village supplies. Additionally, a CRE approach for unbalanced panels allowed me to obtain estimates for important time invariant variables such as membership in farmers' group and risk aversion. Results were consistent with our expectations and can confirm the hypothesis that hold ups in the way of rejection and delay of payment indeed increase transaction uncertainties (and therefore transaction costs) and thus negatively influence farmers' participation in the long run. Smallholders appear much more sensitive to high rejection rates because the produce rejected by the buyer cannot be diverted to the local market anymore and constitute monetary losses. This practice (rooted either in stringency of standards or in opportunistic behavior on the buyer's side) negatively influences farmers' decisions who, as a result, decrease the kilograms of produce delivered to the export market and speed up their withdrawal from the export chain. Delay on payment showed a smaller negative effect, although it becomes important when the days of delay extend for a long period. Also, farmers may accept short delays especially if inflation is low and if they do not have financial obligations involving high interest rates, but this practice becomes a serious problem in cases such as the one analyzed where farmers' payments were usually delayed for more than 60 days. Farmers' organizations constitute institutions that slow down the disintegration process, but are no guarantee of loyalty after an external negative shock, such as the one experienced by our group when the buying exporter went bankrupt and left the scene without paying for the product received. Family ties, in contrast, act in an ambiguous way. If a farmer has a family member working in the collection center, he might see the agreement as more flexible and decide to temporarily divert his produce to other marketing channels. However, when facing difficult periods, farmers seem to support their family members and remain as suppliers of the collection center for longer times. We find no evidence of small farmers' exclusion from participation, but vulnerable groups such as poorer or female headed households might end up locked into risky arrangements (in reference to an arrangement with high uncertainties after an external negative crisis) more easily than larger producers.

Sustainability problems along the high value chain are reflected in the low levels of trust shown by farmers towards their buyers in the export market in both study cases, especially when using signed contracts (case of Costa Rica). Chapter 3 explores the effect of possible opportunistic behavior (in the form of delayed payment) on farmers' trust preferences. In contrast to other studies that use 
survey questions to measure trust, in this analysis trust was elicited through a behavioral framed field experiment. For this, the group of small broccoli farmers who previously took part in a household survey (part of the study case described in Chapter 2) was invited to participate. Our results take into account the possible sample selection introduced when only certain farmers chose to join the experiments. Results showed that generalized trust towards unknown people is extremely low, which could hinder participation in market transactions. The most important contribution to the empirical literature is the study of farmers' behavior when exposed to positive and negative signaling coming from their partner. We conclude that positive signaling (in the form of on time payment) enhances trust and promotes cooperation. However, participants did not react promptly to negative signaling (in the form of delayed payment) and showed similar levels of trust to a control group that did not get any signal at all. The reason for this absence of reaction can have two grounds: the low capacity of these farmers for eliciting trustworthiness or the fact that low initial trust is already a way of protection against opportunism. The consequences for this slow reaction can be severe for the livelihoods of this vulnerable population. Furthermore, if informal rules in the region include weak sanctions, shirking an agreement might be seen as acceptable and this might drive individuals back to the spot market where immediate exchange of product for money takes place leaving less space for opportunism.

Chapter four focuses on the role of different market arrangements in supporting farms' upgrading process and private standard compliance. Cross-section data collected from small and medium export pineapple farmers in the Huetar-Norte region of Costa Rica was used to analyze the determinants of different market arrangements (e.g. signed contracts, verbal agreements and spot market), their influence on standard adoption (Organic, Global Gap and Rain Forest Alliance), and the benefits they bring to producers in terms of revenue and quality of the relationships with the buyer. While verbal agreements only specify the quantity and time of delivery, signed contracts involve closer coordination with buyers facilitating the access of farmers to credits and technical assistance. Yet, both types of arrangements still shift most of the risks (production and price risks) to producers. We find evidence that larger farmers are more likely to engage in some kind of agreement. However we are not clear whether this is a sign of exclusion based on a firm's decision or a matter of self-selection. Smaller farmers might prefer to have more flexibility to deliver their pineapple to the buyer with the best offer once it is ready for harvest. Farmers' organizations again play an important role in facilitating the access to formal contracts and in upgrading the farm to achieve standard adoption. In a further analysis, we notice the importance of vertical coordination for speeding up standard adoption. Even though this can be a signal that contracts stimulate farmers to make specific investments, prompt standard adoption can also be a mandatory requirement imposed by the buyer. Finally, evidence suggests that the monetary benefits of engaging in a market arrangement are significantly positive as the farmer has a secure outlet market and can invest in a larger area, but there are no net benefits when comparing the revenues obtained per hectare, therefore the price obtained is not better than in the other 
options. The option with the better outcome for the producer seems to be an informal verbal arrangement because it leaves the farmer with certain flexibility for negotiation. This is reflected in the higher scores for trust and loyalty towards their buyers shown by the producers holding these arrangements.

\subsection{Implications for policy makers.}

Contract farming involving small farmers should be accompanied by policies involving government support at critical points, by the development of other outlet markets and by improving collective action schemes. However, it is of necessary importance to separately analyze each region and its important crops in order to define the best possible intervention that will achieve growth without endangering the livelihoods and assets of producers.

There is an evident difference between engaging in arrangements where both parties obtain a fair gain and engaging in unequal arrangements where the risks are pushed to the weakest actor and the profits captured by the stronger one. In the extreme cases, producers can end up locked into unfair agreements that in the worst case scenario (weather, pests, low prices or even a financial crisis) could leave them highly indebted. But why would farmers enter these unequal arrangements? They are driven by their expectations of higher incomes and stable secure markets. Also, they can be motivated to join in order to find a solution for missing markets. This reality brings up an urgent need for the intervention of external actors that derive adequate policies to regulate agreements and monitor their compliance. It has been shown that when provided with the adequate support, small and poor farmers are able to comply with strict safety requirements and participate in new emerging markets. Nonetheless, if small farmers should survive and take advantage of the new marketing opportunities, they have to find a way to interact in a beneficial and sustainable way with their buyers and avoid getting trapped in risky deals with partners enduring financial problems. As we have seen, agricultural producers in general, and small farmers livelihoods in particular, could be threatened by strong partners and even by financial shocks over which they have absolutely no control. An adequate legal system and appropriate enforcement mechanisms can help balancing the power and give farmers a real chance of improving their livelihoods in the long run. Our results lead us to the following set of recommendations for policymakers.

\section{New regulations and accessible third party enforcement}

In general terms, there is still the need for governments to encourage firms to work with small famers. Yet, besides from providing these firms with the right incentives to do so, authorities should also demand adequate safeguards to reduce possible opportunistic behavior on the firm side. It is the job of the authorities to provide strong regulations for contract farming systems, to monitor these relationships and to ensure that small farmers can access third party enforcement mechanisms. Local 
governments can support low cost mechanisms to solve contract disputes (i.e. implementation of a third-party control mechanism to increase transparency in the grading process) or provide the economical means to farmers' organizations for making use of the legal system. Producers and producers' groups should also act with care and react promptly to negative signals. Otherwise they could find themselves highly indebted and can end up trapped in a vicious circle where they either have to acquire new debts to pay the old ones and be able to continue as suppliers or they have to sell their assets to honor their debts.

\section{Developing other markets}

If producers have other marketing options, buyers are more likely to comply with the existing agreements to maintain their suppliers. The local market can be attractive to small farmers because the quality requirements are lower, they can find a buyer regardless of the volume and the payment is on the spot. Therefore, external actors should also devote resources to improve the efficiency of domestic chains so producers can obtain higher profits. Additionally, these efforts will contribute to the upgrade of the whole agricultural sector and not only a group of peasants (usually small) trying to reach international markets.

\section{Collective action}

Farmers' organizations play an important role in linking farmers to markets and in negotiating and monitoring the terms of the agreement with the buyers on one side and with the suppliers on the other. They are crucial for coordinating production, assuring quality and developing quality monitoring systems (necessary for standard compliance). Moreover, they also solve input and financial missing markets by providing these services to their members and collecting the money at the end of the cycle. However, the existence of a producer organization does not guarantee its effectiveness. These organizations also face internal and external challenges that can make them collapse. Farmers' organizations often face problems dealing with free riders who do not comply with their obligations bringing discomfort to the complying members. At the same time, decisions are taken collectively which reduce their flexibility in comparison to private single farms. Consequently there is also a need for government and other external support in this field, not only for building and enforcing organizations' capacities but also for monitoring them. More specifically, capacity building is still needed in the managerial areas, with special emphasis on negotiation. More importantly, farmer groups' performance should be constantly measured and these organizations should be closely monitored by an external entity. 
Improving the access to information can also improve the negotiation and coordination mechanisms between buyer and suppliers. Both actors will profit if they get continuous updates on prices, volumes traded, quality requirements, business terms, and reputation of the partner. For this, new and cheap technology can be used such as cellphones.

\subsection{Limitations and ideas for further research}

There are some factors that limit the scope of this study. In this last section I highlight the major limitations faced and provide ideas for future research. First, even though the panel data set used for Chapter 2 was very detailed regarding marketing characteristics in the export market, recall data still had to be collected on socio economic and farm characteristics for the 11 years which might have introduced some measurement error, especially for the initial years. Additionally, there was no information on local market prices for the entire period under study. Local market prices obtained by the farmers for 2012 were collected using recall also. Obtaining accurate values for this variable is quite difficult because prices in the local market are extremely volatile and can drastically change within days. Nonetheless, we used this information as proxy for farmers' bargaining power in the local market as this variable also plays an important role in marketing decisions. We had to assume that farmers negotiation abilities do not vary over time and used this proxy as a time invariant covariate. Regarding the models employed for estimations, other approaches can be implemented to further refine the results. In the correlated random effects model we assume a constant unobserved heterogeneity term for the entire period, but random slopes can be used to determine if farmers' heterogeneity also varies with time or sector.

Additionally, there is still plenty of room for further research in the hold-ups topic, especially concerning downstream links of the high value chain and other marketing channels available for small farmers. Understanding the relationship between exporter and importer would be of great value and allow us to get a better, more complete picture of the current food chain situation. It can be the case that exporters also suffer hold ups that force them to behave opportunistically with their suppliers in order to survive in the business. On the other hand, marketing problems faced by small farmers in the local market should be further analyzed to define policies that make them more efficient and therefore attractive to local producers. Special emphasis should be put on the study of vulnerable groups such as female headed households who can be in a disadvantaged position in markets and could end up locked into unequal arrangements.

Regarding experimental data, the relatively small number of participants showing up to the sessions might bring some limitations when identifying the treatment effect. In addition, participants might have known each other because they came from the same community (communities are relatively 
small). Even though farmers did not know who their partners in the game were, they could have assumed they knew them and therefore acted in a specific way. This study can be followed up in bigger farming communities and in other regions to confirm the observed behavior. It would also be interesting to replicate the experiment with farmers who face higher investment costs (as is the case for long cycle crops such as pineapple) and to whom payment delays might affect more due to the interests they have to pay on their credits. Further research can also deal with the reaction of farmers towards other hold ups such as high rejection rates or monetary penalties for "low” quality.

The results on relational capital (Chapter 3) rely on cross sectional survey data which can have some endogeneity problems related to reverse causality. That is, farmers who show lower trust and loyalty from the beginning are the ones who self select into signed contracts. The findings can be extended by following up on the same households and building up a panel data set that allows to control for such possible problems. Finally, interviewing farmers who had bad experiences with the export market can become a challenge because they might be reluctant to give information or this information might be negatively biased. Therefore, results drawn from subjective questions can be accompanied by results obtained through other methods such as experimental games where farmers behave more realistically. 